\title{
Currents and Undercurrents: Changes in the Distribution of Wealth, 1989-2004
}

\author{
Arthur B. Kennickell \\ Senior Economist and Project Director \\ Survey of Consumer Finances \\ Mail Stop 153 \\ Federal Reserve Board \\ Washington, DC 20551 \\ Phone: (202) 452-2247 \\ Fax: (202) 452-5295 \\ Email: Arthur.Kennickell@frb.gov \\ SCF Web Site: http://www.federalreserve.gov/pubs/oss/oss2/scfindex.html
}

January 30, 2006

\begin{abstract}
This paper considers changes in the distribution of the wealth of U.S. families over the 1989-2004 period using data from the Survey of Consumer Finances (SCF). Real net worth grew broadly over this period. At the same time, there are indications that wealth became more concentrated, but the result does not hold unambiguously across a set of plausible measures. For example, the Gini coefficient shows significant increases in the concentration of wealth from 1989 to 2004, but the wealth share of the wealthiest one percent of families did not change significantly. Graphical analysis suggests that there was a shift in favor of the top of the distribution, while for the broad middle of the distribution increases were about in proportion to earlier wealth. Within this period, there are other interesting patterns. For example, from 1992 to 2004 the wealth share of the least wealthy half of the population fell significantly to 2.5 percent of total wealth. The data show little in the way of significant distributional shifts since the 2001 survey. The paper also presents some information on underlying factors that may explain a part of the distribution of wealth, including capital gains, saving behavior and income, inheritances, and other factors. There are two special topic sections in the paper. The first presents information on the distributions of wealth of African American and Hispanic families. The second presents information on the use of debt across the distribution of wealth.
\end{abstract}

The views presented in this paper are those of the author alone, and they do not necessarily reflect the views of the Board of Governors of the Federal Reserve System or its staff. The author wishes to thank Michael Neal for assistance with the figures in this paper, staff at NORC for collecting the data, and the SCF respondents for generously sharing their information for research purposes. Thanks to Brian Bucks, Gerhard Fries, Diana Hancock, and Kevin Moore for comments. The author bears sole responsibility for any errors. 
This paper considers changes in the distribution of the wealth of U.S. families over the 1989-2004 period, an interval that contains a variety of events that had strong effects on the finances of families. The period includes two recessions, one in 1990-1992 and one in 2001. Leading up to 2001, there was a tech-led boom of the stock market, which deflated in that year and had approximately recovered by the end of 2004. Between 2001 and 2004, real estate prices rose sharply in most areas, while home equity borrowing flourished in a market of relatively low interest rates. Over the whole period strong forces were altering the nature of production, work, and many other aspects of life. For example, at the beginning of the period, the "World Wide Web” was something known to only a relatively small number of technologically sophisticated people, and by the end "www" addresses were commonly seen nearly everywhere. Entirely new markets and jobs were created as older structures faded or transformed themselves to remain competitive. In the underlying demographics, the bulge of baby boomers continued to move through the age distribution, while total population grew about 19 percent over the 15 years, with immigration explaining a non-negligible fraction.

As a consequence of these disparate forces, the distribution of family wealth did shift-most certainly so for individual families. But trends in the overall distribution of wealth are hard to characterize, and often different statistics give different impressions. The data used in this paper, the triennial Survey of Consumer Finances (SCF), supplemented by data from Forbes, offer what is probably the best hope for identifying shifts in the wealth distribution for the whole population. ${ }^{1}$ But despite the special design of the SCF and the great care taken in processing that data, it is still a relatively small survey, and as such it may lack the statistical power to identify some relatively small changes clearly. That said, the data do identify statistically significant shifts in the wealth distribution over the period considered here. But for the 2001-2004 interval, even while the survey clearly records the surge in real estate values and home-secured borrowing, it shows little in the way of significant overall distributional movements.

The first section of this paper characterizes the data used. The second section reports a series of different views of the wealth distribution and its dynamics between 1989 and 2004.

\footnotetext{
${ }^{1}$ See Kopczuk and Saez [2003] for an examination of the wealth of the population sufficiently wealthy to file an estate tax return.
} 
Three special topic sections follow. The first traces some of the sources of wealth variation that can be seen in the SCF data. The second examines the relative wealth of African American families and Hispanic families. The third examines the use of debt across the wealth distribution. A final section offers a summary of key findings.

\section{Data Used in this Paper}

The primary data used in this paper derive from the Survey of Consumer Finances (SCF), a triennial survey sponsored by the Board of Governors of the Federal Reserve System in cooperation with the Statistics of Income Division (SOI) of the Internal Revenue Service. The version of the data used is the full internal data set available only within the SCF group at the Federal Reserve Board. Beginning with the 1989 survey, great efforts have been made to ensure the maximal amount of comparability of the surveys over time. Earlier years of the survey have been used to examine wealth changes (see Kennickell [2003] and references cited therein). This paper focuses on changes relative to the most recently available data at the time this paper was written, the 2004 wave of the survey. ${ }^{2}$ Data collection for this survey and all the surveys beginning with the 1992 survey was undertaken by NORC, a social science and survey research organization at the University of Chicago.

The SCF collects detailed information on the assets and liabilities of families, in addition to data on their work history, their use of financial institutions, their attitudes and expectations, a variety of demographic characteristics, and other variables. The asset and liability data are used to build the measure of net worth used in this paper. ${ }^{3}$ This measure includes the sum of financial assets (checking, savings and money market accounts, certificates of deposit, savings bonds, other types of bond, mutual funds, hedge funds, stocks, annuities, managed investment accounts, trusts, the cash value of life insurance, retirement accounts, and miscellaneous financial assets) and nonfinancial assets (principal residences, other residential real estate, net value of nonresidential real estate, businesses, vehicles, and miscellaneous nonfinancial assets) net of the sum of all outstanding debts (loans on a primary residence or other residential real estate, credit

\footnotetext{
${ }^{2}$ See Bucks, Kennickell, and Moore [2006] for an overview of the 2004 survey and see Kennickell [2000] for a review of the survey methodology.

${ }^{3}$ For comparability, this measure is the same as that used in Bucks, Kennickell, and Moore [2006].
} 
card balances, installment loans, margin loans, loans against cash value life insurance and pension accounts, and miscellaneous debts).

It is important to note that retirement assets are only partly captured in this measure of wealth. The wealth measure is intended to reflect only assets where the family has substantial control or direct interest. Thus, the measure of retirement assets used includes Individual Retirement Accounts (IRAs), Keogh Accounts, and balances in account-type pensions from which withdrawals could be made, either as a simple withdrawal or a loan; other types of employer- or union-based retirement account or annuity right and coverage under the Federal Old Age and Survivors’ Insurance (OASI) are excluded. In 2004, of the 33 percent of families headed by a person with some sort of pension on a current job, 64 percent had at least one account-type plan of the sort included in the net worth measure, 20 percent had at least one account-type plan that would not be included in the wealth measure, and 33 percent had at least one non-account-type plan other than OASI. Although broadening the net worth measure to include the omitted account-type plans would be straightforward, including an appropriate representation of the other plans would not be so simple. ${ }^{4}$ To do so would require computing an expected present value of annuity benefits, which would entail assumptions about the proper framework to use in including or excluding future employer and employee contributions to such plans as well as assumptions about how benefits might be affected by future employment and wages, the rate of future inflation, and future interest rates. There is no consensus about what approach to take in making such assumptions. Moreover, the additional effort that would be required is beyond the scope of this paper.

The data collected in the survey are subjected to an intensive review, with the aim of detecting serious errors on the part of interviewers or respondents. Often comments recorded by interviewers play a key role in this determination, but computer-driven searches for common types of problem are equally important. Sometimes such editing discovers recorded values that are clearly wrong, but there is not sufficient information to determine the correct answer; in such cases, the erroneous value may be set to a missing value. In other instances where there are multiple interrelated responses that are inconsistent, irreconcilable discrepancies may be allowed to stand if there is no information to determine the most reliable of the interrelated values.

\footnotetext{
${ }^{4}$ See Gale and Pence [2005] and Kennickell and Sundén [1997] for approaches for including a present value of annuity benefits in the calculation of net worth.
} 
Missing data in the survey are imputed using a technique of multiple imputation. ${ }^{5}$ Multiple imputation allows an analyst of the imputed data to develop a measure of the uncertainty associated with the fact that some of the values of variables were originally missing.

The sample for the SCF is designed to provide adequate information to examine a broad range of financial behaviors. Because some assets are held very disproportionately by relatively wealthy families, a straightforward area-probability sample (or other such sample with equal selection probabilities) would be unlikely to capture enough wealthy families for meaningful analysis of such variables, unless the sample size were quite large. Short of a huge sample size, an area-probability sample would provide a very inefficient representation of wealthy families, and consequently of assets concentrated among such families. In addition, there are strong indications that wealthy families are far less likely to respond to surveys than other families (see Kennickell [2005]); thus without some means of identifying relative wealth a priori, the realized sample for a survey would be very likely to be biased in terms of its representation of such families.

The SCF addresses both these statistical efficiency and bias concerns through the use of a dual-frame sample design. ${ }^{6}$ A national multi-stage area-probability design provides broad coverage of common economic behavior; this part of the sample provides about two-thirds of the final interviews. The other part of the sample employs information from SOI, under stringent provisions to protect the privacy of taxpayers, to select a sample with disproportionate representation of families more likely to be relatively wealthy; this sample is stratified by a "wealth index" computed using observed capital income flows and related information (see Kennickell [2001]. The two parts of the sample are adjusted for sample nonresponse and combined using weights to provide a representation of families overall.

It is important to note that the SCF excludes one small set of families by design. People who are listed in the October issue of Forbes as being among the 400 wealthiest in the U.S are excluded. This exclusion is made for two reasons. First, it is very unlikely that an interviewer could manage to reach a sufficient number of such people to justify the time and effort to attempt

\footnotetext{
${ }^{5}$ See Rubin [1987] for a discussion of multiple imputation in general and Kennickell [1998] for its application to the SCF.

${ }^{6}$ See Kennickell and Woodburn [1999] and Kennickell [1999] for a discussion of the construction of the SCF sample and weighting design.
} 
to do so. Second, it is almost certain that interviews with such people could not be included in the public version of the SCF data without introducing too large a probability that the identity of the respondent might be compromised. However, it should be noted that there are respondents interviewed for the SCF whose wealth is greater than the lowest value for the Forbes list; these cases are only included in the internal version of the data.

To enable the calculation of statistical hypothesis tests, the SCF uses a replication scheme (Kennickell [2000] and Kennickell and Woodburn [1999]). A set of replicate samples is selected by applying the key dimensions of the original sample stratification to the actual set of completed SCF cases and then applying the full weighting algorithm to each of the replicate samples. To estimate the variability of an estimate from the SCF, independent estimates are made with each replicate and with each of the multiple imputations; a simple rule is used to combine the two sources of variability into a single estimate of the standard error.

\section{The Distribution of Wealth}

\section{A. Forbes Data}

Every October, Forbes publishes a list of what it estimates to be the 400 wealthiest people in the U.S. ${ }^{7}$ These people probably represent the segment of wealthy families best known to the public in general, though their characteristics may well differ from those of families even a fraction of a percentile lower in the wealth distribution. Because, as noted above, the SCF and Forbes samples do not overlap, these sources are, in principle, natural complements in describing the distribution of wealth. For simplicity, the data from the two sources are treated separately.

According to calculations based on the data reported in Forbes, the wealth held by the 400 wealthiest people grew by widely varying amounts over the period covered in this paper

\footnotetext{
${ }^{7}$ See the October 2004 issue of Forbes and Canterbury and Nosari [1985] for details on the methodology. The Forbes data for recent years are available at www.forbes.com; the earlier data are only available in the printed version of the magazine. Unfortunately, on the basis of the very limited documentation available, it is not clear how consistent the Forbes methodology is within a given year and across time. From what is known, the estimates represent an "educated guess," with a variety of inputs. Probably the largest sources of potential error in these estimates are in the assignment of ownership of assets spread within a family and the valuation of assets that may not be publicly traded.
} 
Table 1: Wealth of the Forbes 400; 1989-2004.

\begin{tabular}{|c|c|c|c|c|c|c|c|c|c|}
\hline Year & $\begin{array}{l}\text { Total } \\
\text { wealth } \\
(\$ B)\end{array}$ & $\begin{array}{l}\text { Max } \\
\text { wealth } \\
(\$ B)\end{array}$ & $\begin{array}{l}\text { Min. } \\
\text { wealth } \\
(\$ M)\end{array}$ & $\begin{array}{l}\text { Avg. } \\
\text { top } 10 \\
(\$ B)\end{array}$ & $\begin{array}{l}100^{\text {th }} \\
\text { value } \\
(\$ M)\end{array}$ & Max $\div \min$ & $\begin{array}{l}\text { Avg. top } \\
10 \div \min \\
\text { wealth }\end{array}$ & $\begin{array}{l}100^{\text {th }} \text { value } \\
\div \text { min value }\end{array}$ & $\begin{array}{l}\text { Forb. wealth } \div \\
\text { (Forb. wealth+ } \\
\text { SCF wealth) } \\
\text { (percent) }\end{array}$ \\
\hline 1989 & 396.4 & 7.7 & 405 & 4.5 & 1029.8 & 18.9 & 11.1 & 2.5 & 1.54 \\
\hline 1992 & 402.2 & 8.3 & 350 & 6.7 & 1055.5 & 23.8 & 19.1 & 3.0 & 1.68 \\
\hline 1995 & 439.5 & 18.2 & 418 & 8.1 & 1107.8 & 43.5 & 19.3 & 2.6 & 1.67 \\
\hline 1996 & 547.5 & 22.2 & 340 & 9.2 & 1318.6 & 65.1 & 27.0 & 3.9 & NA \\
\hline 1997 & 732.2 & 46.7 & 557 & 15.4 & 1760.5 & 83.8 & 27.6 & 3.2 & NA \\
\hline 1998 & 854.2 & 67.6 & 579 & 22.0 & 1967.5 & 116.8 & 38.0 & 3.4 & 2.49 \\
\hline 1999 & $1,173.1$ & 96.3 & 708 & 32.2 & 2720.4 & 136.0 & 45.4 & 3.8 & NA \\
\hline 2000 & $1,313.7$ & 69.1 & 795 & 32.6 & 2851.9 & 86.9 & 41.0 & 3.6 & NA \\
\hline 2001 & $1,009.9$ & 57.6 & 640 & 25.6 & 2134.2 & 90.0 & 40.0 & 3.3 & 2.20 \\
\hline 2002 & 916.2 & 45.6 & 578 & 23.6 & 1890.7 & 78.2 & 40.2 & 3.3 & NA \\
\hline 2003 & 980.1 & 47.62 & 616 & 24.4 & 2053.8 & 76.7 & 39.6 & 3.3 & NA \\
\hline 2004 & $1,002.1$ & 51.0 & 750 & 22.7 & 2200.0 & 68.0 & 30.3 & 2.9 & 1.96 \\
\hline
\end{tabular}

(table 1). Based on the three years of data transcribed for the 1989-1995 period, the annualized growth rate in real terms was 0.5 percent over the first three years and 3.0 percent over the second three years. ${ }^{8}$ Reflecting in part the rise and decline of high technology stocks over the succeeding five years, the growth rate hit a high of 33.7 percent in 1997 and a low of 12.0 percent in 2000, before turning strongly negative-minus 23.1 percent in 2001 and minus 9.3 percent in 2002. There was growth of 7.0 percent in 2003 and 2.2 in 2004. From 1989 to 2004, total real wealth of the group grew by 6.4 percent at an annual rate, but obviously with considerable variability within that period.

Within the Forbes group, there were substantial variations in the concentration of wealth held by the group over the 15-year period shown. For example, the ratio of the highest value to the minimum value rose monotonically from 18.9 in 1989 to a peak of 136.0 in 1999—about seven times the ratio in 1989_and then declined with slight interruption to 68.0 in 2004. Although the general shape of the ratio of the average of the highest 10 values to the lowest value is similar over this time, the change is much less dramatic — it peaks at 45.4 , or about four times the value of the ratio in 1989 . The $100^{\text {th }}$ value ranged from 2.5 to 3.8 times the lowest value over the period; at its peak in 1996, this ratio was only about fifty percent higher than its low point in 1989.

\footnotetext{
${ }^{8}$ Except where otherwise noted, all dollar values reported in this paper have been adjusted to 2004 dollars using the CPI-U-RS, a research series computed by the Bureau of Labor statistics that is intended to extend methodological improvements in the current consumer price index back in time to the degree possible.
} 
For the years where the SCF and the Forbes data overlap, it is possible to see what proportion of wealth is, in principle, missing from the SCF. From 1989 to 1995, the total wealth of the Forbes 400 as a proportion of the sum of that wealth and total wealth measured in the SCF ranged from 1.5 to 1.7 percent; following the pattern of growth in the top rank of the Forbes group, the proportion jumped to 2.5 percent in 1998, before falling off a bit in both 2001 and 2004. In 2004 the fraction was 2.0 percent.

Because membership in the Forbes group is not constant over time, these shifts refer to changes in a slice of the wealth distribution, not the fortunes of individual families. However, since the group members are identified by name, it is possible to trace their dynamics. As shown in Kennickell [2003] for the period from 1989 to 2001, of the 400 people in the 2001 list, 230 were not anywhere in the 1989 list. Persistence in the list was highest for people who were in the wealthiest 100_of the people in this group, 45 were in the same group in 1989 and 23 others were elsewhere in the list.

\section{B. SCF Data}

Broad growth. Across the 1989 to 2004 period, the inflation-adjusted wealth distribution rose broadly (table 2), though the pattern for individual families over the period might well have been otherwise. ${ }^{9}$ Although the fraction of families with negative net worth stayed about the same across the fifteen-year period aside from a jump in 1998, the population with non-negative wealth tended overall to shift to higher wealth groups, with some possibly cyclically-influenced deviations within the period. ${ }^{10}$ For example, in 1989, 26.5 percent of families had net worth of less than \$10,000; by 2004 the figure was 22.7 percent. Over the same period, the share of families with at least $\$ 500,000$ in net worth rose from 10.8 percent to 17.7 percent. Beneath this general trend are many undercurrents affecting the distribution of wealth, some of which are explored in this paper.

${ }^{9}$ Panel data would be needed to address wealth changes for individual families. There are SCF panel data only for the 1983-1989 period. Because of the notable substantive and methodological differences between the 1983 data and the cross sectional surveys beginning with 1989, the 1983 information is not used here. See Avery and Kennickell [1991] for an analysis of wealth dynamics based on the 1983 and 1989 SCF.

In the comparisons reported here, no adjustments are made for variations in the size and composition of households. Furthermore, no use is made of the Forbes data in the SCF estimates reported.

\footnotetext{
${ }^{10}$ See Kennickell [2003] for a detailed discussion of families with negative net worth.
} 
Table 2: Percent distribution of net worth in 2004 dollars, 1989-2004.

\begin{tabular}{|c|c|c|c|c|c|c|}
\hline & 1989 & 1992 & 1995 & 1998 & 2001 & 2004 \\
\hline \multirow[t]{2}{*}{$<0$} & 7.2 & 7.2 & 7.1 & 8.0 & 6.9 & 7.1 \\
\hline & 0.6 & 0.4 & 0.4 & 0.4 & 0.3 & 0.3 \\
\hline \multirow[t]{2}{*}{$=0$} & 3.9 & 3.2 & 2.6 & 2.5 & 2.6 & 1.7 \\
\hline & 0.5 & 0.2 & 0.3 & 0.2 & 0.2 & 0.2 \\
\hline \multirow[t]{2}{*}{$1-999$} & 4.0 & 3.0 & 2.4 & 3.2 & 2.7 & 2.3 \\
\hline & 0.4 & 0.3 & 0.3 & 0.3 & 0.2 & 0.2 \\
\hline \multirow[t]{2}{*}{$1 \mathrm{~K}-2.49 \mathrm{~K}$} & 3.1 & 3.6 & 2.5 & 2.4 & 2.3 & 3.2 \\
\hline & 0.3 & 0.3 & 0.2 & 0.2 & 0.2 & 0.2 \\
\hline \multirow[t]{2}{*}{$2.5 \mathrm{~K}-4.9 \mathrm{~K}$} & 4.3 & 3.4 & 3.4 & 3.2 & 3.3 & 4.0 \\
\hline & 0.5 & 0.3 & 0.2 & 0.2 & 0.3 & 0.2 \\
\hline \multirow[t]{2}{*}{$5 \mathrm{~K}-9.9 \mathrm{~K}$} & 4.0 & 4.9 & 5.5 & 4.7 & 4.6 & 4.4 \\
\hline & 0.4 & 0.3 & 0.3 & 0.3 & 0.3 & 0.3 \\
\hline \multirow[t]{2}{*}{$10 \mathrm{~K}-24.9 \mathrm{~K}$} & 8.0 & 9.2 & 9.2 & 7.9 & 7.9 & 7.8 \\
\hline & 0.6 & 0.4 & 0.5 & 0.5 & 0.3 & 0.4 \\
\hline \multirow[t]{2}{*}{$25 K-49.9 K$} & 9.3 & 10.5 & 10.0 & 9.4 & 9.0 & 8.8 \\
\hline & 0.6 & 0.6 & 0.5 & 0.4 & 0.4 & 0.5 \\
\hline \multirow[t]{2}{*}{$50 \mathrm{~K}-99.9 \mathrm{~K}$} & 13.3 & 14.2 & 15.8 & 12.5 & 12.2 & 11.9 \\
\hline & 0.6 & 0.6 & 0.6 & 0.6 & 0.5 & 0.5 \\
\hline \multirow[t]{2}{*}{$100 \mathrm{~K}-249.9 \mathrm{~K}$} & 20.8 & 21.5 & 22.2 & 21.9 & 19.1 & 18.6 \\
\hline & 1.0 & 0.9 & 0.7 & 0.9 & 0.6 & 0.7 \\
\hline \multirow[t]{2}{*}{ 250K-499.9K } & 11.3 & 10.0 & 9.9 & 12.5 & 13.5 & 12.4 \\
\hline & 0.7 & 0.5 & 0.3 & 0.8 & 0.6 & 0.6 \\
\hline \multirow[t]{2}{*}{ 500K-999.9K } & 5.6 & 5.2 & 5.5 & 6.5 & 8.4 & 9.6 \\
\hline & 0.5 & 0.3 & 0.3 & 0.6 & 0.6 & 0.7 \\
\hline \multirow[t]{2}{*}{$>=1 \mathrm{M}$} & 5.2 & 4.2 & 3.8 & 5.3 & 7.5 & 8.1 \\
\hline & 1.3 & 0.2 & 0.2 & 0.3 & 0.4 & 0.3 \\
\hline
\end{tabular}

Means and quantile

indicators. The relationship between the mean and the median of net worth is often taken as a simple indicator of changes in distribution. From 1989 to 2004, the mean value of wealth measured in the SCF rose 61.2 percent, while the median rose 35.3 percent (table 3 ). Although the mean and median both grew, the difference in these growth rates over the 15-year period signals that wealth moved in relative terms to the upper half of the distribution during this time. At the beginning of the period, the mean was 4.0 times the median, and owing the differences in growth rates, the mean was 4.8 times the median at the end. It is noteworthy that the ratio of the mean to the median was relatively little changed from 1989 until 2001, when it rose 0.7 percentage point. Yet, it was in 2001 that the wealth of the Forbes 400 saw the largest percentage decline over the period considered here. This difference suggests that changes for the Forbes group may be relatively loosely coupled with those for other families.

Examination of other key percentiles of the distribution suggests that the overall picture is less straightforward than that shown by the means and medians. Although there was growth from 1989 to 2004 at the $10^{\text {th }}, 25^{\text {th }}, 75^{\text {th }}$ and $90^{\text {th }}$ percentiles, the ratio of the $75^{\text {th }}$ and $90^{\text {th }}$ percentiles of the wealth distribution to the value of the $25^{\text {th }}$ percentile declined over the period 
Table 3: Mean, $10^{\text {th }}$ and $25^{\text {th }}$ percentiles, median, $75^{\text {th }}$ and $90^{\text {th }}$ percentiles of the distribution of net worth; 1989-2004.

\begin{tabular}{|c|c|c|c|c|c|c|c|c|c|}
\hline & \multicolumn{6}{|c|}{ Thousands of 2004 dollars } & \multicolumn{3}{|c|}{ Memo: Ratio } \\
\hline & Mean & P10 & P25 & Median & P75 & P90 & P75/P25 & P90/P25 & Mean/Median \\
\hline \multirow[t]{2}{*}{1989} & $277.9 *$ & 0.0 & $8.1^{*}$ & $68.8^{*}$ & $216.2^{*}$ & $539.5^{*}$ & 26.7 & 66.6 & $4.0 *$ \\
\hline & 22.2 & 0.0 & 1.0 & 3.8 & 11.1 & 79.1 & 3.8 & 13.3 & 0.3 \\
\hline \multirow[t]{2}{*}{1992} & $246.1 *$ & 0.0 & $9.6^{*}$ & $65.3^{*}$ & $194.6^{*}$ & $470.2^{*}$ & $20.3^{*}$ & $49.0 *$ & $3.8^{*}$ \\
\hline & 7.3 & 0.0 & 0.7 & 3.3 & 6.7 & 18.8 & 1.3 & 3.6 & 0.2 \\
\hline \multirow[t]{2}{*}{1995} & $260.7 *$ & 0.1 & 12.3 & $70.8^{*}$ & $197.8^{*}$ & $469.0 *$ & $16.1 *$ & $38.2^{*}$ & $3.7^{*}$ \\
\hline & 6.4 & 0.1 & 0.9 & 2.4 & 4.3 & 17.2 & 1.3 & 3.2 & 0.1 \\
\hline \multirow[t]{2}{*}{1998} & $328.5^{*}$ & 0.0 & 11.5 & $83.2^{*}$ & $242.2^{*}$ & $572.9 *$ & $21.0 *$ & $49.7^{*}$ & $3.9 *$ \\
\hline & 10.7 & 0.0 & 0.7 & 3.2 & 12.9 & 22.8 & 1.6 & 3.5 & 0.2 \\
\hline \multirow[t]{2}{*}{2001} & 423.9* & 0.1 & 13.6 & 91.7 & 301.7 & 782.2 & 22.3 & 57.7 & 4.6 \\
\hline & 7.1 & 0.1 & 0.8 & 3.3 & 31.5 & 11.4 & 1.3 & 4.1 & 0.2 \\
\hline \multirow[t]{2}{*}{2004} & 448.0 & 0.2 & 13.3 & 93.1 & 328.5 & 831.6 & 24.8 & 62.8 & 4.8 \\
\hline & 9.7 & 0.1 & 0.8 & 4.3 & 17.0 & 24.8 & 1.5 & 3.6 & 0.2 \\
\hline
\end{tabular}

with considerable variation within the period. ${ }^{11}$ But this decline was not statistically significant, owing in part to the unusually large standard errors for the 1989 estimates. However, if 1992 is taken as the starting point of the period, the ratios increase significantly by 2004 and roughly in parallel with the ratio of the mean to the median. Thus, the data at this level generally support the idea that wealth may have shifted toward the upper part of the distribution at least from 1992 to 2004.

Gini coefficient. Another common indicator of the distribution of wealth is the Gini coefficient, which is defined in terms of the Lorenz curve, a graph of the cumulative percent of wealth against the cumulative percent of families, where the families are sorted by wealth. The wealth Gini coefficient is given as one minus twice the area under the Lorenz curve. In a world of perfect equality, (where the lorenz curve would be a 45 degree line) the value would be zero, and in a world where all wealth was held by one person, the value would be approximately one. Thus, the wealth Gini coefficient gives a measure of the relative size of the deviation of a distribution from perfect equality. Two important and interrelated auxiliary points are that the deviations are weighted equally, independently of location in the distribution, and that two

\footnotetext{
${ }^{11}$ The table shows the ratio of the $90^{\text {th }}$ and $25^{\text {th }}$ percentiles, rather than the ratio of the $90^{\text {th }}$ and $10^{\text {th }}$ percentiles more familiar from analysis of income distributions, because the $10^{\text {th }}$ percentile is often zero or a very small positive or (absolute) negative value.
} 
Table 4: Gini coefficients for net worth, assets, debt and income, 1989-2004.

\begin{tabular}{|lllll|}
\hline & Net worth & Assets & Debt & Income \\
& & & & \\
& & & & \\
1989 & $0.7863^{*}$ & 0.7481 & $0.7447^{*}$ & 0.5399 \\
& 0.0055 & 0.0080 & 0.0063 & 0.0086 \\
1992 & $0.7808^{*}$ & $0.7379^{*}$ & $0.7479^{*}$ & $0.5005^{*}$ \\
& 0.0061 & 0.0064 & 0.0049 & 0.0049 \\
1995 & $0.7841^{*}$ & $0.7323^{*}$ & $0.7243^{*}$ & $0.5146^{*}$ \\
& 0.0043 & 0.0044 & 0.0040 & 0.0042 \\
1998 & 0.7935 & 0.7444 & 0.7138 & 0.5302 \\
& 0.0051 & $0.0052 b$ & 0.0037 & 0.0040 \\
2001 & 0.8034 & 0.7603 & 0.7104 & $0.5643^{*}$ \\
& 0.0041 & 0.0042 & 0.0034 & 0.0037 \\
2004 & 0.8047 & 0.7540 & 0.7053 & 0.5406 \\
& 0.0049 & 0.0051 & 0.0036 & 0.0040 \\
& & & & \\
Standard errors are given in italics. & & & \\
$*=$ significantly different from the 2004 level at 95 percent confidence. &
\end{tabular}

different distributions could generate the same Gini coefficient. Thus, the Gini coefficient does not provide an unambiguous and neutral index of the wealth distribution.

From 1989 to 2004, the wealth Gini coefficient rose from 0.79 to 0.80 , a relatively small but statistically significant change (table 4). At the same time, there was a slight increase in the comparable Gini coefficient computed for assets

and a slight decrease in the Gini coefficient for debt. In contrast, the coefficient for income began the period at about the same level at which it ended, after having fallen and risen in between; moreover, it is about two-thirds the level of the coefficient for wealth.

Concentration ratios. Because the Gini coefficient attempts to summarize many complex changes in terms of a single number, it may miss important variation for particular parts of a distribution or for particular subpopulations. A more detailed means of summarizing the relative distribution of wealth is the use of concentration ratios, the proportion of total wealth held by specific groups. In 2004, slightly more than one-third of total net worth was held by the wealthiest one percent of families (table 5). Although the estimated level of this share has changed over the surveys since 1989, the differences are not statistically significant. In 2004, the next-wealthiest nine percent of families held 36.1 percent of total wealth, again, a figure not significantly changed over the course of the surveys. This leaves less than a third of the total for the remaining ninety percent of the population. A subset of that group, families in the bottom half of wealth distribution, held only 2.5 percent of total wealth in 2004, and this figure is significantly different from the higher estimates for 1995, 1998, and 2001; of course, those differences reflect movements elsewhere in the distribution, but the statistical power of the tests is not sufficient to identify where among the groups shown the offsetting changes occurred. A possible explanation of the decline for the lowest wealth group might be changes in their use of debt, but a separate examination of gross assets yields a pattern similar to that seen for net worth. 
Table 5: Proportions of total net worth and of gross assets held by various percentile groups, 1989-2004.

\begin{tabular}{|c|c|c|c|c|c|}
\hline \multicolumn{6}{|c|}{ Proportion of total net worth held by group } \\
\hline & \multicolumn{5}{|c|}{ Net worth percentile group } \\
\hline & $0-50$ & $50-90$ & $90-95$ & $95-99$ & $99-100$ \\
\hline \multirow[t]{2}{*}{1989} & 3.0 & 29.9 & 13.0 & 24.1 & 30.1 \\
\hline & 0.3 & 1.8 & 1.6 & 2.3 & 2.3 \\
\hline \multirow[t]{2}{*}{1992} & $3.3^{*}$ & 29.6 & 12.5 & 24.4 & 30.2 \\
\hline & 0.2 & 1.1 & 0.7 & 1.3 & 1.4 \\
\hline \multirow[t]{2}{*}{1995} & $3.6^{*}$ & 28.6 & 11.9 & 21.3 & 34.6 \\
\hline & 0.2 & 0.7 & 0.6 & 0.9 & 1.3 \\
\hline \multirow[t]{2}{*}{1998} & $3.0 *$ & 28.4 & 11.4 & 23.3 & 33.9 \\
\hline & 0.2 & 0.9 & 0.6 & 1.2 & 1.5 \\
\hline \multirow[t]{2}{*}{2001} & $2.8^{*}$ & 27.4 & 12.1 & 25.0 & 32.7 \\
\hline & 0.1 & 0.7 & 0.7 & 1.1 & 1.4 \\
\hline \multirow[t]{2}{*}{2004} & 2.5 & 27.9 & 12.0 & 24.1 & 33.4 \\
\hline & 0.1 & 0.9 & 0.7 & 1.2 & 1.2 \\
\hline \multicolumn{6}{|c|}{ Proportion of total gross assets held by group } \\
\hline & \multicolumn{5}{|c|}{ Net worth percentile group } \\
\hline & $0-50$ & $50-90$ & $90-95$ & $95-99$ & $99-100$ \\
\hline \multirow[t]{2}{*}{1989} & 5.4 & 32.5 & 12.6 & 22.3 & 27.1 \\
\hline & 0.4 & 1.8 & 1.6 & 2.1 & 2.1 \\
\hline \multirow[t]{2}{*}{1992} & $6.6^{*}$ & 32.1 & 12.0 & 22.6 & 26.7 \\
\hline & 0.3 & 1.1 & 0.7 & 1.2 & 1.3 \\
\hline \multirow[t]{2}{*}{1995} & $7.5^{*}$ & 31.2 & 11.4 & 19.5 & 30.4 \\
\hline & 0.3 & 0.7 & 0.6 & 0.8 & 1.2 \\
\hline \multirow[t]{2}{*}{1998} & $6.7^{*}$ & 30.8 & 10.9 & 21.7 & 29.9 \\
\hline & 0.3 & 0.9 & 0.6 & 1.2 & 1.4 \\
\hline \multirow[t]{2}{*}{2001} & 5.6 & 29.9 & 11.7 & 23.4 & 29.5 \\
\hline & 0.2 & 0.8 & 0.7 & 1.0 & 1.3 \\
\hline \multirow[t]{2}{*}{2004} & 5.8 & 31.0 & 11.4 & 22.2 & 29.5 \\
\hline & 0.2 & 0.9 & 0.7 & 1.2 & 1.1 \\
\hline \multicolumn{6}{|c|}{$\begin{array}{l}\text { Standard errors are given in italics. } \\
*=\text { significantly different from the } 2004 \text { level at } 95 \text { percent confidence. }\end{array}$} \\
\hline
\end{tabular}

Graphical analysis. A more direct and comprehensive way of characterizing changes across the wealth distribution is to use a quantile-difference (QD) plot, a graph of differences between the levels of two distribution at each quantile of the distributions. Figure 1a shows a QD plot of the difference between the wealth distributions for 2001 and 2004, where the line plotted represents the 2004 level minus the 2001 level. ${ }^{12}$ At the bottom of the distribution, the estimate shows that wealth became more negative in that range, though the changes are not significantly different from zero. From there up to about the $50^{\text {th }}$ percentile, there was very little change in levels between the two years. Above that point, the estimates show some substantial gains, but they are significantly different from zero in this point-wise sense only from about the $75^{\text {th }}$ to the $85^{\text {th }}$ percentiles.

In general, the level changes may be misleading as indicators of shifts of wealth shares across the distribution; for a group to increase its share of wealth, its wealth has to grow at a faster rate than the wealth of other families. A relative quantile-difference (RQD) plot addresses this point by normalizing the change in a QD plot by the level of the base year; that is, the amount shown for each common quantile in the two distributions is the percent change in the level of wealth corresponding to the quantile. Viewed in this way, the changes in the lowest fifteen percent of the distribution tend to explode, largely because the denominator is quite small

\footnotetext{
${ }^{12}$ The dots around the central line indicate the 95 percent point-wise confidence intervals at selected points across the distribution. The vertical axis is scaled using the inverse hyperbolic sine transformation (with a scale factor of 0.0001), which has the convenient property of being approximately linear around zero and approximately logarithmic away from zero.
} 
over much of this range (figure 1b). For the next approximately ten percent, the relatively small dollar changes in the levels are shown to be more substantial as a proportion-on the order of minus ten percent. For those higher in the distribution, the main effect of the normalizing is progressively to flatten the differences. But as with the QD plot, the only changes that were significantly different from zero were those in the range of about the $75^{\text {th }}$ to 85 percentiles.

It is somewhat surprising over a three-year period when there were substantial increases in real estate values and some recovery of earlier stock market losses that there were not more notable changes at this level of distributional analysis, but the data suggest that the implied wealth changes were offset to a substantial degree by borrowing and were also diffused fairly broadly across the wealth distribution. Over longer periods, economic forces may have an opportunity to play out more fully. Figure 2a shows change over the longest period possible with the consistent series of SCF data, from 1989 to 2004. ${ }^{13}$ Here there are statistically significant increases in wealth almost everywhere across the distribution. Above about the $10^{\text {th }}$ percentile, the plot slopes linearly upward in inverse hyperbolic sine space (an approximately logarithmic transformation over most of this range) until about the $95^{\text {th }}$ percentile, from which point the line spikes sharply upward. In the RQD transformation (figure 2b), the data show large proportional changes below the $25^{\text {th }}$ percentile, but with very wide confidence intervals. Between the $25^{\text {th }}$ and $80^{\text {th }}$ percentiles, the graph forms a rough "bowl" shape, where the bowl is flat across the middle at about 35 percent-implying about 2 percent growth on an annual basis over the period. From the $80^{\text {th }}$ percentile, the line drops off again before spiking upward in the top few percentiles. The spike is sufficiently well estimated that it is significantly different from the other changes above the $25^{\text {th }}$ percentile. Thus, this plot does provide some support for the increase in wealth concentration at the very top, as one would expect from the Forbes data over the same period.

Variability of cross-sectional wealth over time. Because only cross sectional data are available from the SCF in the period considered here, it is not possible to examine the movements of families in the wealth distribution over time. Still, it is of macroeconomic interest to know how variable the overall distribution was over the period. To this end, figure 3a shows an estimate of the coefficient of variation (the standard deviation divided by the mean) of the

\footnotetext{
${ }^{13}$ Both QD and RQD plots are given in the appendix for 2004 relative to all of the other intervening survey years.
} 
level of wealth associated with each quantile in the six surveys from 1989 to 2004 (a QCV plot). The shape of the figure looks like a somewhat exaggerated version of the RQD plot for 1989-2004 shown in figure 3a. That is, excluding the range of negative and zero wealth, the least variability is in the middle of the distribution with generally increasing variability on either side. Note that because the data are not de-trended, there is a substantial baseline level of variability, and because growth differed notably across the distribution, some of the differences in the figure may be largely a product of the spread induced by variations in the trend in growth rates across the distribution. ${ }^{14}$ Adjusting the 1989-2004 figures for each quantile to remove the geometric mean of growth over the period yields the graph of de-trended variation shown in figure 3b. Restricting attention to the meaningful range for interpretation, beginning around the $20^{\text {th }}$ percentile, the highest variability by far is for the lowest and highest wealth groups. Because wealth for these lowest groups is a relatively small buffer against personal and macroeconomic shocks, it is not surprising to see such high variation across a period that included two recessions as well as important restructuring of employment. A minimum of variation is reached at about the $35^{\text {th }}$ percentile, and above that point, variability increases approximately linearly until the very top of the distribution. The rising variation across the upper 65 percent of the distribution reflects the riskiness of the underlying portfolios, a factor discussed later in this section.

\footnotetext{
${ }^{14}$ The precision of estimation of each cross sectional element may vary because of differences in the degree of sampling error. Thus, some of the differences observed in cross sectional variability may reflect the differences in sampling error.
} 
Figure 1a: QD plot for net worth, 2004 minus 2001.

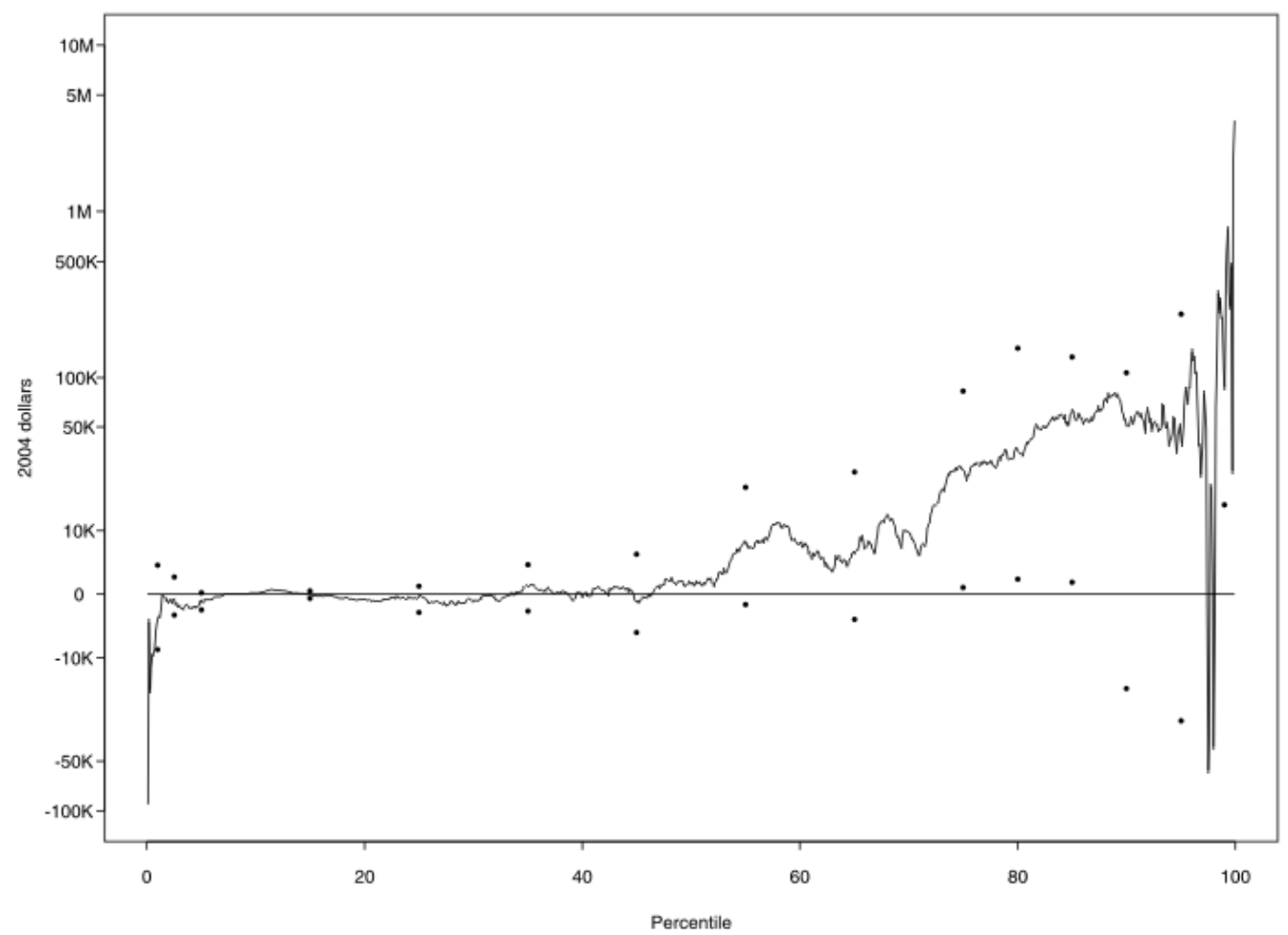

Figure 1b: RQD plot for net worth, 2004 minus 2001 as a percent of 2001.

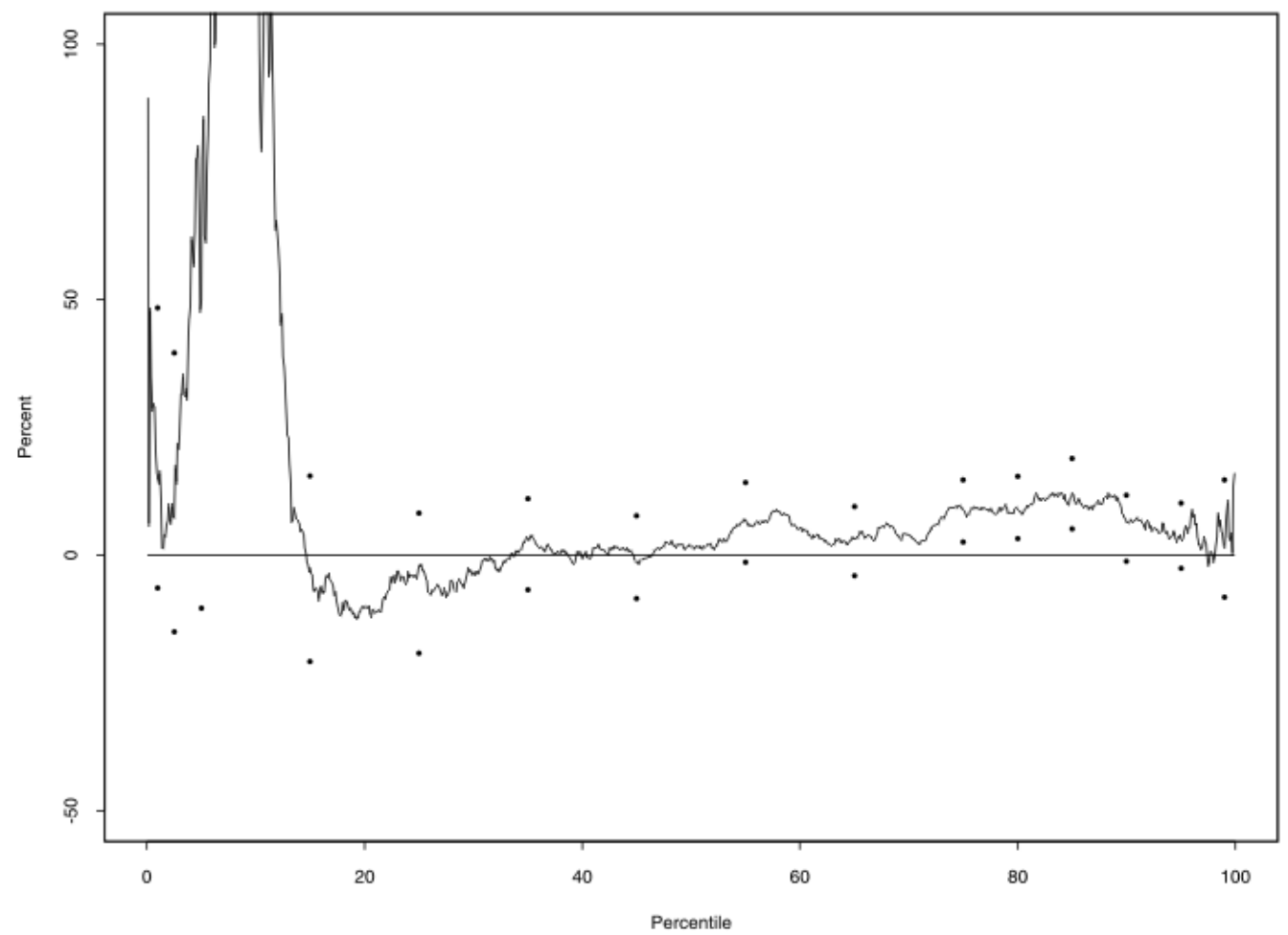


Figure 2a: QD plot for net worth, 2004 minus 1989.

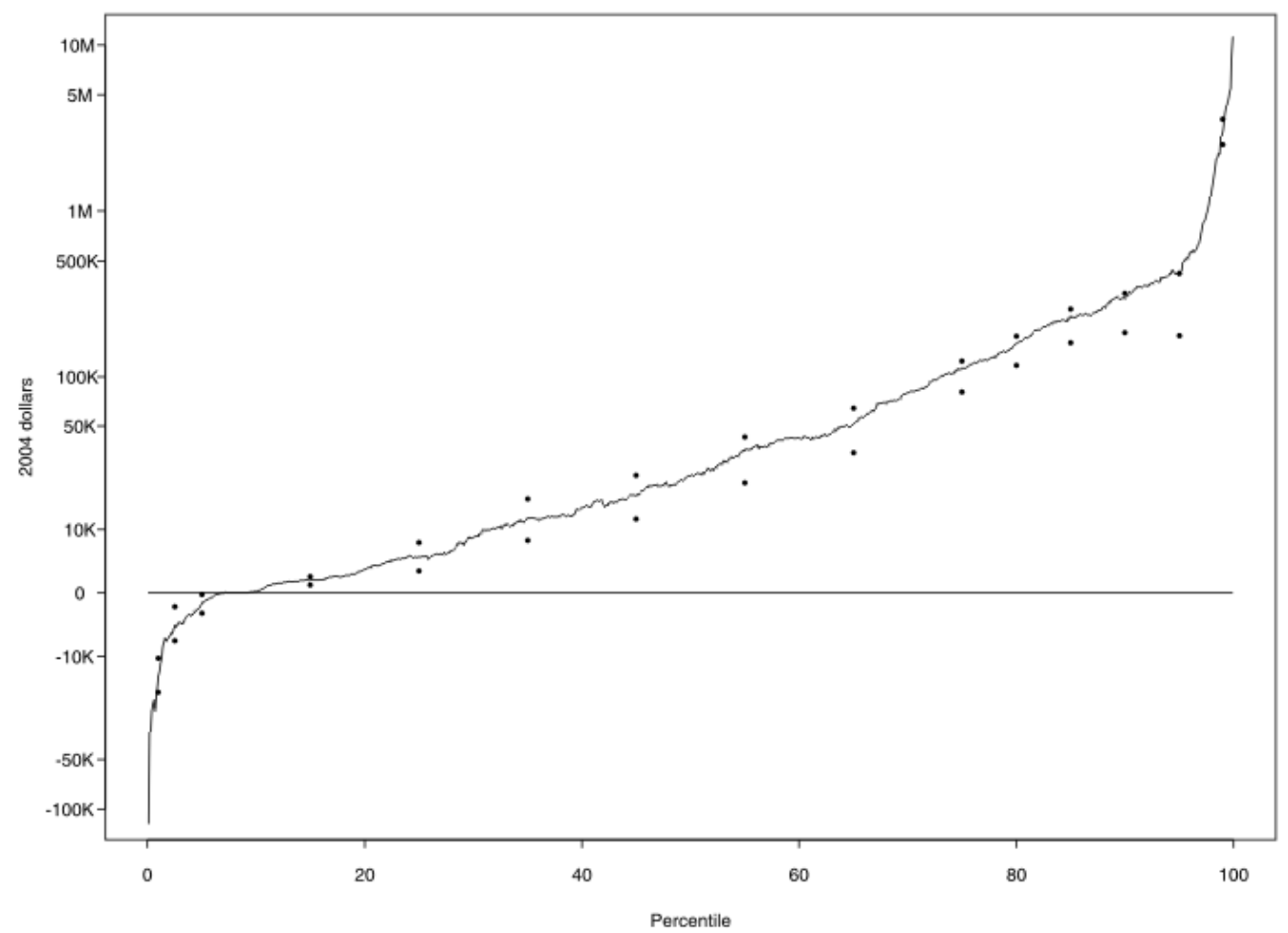

Figure 2b: RQD plot for net worth, 2004 minus 1989 as a percent of 1989.

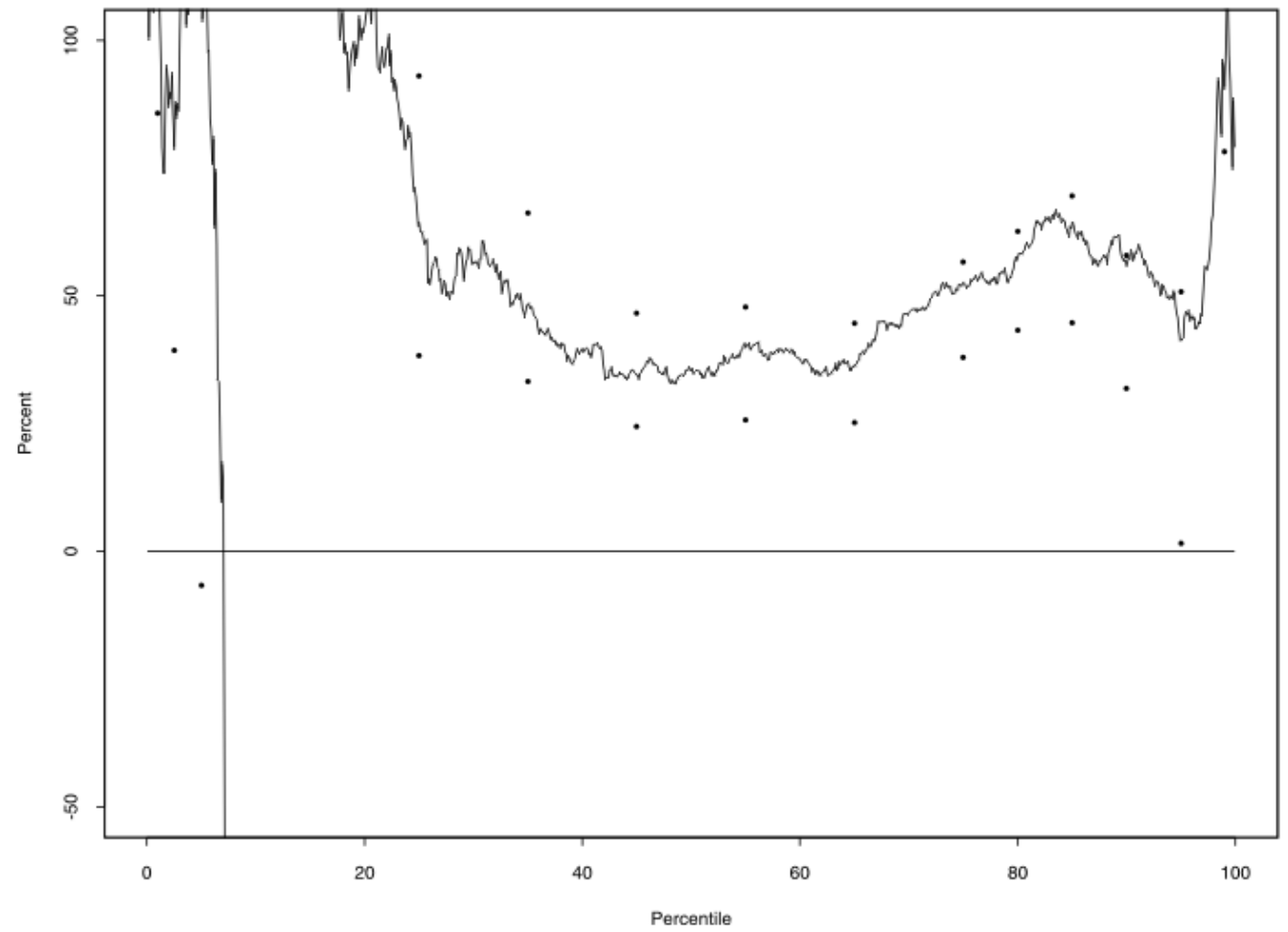


Figure 3a: QCV plot for net worth, not de-trended, 1989-2004.

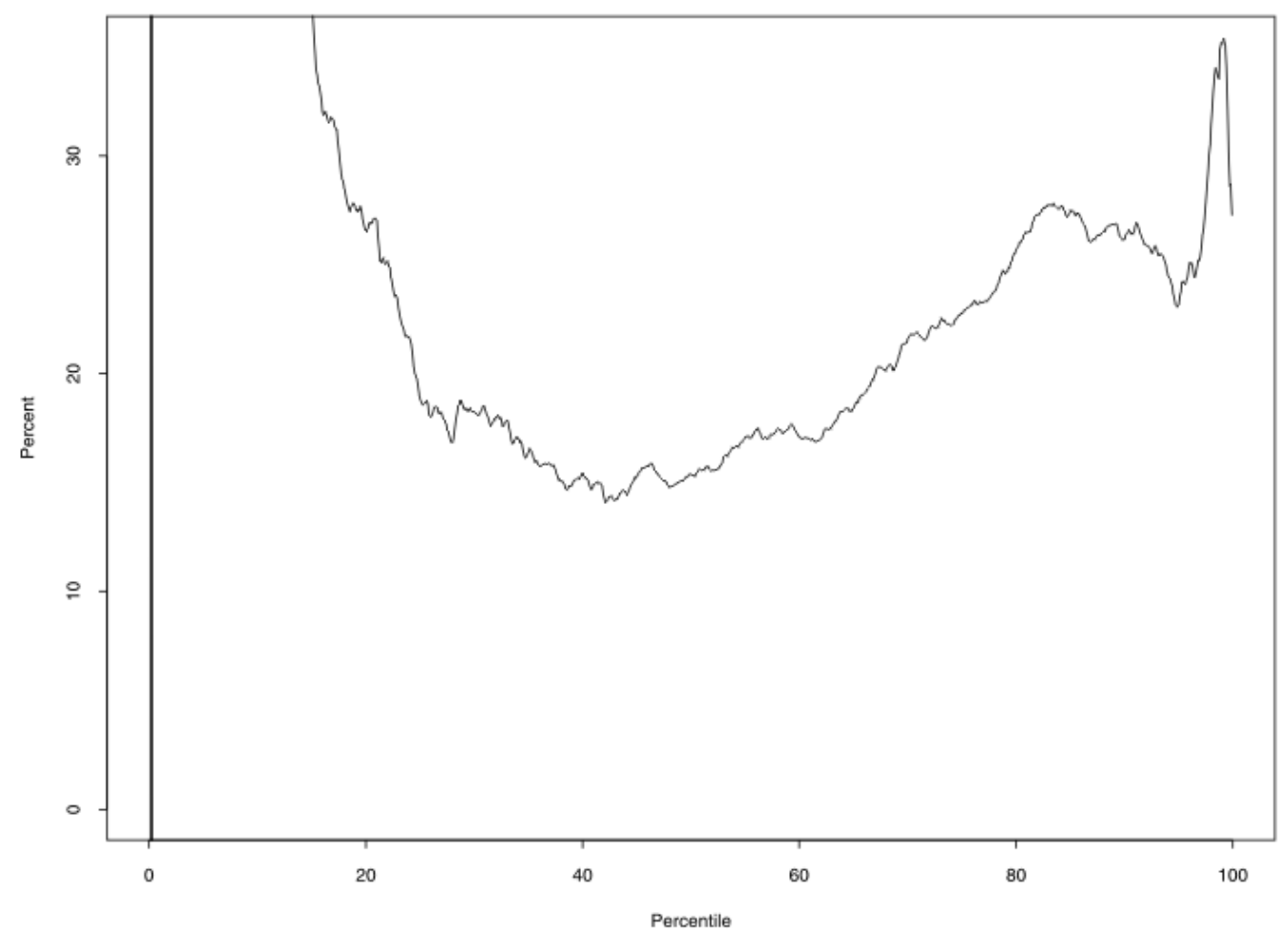

Figure 3b: QCV plot for net worth, de-trended, 1989-2004.

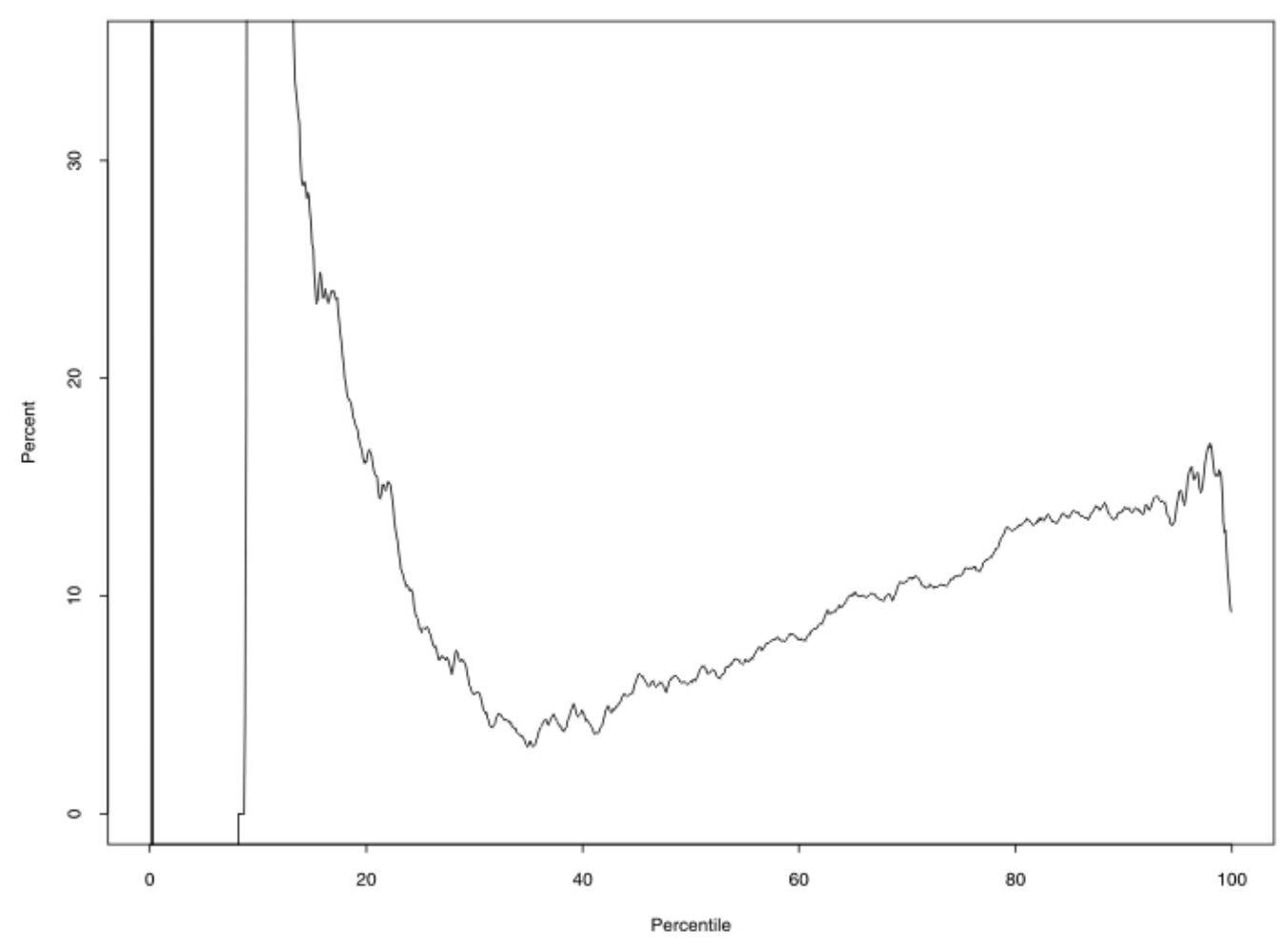




\section{Sources of Wealth Changes}

Changes in wealth overall are due to capital gains and losses_-realized and unrealized — on portfolio items and to variations in saving out of varying current income, including returns on assets. Portfolio selections, inheritance or gifts-both those received and those given-and changes in household structure and other demographic factors may also be important for individual families. Given the cross-sectional nature of the SCF data and the lack of relevant retrospective information in the survey, these points can be addressed only obliquely. Here income, saving behavior, capital gains, inheritances, portfolio structure, and demographics are addressed separately as contributors to the shape of the wealth distribution.

The role of income. Two relevant sources of income data are available for this analysis. There are six cross sections of SCF data, and for the period 1999 to 2001 there is information on the variability of income over time for individual observations from the SOI data used in the design of the 2004 SCF sample.

When the SCF cross sections are analyzed with a QCV plot, the result is that the data show very little difference in variability across almost all of the income distribution (figure $4 a) .{ }^{15}$ Only at the extremes of the distribution does the variability increase substantially. The lowest region of variability is the area around the median. De-trending the data by quantiles makes the plot more spikey, but other than shifting the low point to about the $25^{\text {th }}$ percentile, the relative pattern is maintained (figure 4b). These results reflect the volatility of the income distribution, so if families remained at the same relative position over the period, the volatility would have implications for the plausibility of income shocks as a driver of wealth changes. But the small changes compared to wealth shifts over the period suggests that idiosyncratic variations are key or that income is not the primary driver of changes in wealth distribution.

\footnotetext{
${ }^{15}$ The appendix provides QD and RQD plots comparing the distribution of family income in 2004 with that in the earlier surveys.
} 
Figure 4a: QCV plot for income, not detrended, 1989-2004.

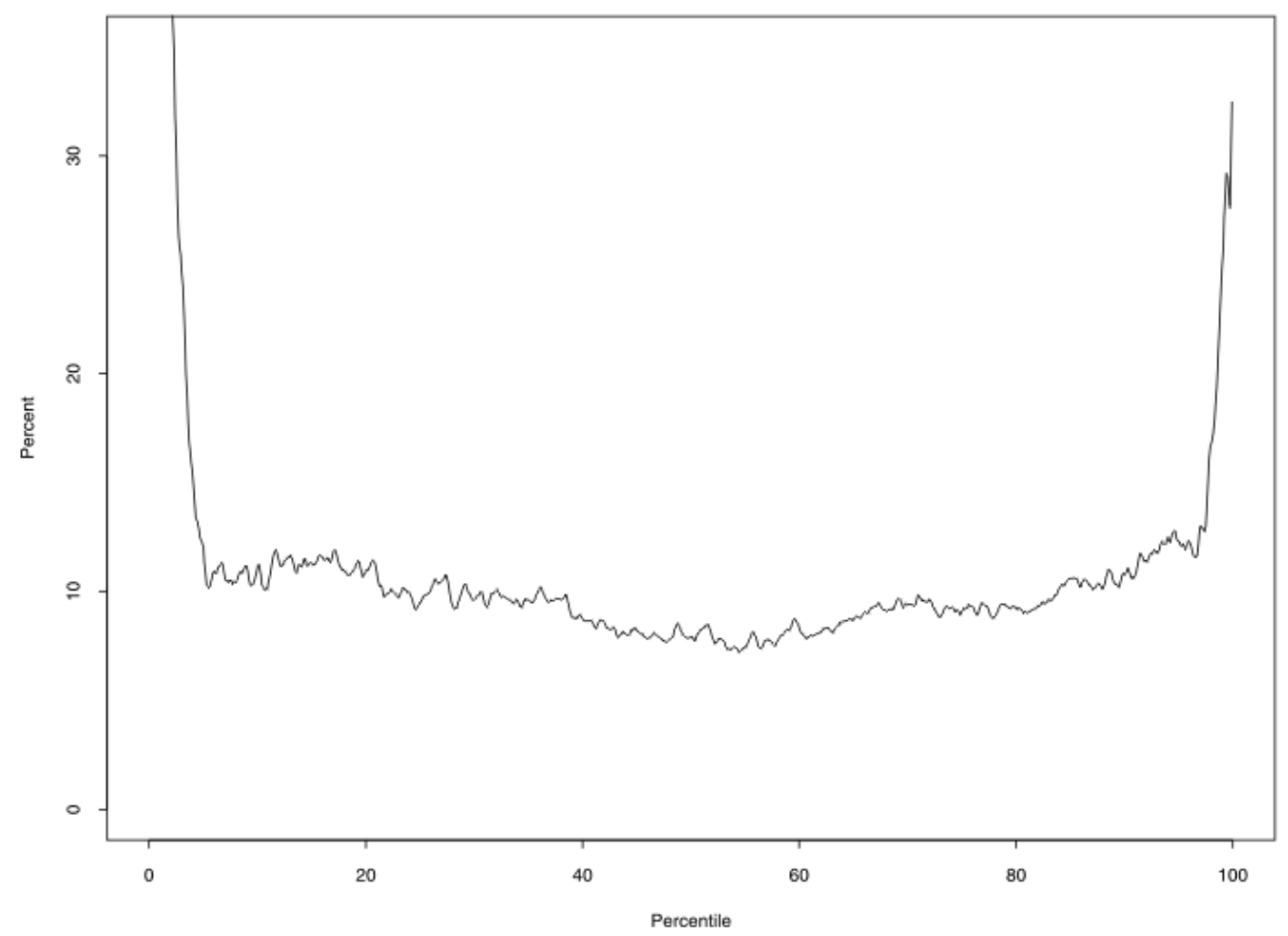

Figure 4b: QCV plot of income, detrended, 1989-2004.

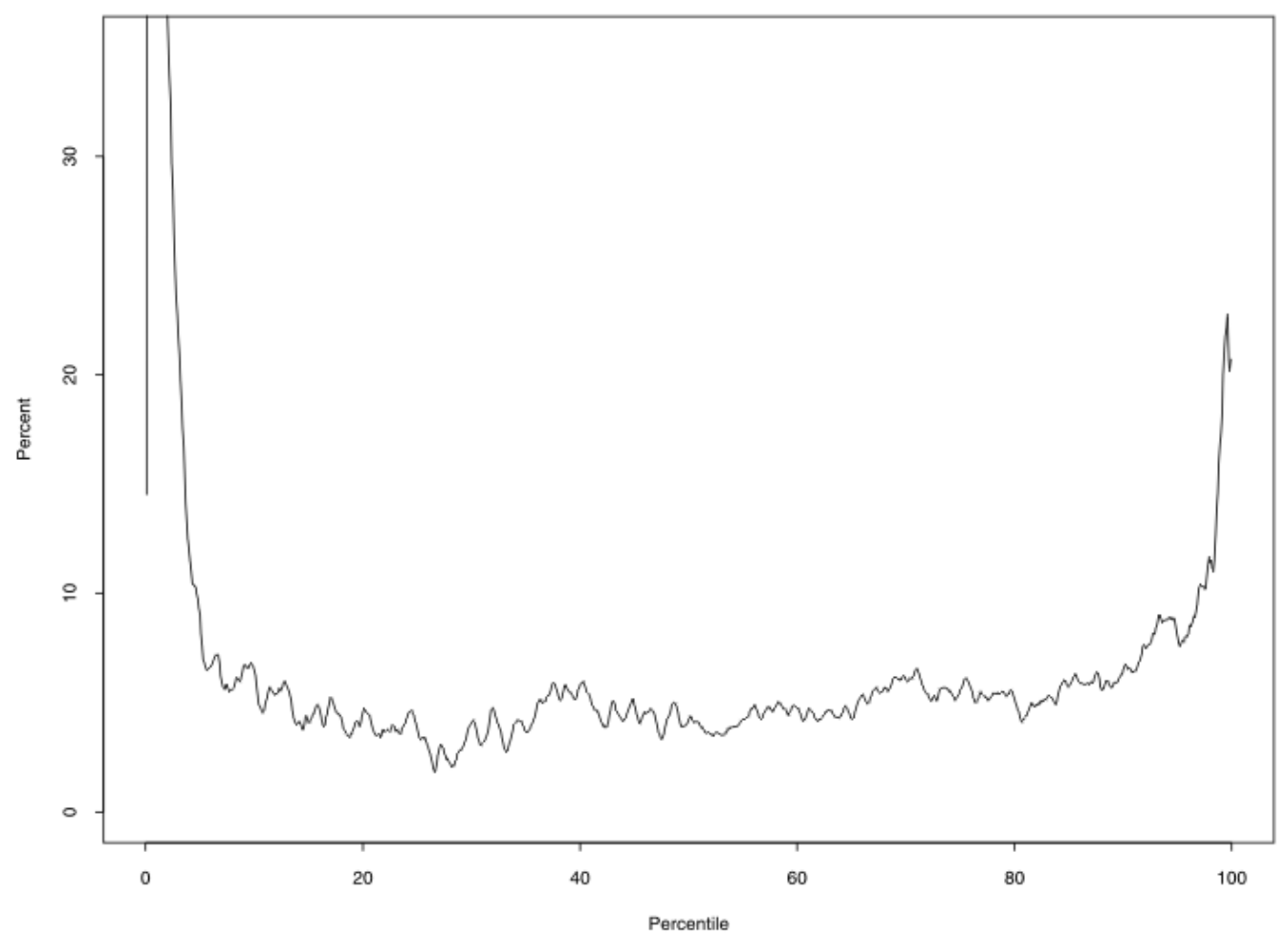


Figure 5: Distribution of the coefficient of variation of income, 1999-2001, by wealth index stratum; $25^{\text {th }}, 50^{\text {th }}, 75^{\text {th }}$, and $90^{\text {th }}$ percentiles.

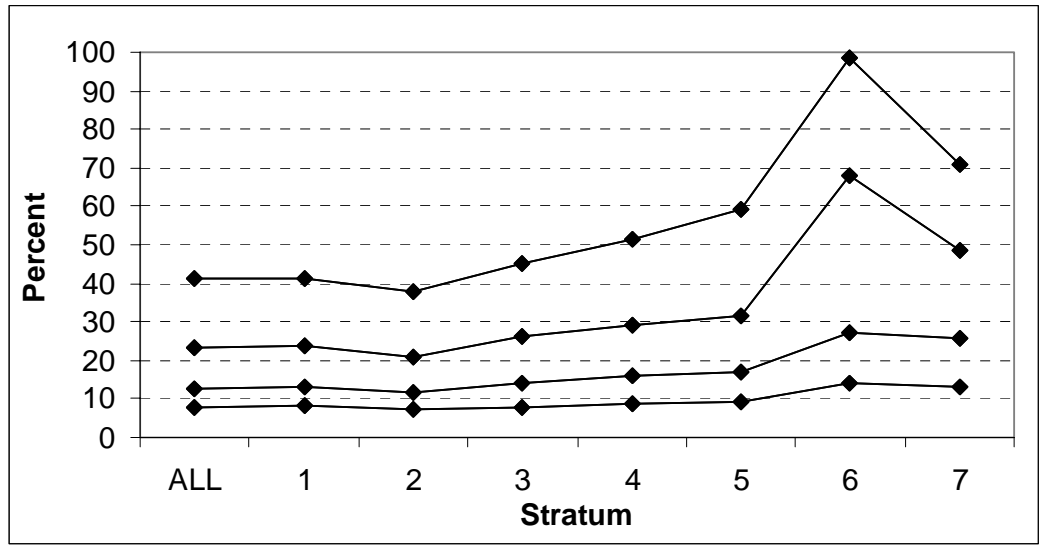

Individual-specific income information is available in the SOI data used to construct the list sample for the SCF. To support the selection of that sample and later nonresponse adjustments, every observation of domestic residents in the file is assigned a value of the wealth index used to create the strata

for sample selection. For the great majority of cases, this assignment is made on the basis of three years of data on the components of income, with the intent of smoothing transitory shocks in the estimation of the wealth index. ${ }^{16}$ In addition to its utility for the subject of this paper, the inspection of the variability of the SOI income data is an important element of the evaluation of the sample design. For each wealth-index stratum in the SOI data, figure 5 reports selected quantiles $\left(25^{\text {th }}, 50^{\text {th }}, 75^{\text {th }}\right.$, and $\left.90^{\text {th }}\right)$ of the distribution of the coefficient of variation of total income, where the underlying coefficients of variation are computed using three observations for each of the individual taxpayer units. ${ }^{17}$ Although the exact correspondences of the stratum indicators with income and wealth are not disclosable, it can be said that the first stratum encompasses approximately the lowest 75 percent of the wealth index distribution and the strata above the third one encompass about the highest 2 percent of the distribution.

What is clear in the figure is that there is a longer right-hand tail for the higher strata. Variability of labor income is the most important factor at the bottom end of the distribution and variability of capital income is the most important factor at the other end. According to financial theory, risky assets (those more variable in price) should have a higher expected rate of return. Thus, loosely speaking, one would expect to see a relatively greater density of higher positive returns for risky assets than would be the case for safer assets. For some families in this data set,

\footnotetext{
${ }^{16}$ Cases where more limited income information is used include those where there was a change in filing status (typically from married filing jointly to filing separately, or vice versa) or where a return was not filed at all.

${ }^{17}$ Note that the wealth index turns more strongly on capital income flows (e.g., interest, dividend, and business income and capital gains and losses) than on total income. Observations with fewer than three years of income data are not included in the plot.
} 
the spikes in returns could then be taken as directly reflective of one reason they were as wealthy as they were. However, it may also be that other families, particularly very wealthy ones, acted over this time in a deliberate way to time their income receipts, either for tax-related purposes or for more narrow personal purposes. In this case, the variability would have no direct implication for wealth.

For many families, the income measured either in the SCF or in SOI data is, in principle, reasonably close to their true economic income. For others, employer contributions to retirement plans and health insurance may be important elements in a broader concept of income.

According to the 2004 SCF, 7.7 percent of families had some sort of employer-provided vehicle that could be used for personal purposes. Some families have access to perquisites such as employer-provided vacation properties. But surely the largest hole in the measurement of the income of U.S. families is unrealized capital gains. Some gains may be realized only very rarely-for example, upon the sale of a house-and others may never be realized as income-for example, an appreciated business passed to heirs. As discussed in more detail later in this section, unrealized gains appear to be a very important factor in the observed distribution of wealth.

Saving out of income. The SCF also contains information on families' saving practices. Respondents are asked to describe their family’s typical saving practices and then to characterize the level of their expenditures (excluding capital investments) relative to their income. In 2004, the proportion of families that routinely spent at least as much as their income declines across wealth percentile groups - from 42.7 percent in the bottom quartile of the wealth distribution to 5.9 percent in the highest one percent of the distribution (table 6). ${ }^{18}$ The proportion of families with some type of saving plan rises from 26.5 percent in the bottom quartile to 69.1 percent for the top one percent. A substantial proportion in every wealth group saves whatever is "left over" at the end of the month. A very similar pattern of increasing saving with wealth is seen in the data on the actual saving behavior of families in the preceding year. Thus, it seems reasonable to characterize relatively wealthy families as being ones where it is more likely that at least additional wealth is generated by active saving out of current income.

\footnotetext{
${ }^{18}$ Because the general patterns across wealth groups of both typical saving behavior and saving over the previous year are very similar across the 1989-2004 surveys, only the 2004 data are shown.
} 
Table 6: Usual saving behavior and saving behavior last year, by percentile of the distribution of net worth, percent, 2004.

\begin{tabular}{|lrrrrrrrr|}
\hline & All & $0-25$ & $25-50$ & $50-75$ & $75-90$ & $90-95$ & $95-99$ & $99-100$ \\
& & & & & & & & \\
Usual saving: & & & & & & & & \\
$\quad$ Spend more than income & 7.0 & 13.5 & 7.6 & 4.2 & 3.4 & 2.8 & 1.6 & 1.5 \\
$\quad$ Spend same as income & 16.3 & 29.2 & 18.0 & 11.5 & 6.5 & 5.7 & 7.0 & 4.4 \\
$\quad$ Save "left over" income & 30.2 & 30.8 & 33.0 & 30.3 & 27.0 & 25.2 & 28.5 & 25.0 \\
$\quad$ Some saving plan & 46.5 & 26.5 & 41.4 & 54.1 & 63.0 & 66.3 & 62.8 & 69.1 \\
& & & & & & & & \\
Saving last year: & & & & & & & & \\
$\quad$ Spent more than income & 15.4 & 24.8 & 16.4 & 11.2 & 10.4 & 6.8 & 9.3 & 5.9 \\
$\quad$ Spent same as income & 28.5 & 40.4 & 30.0 & 26.7 & 17.2 & 21.5 & 12.8 & 4.4 \\
$\quad$ Spent less than income & 56.1 & 34.8 & 53.6 & 62.2 & 72.4 & 71.6 & 78.0 & 89.8 \\
\hline
\end{tabular}

Capital gains and wealth. Many families accumulate wealth simply by continuing to own certain assets. The Federal Reserve Board's flow of funds accounts provide data on aggregate capital gains for several assets owned by the household sector (Z.1 Release, table R.100). ${ }^{19}$ For most of the years considered in this paper, holding gains on assets explain a very large fraction of the change in net worth in the flow of funds accounts; for example, in the fourth quarter of 2004, holding gains accounted for about 92 percent of the change in the net worth of the household sector.

For assets held directly by households, gains are relevant mainly for real estate investments, private businesses, mutual funds, and publicly traded stocks. The SCF contains

Table 7: Median ratio of capital gains to assets and ratio of aggregate capital gains to aggregate assets, by percentiles of the wealth distribution, 1989-2004, percent.

\begin{tabular}{|c|c|c|c|c|c|c|c|c|c|c|c|c|}
\hline & $\begin{array}{l}1989 \\
\text { Median } \\
\text { ratio }\end{array}$ & $\begin{array}{l}\text { Agg. } \\
\text { ratio }\end{array}$ & $\begin{array}{l}1992 \\
\text { Median } \\
\text { ratio }\end{array}$ & $\begin{array}{l}\text { Agg. } \\
\text { ratio }\end{array}$ & $\begin{array}{l}1995 \\
\text { Median } \\
\text { ratio }\end{array}$ & $\begin{array}{l}\text { Agg. } \\
\text { ratio }\end{array}$ & $\begin{array}{l}1998 \\
\text { Median } \\
\text { ratio }\end{array}$ & $\begin{array}{l}\text { Agg. } \\
\text { ratio }\end{array}$ & $\begin{array}{l}2001 \\
\text { Median } \\
\text { ratio }\end{array}$ & $\begin{array}{l}\text { Agg. } \\
\text { ratio }\end{array}$ & $\begin{array}{l}2004 \\
\text { Median } \\
\text { ratio }\end{array}$ & $\begin{array}{l}\text { Agg. } \\
\text { ratio }\end{array}$ \\
\hline All & 11.1 & 34.0 & 7.9 & 32.1 & 5.6 & 27.3 & 7.6 & 28.3 & 8.8 & 28.8 & 11.2 & 30.7 \\
\hline $0-25$ & 0.0 & -6.2 & 0.0 & -7.5 & 0.0 & 1.1 & 0.0 & 2.2 & 0.0 & 0.0 & 0.0 & 5.7 \\
\hline $25-50$ & 5.4 & 14.5 & 4.6 & 13.7 & 2.9 & 11.2 & 5.5 & 13.3 & 6.8 & 13.6 & 8.4 & 16.0 \\
\hline $50-75$ & 30.2 & 28.1 & 22.0 & 24.5 & 19.5 & 21.4 & 18.8 & 21.1 & 20.1 & 23.5 & 24.8 & 27.0 \\
\hline 75-90 & 32.0 & 32.0 & 28.9 & 29.1 & 24.2 & 25.6 & 21.0 & 23.9 & 20.7 & 25.7 & 24.3 & 27.5 \\
\hline 90-95 & 32.2 & 32.7 & 27.5 & 29.1 & 21.4 & 20.9 & 21.0 & 24.9 & 21.3 & 24.3 & 26.7 & 28.0 \\
\hline 95-99 & 31.9 & 33.3 & 31.1 & 33.5 & 21.1 & 26.0 & 26.1 & 29.0 & 24.5 & 28.0 & 30.0 & 32.7 \\
\hline $99-100$ & 42.1 & 44.2 & 41.1 & 43.8 & 33.6 & 38.6 & 39.6 & 42.0 & 33.7 & 38.9 & 31.2 & 37.0 \\
\hline
\end{tabular}

\footnotetext{
${ }^{19}$ The household sector includes actual households as well as non-profit organizations.
} 
information on the unrealized gains embedded in all of these assets. ${ }^{20}$ For principal residences, the original purchase price and subsequent improvements are known; for other real estate, only the original price is known; for private businesses, the tax basis is known; and for mutual funds and directly-held stocks, the amount of gain or loss in the current value is known.

For families in the lowest 25 percent of the wealth distribution (table 7), capital gains explain very little of a typical family's wealth, and even in aggregate the fraction is quite small for the group (or negative in periods where the total wealth of the group is negative); this finding reflects the fact that ownership of assets that experience capital gains is relatively less common in this group. For the second 25 percent of the wealth distribution, the median ratio of gains to assets ranged only between 2.9 and 8.4 percent over the 1989-2004 period and the aggregate ratio of gains to assets ranged between 11.2 and 16.0 percent. But for the remaining half of the wealth distribution, both the median and aggregate ratios are generally above 20 percent, and for the highest 1 percent of the wealth distribution, the ratio ranges even higher-over 40 percent; the difference reflects the much higher rate of ownership among this group of the relatively risky assets that experience capital gains.

Some families may turn over their assets frequently and receive capital gains as a regular part of their financial management, but have little in the way of unrealized gains; others may have realized more sporadic gains in the past. Although the survey does not provide historical data on gains and losses, it does provides information on realized gains and losses in the calendar year preceding the survey. ${ }^{21}$ The 2004 survey’s information for 2003 income indicates that 10.7 percent of families had gains or losses, the median amount for those having losses or gains was $\$ 20,600$, and the ratio of the total amount of realized gains and losses to total assets was 0.4 percent.

Inheritances and wealth. Depending on how they are divided, inheritances and gifts may affect the shape of the overall wealth distribution. In principle, the SCF provides information on all inheritances and substantial gifts received by the family, though nothing is known about the

\footnotetext{
${ }^{20} \mathrm{An}$ important omission in the survey for this purpose is the lack of information about capital gains on assets held through retirement accounts and trusts.

${ }^{21}$ SOI data for the same period shows about twice as much in realized gains as the SCF. Although the SCF income data should, in principle, follow the classification of a personal income tax return, it may differ in some instances. For example, families that experience gains and losses through a sole proprietorship or other business may report gains as business income that should appear separately on a tax return.
} 
wealth of the person making the transfer; substantial gifts given by the family are less well covered in the survey. ${ }^{22}$

Table 8: Percent of families having ever received an inheritance or substantial gift, by wealth percentile group, 1989-2004.

\begin{tabular}{|llrrrrr|}
\hline \multirow{2}{*}{ Year } & \multicolumn{7}{l|}{ Wealth percentile group } \\
\cline { 2 - 7 } & All & $0-50$ & $50-90$ & $90-95$ & $95-99$ & $99-100$ \\
1989 & 23.4 & 12.5 & 31.5 & 47.7 & 45.7 & 50.8 \\
1992 & 20.7 & 11.2 & 27.0 & 37.2 & 48.6 & 48.5 \\
1995 & 21.4 & 12.5 & 26.0 & 46.8 & 50.1 & 39.9 \\
1998 & 20.4 & 12.6 & 25.4 & 33.9 & 44.3 & 43.3 \\
2001 & 17.8 & 9.4 & 23.4 & 34.6 & 40.4 & 44.9 \\
2004 & 20.3 & 12.6 & 25.3 & 40.0 & 38.9 & 33.3 \\
\hline
\end{tabular}

From 1989 to 2004, the share of families that reported having ever received an inheritance or substantial gift fell from 23.4 percent to 20.4 percent (table 8), with nearly all of that decline occurring from 1989 to 1992. Although the set of families in existence changes over time, it seems likely that the drop in 1992 and the similarly large dip in 2001

are at least partially reflective of variability due to sampling error. Receipt of such transfers varied somewhat during the 1989-2004 period for the lower half of the wealth distribution, but was almost unchanged from 1989 at 12.6 percent of families in 2004. Receipt is much more common in the higher wealth groups, but it appears that the proportion of families who had received these transfers tended to decline. For example, in 198950.8 percent of the wealthiest 1 percent of families had received such transfers at some time, whereas in 2004 the figure was 33.3 percent.

Families may receive inheritances and gifts at various times over their lives, and they may choose to consume part of what they receive. Adjustments for differences in the price level between the time of the receipt and the time of the survey may be made using an historical CPI series. But three other questions must be faced before evaluating the contribution of inheritances and gifts to the current distribution of wealth: what to do about the wealth generated through gains and income from assets received earlier, what to do about the possibility that the amount was invested unfortunately and incurred losses, and what to do about the possibility that the receiver either spent or gave away part of the assets received. Here several alternatives are considered in order to gain a sense of the robustness of the relationships in the data.

First, the values of all inheritances and substantial gifts are first adjusted to dollars of the survey year using the historical CPI. A second measure is created assuming that the inflationin the survey.

${ }^{22}$ Transfers such as payments for education and intangible transfers such as “connections” are not captured 
adjusted amount grew at a real rate of three percent since it was received. ${ }^{23}$ Then two additional measures are created by truncating the two "current" measures of the amount received at the level of gross assets.

Total untruncated gifts and inheritances as a percent of total wealth declined from a high of 13.8 percent in 1989 to a low of 5.7 percent in 2001, before turning up again in 2004 (table 9). The untruncated measure incorporating earnings on the gifts and inheritances ranges much higher-to 31.6 percent in 1989-but also follows the same relative path. The truncated versions show a similar relative path at a lower level, as expected, but with a weaker terminal up-tick. The same patterns hold if the ratio is taken relative to gross assets instead of net worth.

When the ratios are broken out by wealth percentile groups, the time paths appear considerably noisier, particularly in the untruncated series. However, for the truncated measures involving net worth in all the years except 1989, the wealthiest one percent had the smallest fraction of its net worth from inheritances. For the truncated measures involving gross assets, the relative importance of inheritances tends to be greatest among the groups between the $90^{\text {th }}$ and $99^{\text {th }}$ percentiles; the levels in these groups roughly track the overall movement. One could interpret the data as suggesting that inheritances are responsible for an important part of the wealth of each wealth group and that the wealthiest families were more likely than most to have come by their wealth by means other than inheritances, though a "seed" of inherited resources may still have been a critical factor in their achieving such a high wealth level.

\footnotetext{
${ }^{23}$ Obviously, returns have vary considerably over time and across people depending on how assets are invested. One might also adjust the amount of inheritances using particular market indicators, such as the Wilshire 5000 index or the thirty-year Treasury rate.
} 
Table 9: Untruncated and truncated total inheritances as a percent of total assets and total net worth, by wealth percentile groups, inheritances adjusted for inflation and inheritances adjusted for inflation and 3 percent growth, 1989-2004.

\begin{tabular}{|c|c|c|c|c|c|c|c|c|}
\hline \multirow{3}{*}{$\begin{array}{l}\text { Survey year } \\
\text { Wealth prcntl }\end{array}$} & \multicolumn{4}{|c|}{ As a percent of net worth } & \multicolumn{4}{|c|}{ As a percent of gross assets } \\
\hline & \multicolumn{2}{|c|}{ Inflation adj. } & \multicolumn{2}{|c|}{ Infl. \& growth adj. } & \multicolumn{2}{|c|}{ Inflation adj. } & \multicolumn{2}{|c|}{ Infl. \& growth adj. } \\
\hline & Sum & Trunc. sum & Sum & Trunc. sum & Sum & Trunc. sum & Sum & Trunc. sum \\
\hline \multicolumn{9}{|l|}{1989} \\
\hline All families & 13.8 & 9.5 & 31.6 & 16.4 & 12.1 & 9.5 & 27.7 & 14.5 \\
\hline $0-50$ & 26.4 & 7.8 & 57.9 & 21.6 & 12.6 & 7.8 & 27.6 & 10.3 \\
\hline $50-90$ & 13.0 & 8.1 & 25.6 & 15.0 & 10.5 & 8.1 & 20.7 & 12.1 \\
\hline $90-95$ & 17.5 & 11.4 & 35.4 & 18.2 & 15.9 & 11.4 & 32.1 & 16.5 \\
\hline $95-99$ & 14.4 & 10.0 & 38.7 & 18.2 & 13.6 & 10.4 & 36.5 & 17.1 \\
\hline $99-100$ & 11.2 & 9.7 & 27.5 & 15.3 & 11.0 & 9.7 & 26.9 & 15.0 \\
\hline \multicolumn{9}{|l|}{1992} \\
\hline All families & 13.4 & 9.6 & 28.5 & 14.0 & 11.5 & 8.3 & 24.4 & 11.9 \\
\hline $0-50$ & 16.1 & 11.3 & 30.5 & 15.7 & 6.9 & 4.9 & 13.2 & 6.8 \\
\hline $50-90$ & 12.2 & 9.5 & 25.7 & 13.3 & 9.7 & 7.5 & 20.3 & 10.5 \\
\hline $90-95$ & 15.5 & 10.9 & 31.8 & 14.8 & 13.8 & 9.7 & 28.3 & 13.2 \\
\hline $95-99$ & 13.5 & 11.2 & 30.9 & 17.0 & 12.4 & 10.3 & 28.5 & 15.6 \\
\hline $99-100$ & 13.5 & 7.8 & 27.9 & 11.6 & 13.0 & 7.6 & 26.9 & 11.2 \\
\hline \multicolumn{9}{|l|}{1995} \\
\hline All families & 11.7 & 7.6 & 23.9 & 11.1 & 10.0 & 6.5 & 20.4 & 9.5 \\
\hline $0-50$ & 14.4 & 10.0 & 24.4 & 12.6 & 5.9 & 4.1 & 10.0 & 5.1 \\
\hline $50-90$ & 10.3 & 8.8 & 20.6 & 12.3 & 8.1 & 6.9 & 16.2 & 9.6 \\
\hline $90-95$ & 10.4 & 10.2 & 17.1 & 14.5 & 9.2 & 9.0 & 15.2 & 12.9 \\
\hline $95-99$ & 20.4 & 8.3 & 39 & 11.9 & 19.0 & 7.8 & 36.4 & 11.1 \\
\hline $99-100$ & 7.6 & 5.0 & 19.6 & 8.4 & 7.4 & 4.9 & 19 & 8.1 \\
\hline \multicolumn{9}{|l|}{1998} \\
\hline All families & 7.6 & 6.6 & 17.9 & 9.0 & 6.6 & 5.7 & 15.3 & 7.7 \\
\hline $0-50$ & 20.7 & 13.3 & 36.0 & 16.5 & 8.0 & 5.1 & 13.9 & 6.4 \\
\hline $50-90$ & 8.2 & 7.0 & 13.1 & 9.2 & 6.5 & 5.6 & 10.4 & 7.3 \\
\hline $90-95$ & 8.0 & 7.8 & 12.8 & 10.1 & 7.1 & 7.0 & 11.5 & 9.1 \\
\hline $95-99$ & 7.5 & 7.4 & 11.9 & 10.4 & 6.9 & 6.8 & 10.9 & 9.6 \\
\hline $99-100$ & 6.0 & 4.8 & 26.1 & 6.7 & 5.9 & 4.7 & 25.4 & 6.5 \\
\hline \multicolumn{9}{|l|}{2001} \\
\hline All families & 5.7 & 5.1 & 9.0 & 6.6 & 5.0 & 4.5 & 7.9 & 5.8 \\
\hline $0-50$ & 12.0 & 8.6 & 20.4 & 10.3 & 5.3 & 3.8 & 9.0 & 4.5 \\
\hline $50-90$ & 8.9 & 7.2 & 14.4 & 8.8 & 7.2 & 5.8 & 11.6 & 7.1 \\
\hline $90-95$ & 6.8 & 6.7 & 11.5 & 8.9 & 6.2 & 6.1 & 10.5 & 8.1 \\
\hline $95-99$ & 4.7 & 4.7 & 6.8 & 6.5 & 4.5 & 4.4 & 6.4 & 6.1 \\
\hline $99-100$ & 2.7 & 2.7 & 4.0 & 3.8 & 2.7 & 2.7 & 3.9 & 3.7 \\
\hline \multicolumn{9}{|l|}{2004} \\
\hline All families & 8.6 & 6.2 & 17.0 & 7.2 & 7.3 & 5.3 & 14.5 & 6.1 \\
\hline $0-50$ & 26.1 & 14.1 & 63.3 & 15.3 & 9.8 & 5.3 & 23.7 & 5.7 \\
\hline $50-90$ & 9.6 & 7.1 & 17.4 & 8.5 & 7.3 & 5.4 & 13.3 & 6.5 \\
\hline $90-95$ & 7.8 & 7.5 & 11.2 & 8.8 & 7. & 6.7 & 10.0 & 7.9 \\
\hline $95-99$ & 6.9 & 6.2 & 9.1 & 7.2 & 6.3 & 5.7 & 8.4 & 6.6 \\
\hline $99-100$ & 8.0 & 4.3 & 21.0 & 5.0 & 7.7 & 4.2 & 20.2 & 4.8 \\
\hline
\end{tabular}


Portfolio composition. The key role of capital gains in observed wealth serves to emphasize the importance of portfolio composition on families' wealth. For families in the highest 10 percent of the wealth distribution, the ownership rates of directly- and indirectly-held stock was above 87 percent in 2004, and that for principal residences was over 90 percent (table 10). Even within the top 10 percent, ownership rates rise strongly with wealth for real estate (residential and nonresidential) and for businesses. Ownership rates for every type of asset are lower—generally much lower—-for the bottom 50 percent of the wealth distribution; the ownership rate for principal residences was 43.3 percent and that for stock equity was 24.7 percent in 2004. Use of debt overall shows less variation across the wealth groups, but there is more variation in the use of specific types of debt. For example, installment borrowing and credit card balances are more common among lower wealth groups than among higher ones.

Across all wealth groups from 1989 to 2004, there were increases in ownership of principal residences, directly- and indirectly-held corporate equities, and tax-deferred retirement accounts; curiously, over wealth groups, home ownership grew most for the wealthiest 1 percent. Over the same period, ownership of certificates of deposit, bonds, and cash value life insurance fell notably all across the wealth distribution. Along with the increase in ownership of principal residences, use of mortgages on such properties also rose broadly; the prevalence of installment borrowing fell for all except the top wealth group, and that for credit card balances rose for all groups except the wealthiest. The declines in the prevalence of non-mortgage borrowing may reflect substitution of borrowing based on home equity. 
Table 10: Ownership of assets and liabilities, by wealth percentile groups, percent, 1989 and 2004.

\begin{tabular}{|c|c|c|c|c|c|c|c|c|c|c|c|c|}
\hline & $\begin{array}{l}1989 \\
\text { Perce }\end{array}$ & ntile gr & oup & & & & $\begin{array}{l}2004 \\
\text { Perce } \\
\end{array}$ & ntile gr & oup & & & \\
\hline & All & $0-50$ & $50-90$ & $90-95$ & 95-99 & $99-100$ & All & $0-50$ & $50-90$ & $90-95$ & 95-99 & $99-100$ \\
\hline ASSET & 94.7 & 89.3 & 100.0 & 100.0 & 100.0 & 100.0 & 97.9 & 95.9 & 100.0 & 100.0 & 100.0 & 100.0 \\
\hline FIN & 88.9 & 78.8 & 98.7 & 100.0 & 100.0 & 100.0 & 93.8 & 87.9 & 99.6 & 100.0 & 100.0 & 100.0 \\
\hline LIQ & 85.6 & 73.0 & 97.7 & 100.0 & 100.0 & 100.0 & 91.3 & 83.8 & 98.6 & 100.0 & 100.0 & 100.0 \\
\hline CDS & 19.9 & 7.7 & 28.9 & 43.5 & 48.3 & 32.5 & 12.7 & 4.4 & 19.0 & 29.9 & 28.7 & 26.3 \\
\hline SAVBND & 23.9 & 14.1 & 33.8 & 35.6 & 34.3 & 18.2 & 17.6 & 9.7 & 24.8 & 29.1 & 30.0 & 17.8 \\
\hline BOND & 5.7 & 0.7 & 5.9 & 21.1 & 37.2 & 45.8 & 1.8 & 0.1 & 1.3 & 7.4 & 15.2 & 30.6 \\
\hline STOCKS & 16.9 & 5.6 & 21.3 & 46.2 & 62.4 & 72.7 & 20.7 & 6.5 & 27.8 & 56.3 & 68.8 & 69.6 \\
\hline NMMF & 7.3 & 1.6 & 8.8 & 25.9 & 31.4 & 39.3 & 15.0 & 4.6 & 20.0 & 39.5 & 57.3 & 44.9 \\
\hline RETQLIQ & 37.0 & 18.8 & 51.5 & 67.3 & 72.6 & 71.6 & 49.7 & 28.7 & 67.7 & 80.3 & 84.4 & 82.7 \\
\hline CASHLI & 35.5 & 21.0 & 47.3 & 58.9 & 62.6 & 64.8 & 24.2 & 13.5 & 32.6 & 43.6 & 42.4 & 48.1 \\
\hline OTHMA & 3.7 & 0.7 & 5.0 & 9.9 & 14.9 & 26.6 & 7.3 & 1.2 & 11.5 & 19.7 & 20.7 & 26.3 \\
\hline OTHFIN & 13.8 & 12.4 & 12.2 & 26.8 & 25.6 & 32.1 & 9.9 & 8.2 & 10.5 & 14.1 & 16.2 & 28.2 \\
\hline NFIN & 89.2 & 78.9 & 99.5 & 100.0 & 99.9 & 99.3 & 92.5 & 85.6 & 99.3 & 99.9 & 100.0 & 100.0 \\
\hline VEHIC & 83.8 & 72.9 & 94.8 & 94.2 & 94.5 & 90.7 & 86.3 & 79.5 & 93.3 & 94.7 & 90.8 & 94.2 \\
\hline HOUSES & 63.9 & 34.9 & 92.9 & 93.6 & 92.3 & 86.5 & 69.1 & 43.3 & 94.3 & 97.3 & 96.3 & 97.5 \\
\hline ORESRE & 13.2 & 3.3 & 17.7 & 37.3 & 49.4 & 62.7 & 12.5 & 2.7 & 16.5 & 37.6 & 51.4 & 64.7 \\
\hline NNRESRE & 11.1 & 3.1 & 14.8 & 28.1 & 42.4 & 54.7 & 8.3 & 2.1 & 10.9 & 24.9 & 27.9 & 49.7 \\
\hline BUS & 11.7 & 3.4 & 13.1 & 34.9 & 55.2 & 72.8 & 11.5 & 3.2 & 14.5 & 30.6 & 45.3 & 72.1 \\
\hline OTHNFIN & 12.4 & 7.0 & 14.9 & 28.6 & 28.0 & 41.9 & 7.8 & 4.2 & 9.6 & 13.3 & 23.5 & 27.8 \\
\hline DEBT & 72.3 & 69.4 & 76.6 & 67.9 & 71.3 & 65.3 & 76.4 & 74.4 & 80.0 & 74.8 & 70.6 & 67.9 \\
\hline MRTHEL & 39.5 & 22.5 & 58.5 & 51.1 & 47.1 & 36.0 & 47.9 & 32.7 & 64.3 & 60.7 & 56.8 & 51.5 \\
\hline RESDBT & 5.2 & 1.2 & 6.4 & 17.2 & 23.0 & 21.7 & 4.0 & 0.7 & 5.0 & 11.5 & 21.1 & 23.1 \\
\hline INSTALL & 49.4 & 53.7 & 48.2 & 33.5 & 34.8 & 17.9 & 46.0 & 50.0 & 45.7 & 28.5 & 25.3 & 26.1 \\
\hline OTHLOC & 3.2 & 3.4 & 2.6 & 3.4 & 5.0 & 6.6 & 1.6 & 1.5 & 1.7 & 0.3 & 2.1 & 4.1 \\
\hline CCBAL & 39.7 & 37.9 & 46.9 & 23.7 & 16.0 & 14.8 & 46.2 & 49.2 & 48.2 & 25.9 & 22.6 & 13.3 \\
\hline ODEBT & 6.7 & 5.6 & 6.5 & 9.2 & 16.9 & 14.6 & 7.6 & 7.8 & 7.1 & 8.7 & 8.8 & 11.6 \\
\hline $\begin{array}{l}\text { Memo item: } \\
\text { EQUITY }\end{array}$ & 31.8 & 13.9 & 43.1 & 69.9 & 79.3 & 86.8 & 48.6 & 25.8 & 66.5 & 87.8 & 93.3 & 93.3 \\
\hline
\end{tabular}

Ownership shares. For some assets, the distributions of the amounts held are far more disproportionate than the differences in ownership rates. Most striking is the 62.3 percent share of business assets owned by the wealthiest 1 percent of the wealth distribution in 2004 (table 11a); the next-wealthiest 4 percent owned another 22.4 percent of the total. Other key items subject to capital gains also show strong disproportions: the wealthiest 5 percent of families owned 61.9 percent of residential real estate other than principal residences, 71.7 percent of nonresidential real estate, and 65.9 percent of directly- and indirectly-held stocks. For bonds, 93.7 percent of the total was held by this group. The lowest 50 percent of the wealth 
distribution, which held only 2.5 percent of total net worth in 2004, came close to its population share only in holdings of installment debt (46.2 percent of the total) and credit card debt (45.7 percent of total outstanding balances). Although the $50^{\text {th }}$-to- $90^{\text {th }}$ percentile group held only 27.9 percent of total net worth, they came closer to holding their population share than any of the other wealth groups. In the case of principal residences and associated debts, vehicles, and credit card balances, they exceeded their population share; note that their income share was equal to their population share in 2004.

Relative to the balance sheet for the wealth percentile groups in 1989 (table 11b), there were substantial changes in amounts by 2004-for example total net worth rose 94.4 percent over the period. At the same time, there was remarkably little change in ownership shares that was statistically consistent. However, for principal residences and other residential real estate, the data do show a significant increase in the share of the wealthiest 1 percent, which was mainly offset by declines for the $50^{\text {th }}$-to- $90^{\text {th }}$ percentile group. 
Table 11a: Amounts (billions of 2004 dollars) and shares of net worth and components distributed by net worth groups, 2004.

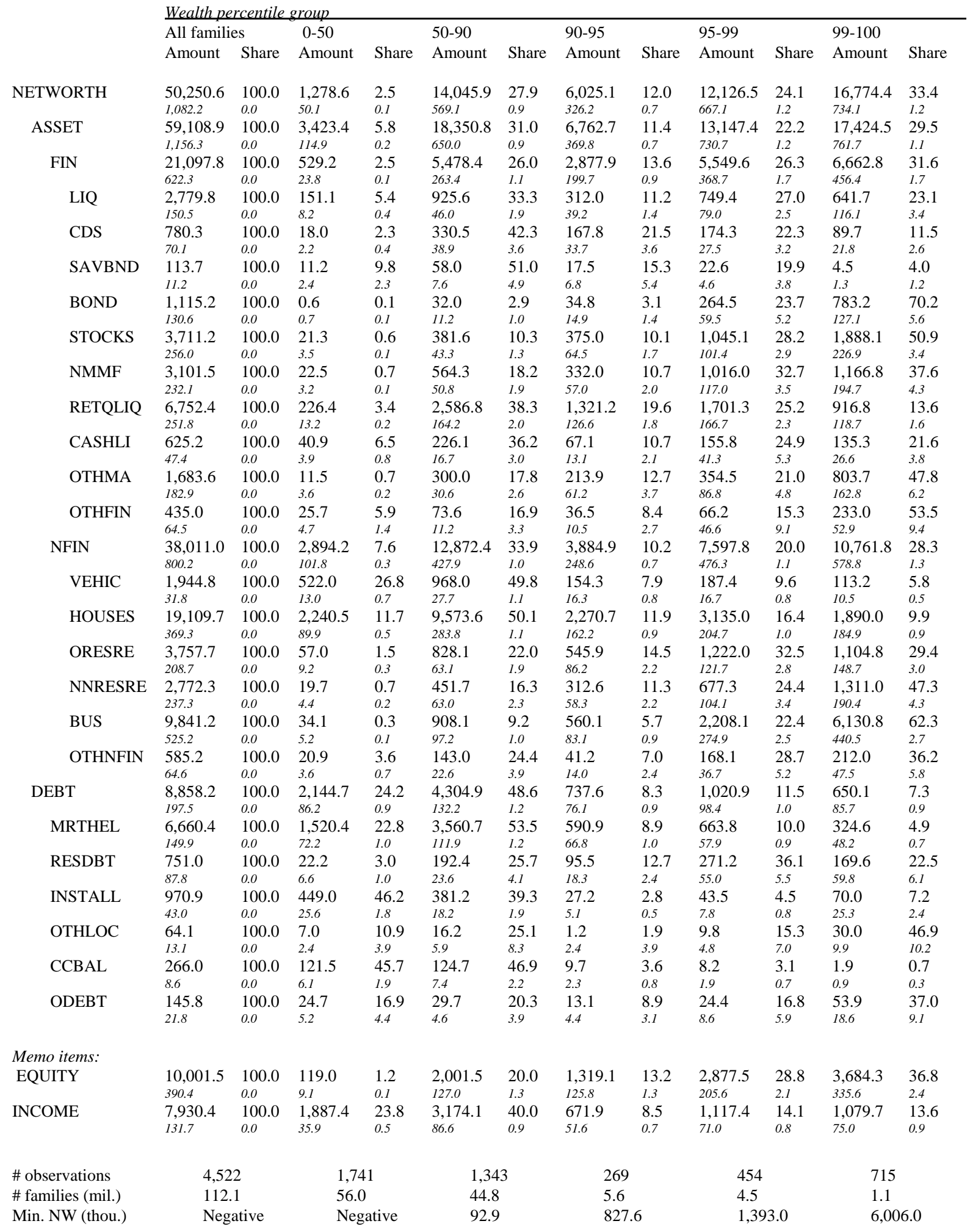

See appendix table A1 for variable definitions. 
Table 11b: Amounts (billions of 2004 dollars) and shares of net worth and components distributed by net worth groups, 1989.

\begin{tabular}{|c|c|c|c|c|c|c|c|c|c|c|c|c|}
\hline & \multicolumn{12}{|c|}{ Wealth percentile group } \\
\hline & \multicolumn{2}{|c|}{ All families } & \multicolumn{2}{|l|}{$0-50$} & \multicolumn{2}{|l|}{$50-90$} & \multicolumn{2}{|l|}{$90-95$} & \multicolumn{2}{|l|}{$95-99$} & \multicolumn{2}{|l|}{$99-100$} \\
\hline & Amount & Share & Amount & Share & Amount & Share & Amount & Share & Amount & Share & Amount & Share \\
\hline \multirow[t]{2}{*}{ NETWORTH } & $25,853.7$ & 100.0 & 763.3 & 3.0 & $7,714.4$ & 29.9 & $3,373.8$ & 13.0 & $6,226.5$ & 24.1 & $7,775.7$ & 30.1 \\
\hline & $2,061.0$ & 0.0 & 31.4 & 0.3 & 411.3 & 1.8 & 617.9 & 1.6 & 988.9 & 2.3 & 798.0 & 2.3 \\
\hline \multirow[t]{2}{*}{ ASSET } & $29,417.3$ & 100.0 & $1,597.8$ & 5.4 & 9,549.1 & 32.5 & $3,727.3$ & 12.6 & $6,573.7$ & 22.3 & $7,969.4$ & 27.1 \\
\hline & $2,168.7$ & 0.0 & 57.1 & 0.4 & 470.1 & 1.8 & 690.2 & 1.6 & 993.8 & 2.1 & 845.6 & 2.1 \\
\hline \multirow[t]{2}{*}{ FIN } & $9,079.3$ & 100.0 & 311.4 & 3.4 & $2,541.1$ & 28.0 & $1,238.2$ & 13.6 & $2,424.7$ & 26.7 & $2,564.0$ & 28.3 \\
\hline & 760.6 & 0.0 & 16.4 & 0.4 & 204.3 & 1.9 & 170.8 & 1.4 & 396.0 & 3.0 & 391.5 & 3.5 \\
\hline LIQ & $1,688.0$ & 100.0 & 101.2 & 6.0 & 542.0 & 32.2 & 222.3 & 13.2 & 365.7 & 21.7 & 456.9 & 26.9 \\
\hline & 159.4 & 0.0 & 5.6 & 0.7 & 43.4 & 3.7 & 28.7 & 2.2 & 102.1 & 5.7 & 193.1 & 9.3 \\
\hline CDS & 896.2 & 100.0 & 36.7 & 4.1 & 392.1 & 43.8 & 148.7 & 16.6 & 228.2 & 25.3 & 90.4 & 10.2 \\
\hline & 81.2 & 0.0 & 5.8 & 0.7 & 36.9 & 4.0 & 23.7 & 2.7 & 73.1 & 6.2 & 38.8 & 4.1 \\
\hline SAVBND & 134.0 & 100.0 & 9.0 & 6.7 & 63.9 & 47.6 & 25.3 & 19.1 & 26.2 & 19.3 & 9.7 & 7.3 \\
\hline & 20.3 & 0.0 & 1.6 & 1.7 & 10.9 & 7.4 & 10.2 & 6.9 & 12.4 & 6.6 & 5.6 & 4.3 \\
\hline BOND & 897.8 & 100.0 & 2.9 & 0.3 & 69.6 & 7.8 & 99.7 & 11.0 & 261.6 & 29.1 & 463.9 & 51.8 \\
\hline & 188.1 & 0.0 & 1.3 & 0.1 & 12.7 & 1.8 & 38.7 & 3.7 & 74.8 & 6.2 & 148.9 & 8.3 \\
\hline STOCKS & $1,385.4$ & 100.0 & 17.0 & 1.2 & 218.7 & 15.8 & 142.2 & 10.1 & 434.3 & 31.4 & 573.1 & 41.3 \\
\hline & 183.5 & 0.0 & 4.5 & 0.4 & 24.7 & 2.3 & 55.1 & 3.3 & 85.1 & 5.8 & 137.8 & 6.7 \\
\hline NMMF & 486.6 & 100.0 & 4.4 & 0.9 & 74.1 & 15.3 & 78.7 & 16.2 & 166.5 & 34.1 & 163.0 & 33.5 \\
\hline & 80.5 & 0.0 & 2.5 & 0.5 & 17.0 & 4.1 & 22.0 & 4.5 & 56.2 & 8.4 & 54.2 & 8.4 \\
\hline RETQLIQ & $1,925.6$ & 100.0 & 64.7 & 3.4 & 778.2 & 40.5 & 289.4 & 15.1 & 509.7 & 26.3 & 283.7 & 14.8 \\
\hline & 220.3 & 0.0 & 8.4 & 0.6 & 96.1 & 3.5 & 43.4 & 2.2 & 126.8 & 4.2 & 65.8 & 3.1 \\
\hline CASHLI & 539.3 & 100.0 & 47.5 & 8.8 & 230.6 & 42.8 & 86.2 & 16.0 & 88.7 & 16.4 & 86.4 & 15.9 \\
\hline & 55.7 & 0.0 & 6.7 & 1.7 & 23.7 & 4.2 & 16.4 & 3.0 & 22.1 & 3.4 & 35.1 & 5.2 \\
\hline OTHMA & 669.8 & 100.0 & 2.7 & 0.4 & 89.5 & 13.3 & 78.7 & 11.4 & 191.6 & 29.4 & 307.3 & 45.5 \\
\hline & 149.0 & 0.0 & 1.1 & 0.2 & 22.5 & 3.0 & 54.5 & 7.2 & 99.9 & 13.6 & 116.0 & 10.9 \\
\hline OTHFIN & 456.6 & 100.0 & 25.2 & 5.6 & 82.6 & 18.3 & 67.0 & 14.9 & 152.3 & 33.2 & 129.6 & 28.0 \\
\hline & 102.0 & 0.0 & 4.4 & 1.5 & 14.4 & 4.3 & 25.1 & 5.4 & 61.5 & 7.7 & 51.7 & 7.6 \\
\hline NFIN & $20,338.0$ & 100.0 & $1,286.4$ & 6.3 & $7,007.9$ & 34.5 & $2,489.2$ & 12.2 & $4,149.0$ & 20.4 & $5,405.4$ & 26.6 \\
\hline & $1,555.0$ & 0.0 & 54.4 & 0.5 & 295.5 & 2.1 & 552.7 & 2.0 & 702.9 & 2.3 & 681.1 & 2.3 \\
\hline VEHIC & $1,125.1$ & 100.0 & 288.1 & 25.6 & 547.4 & 48.7 & 106.9 & 9.5 & 117.2 & 10.4 & 65.4 & 5.8 \\
\hline & 46.6 & 0.0 & 10.9 & 1.3 & 22.0 & 2.2 & 12.7 & 1.1 & 17.7 & 1.4 & 38.9 & 2.9 \\
\hline HOUSES & $9,247.8$ & 100.0 & 899.7 & 9.7 & $5,148.3$ & 55.7 & $1,185.5$ & 12.8 & $1,403.3$ & 15.2 & 610.9 & 6.6 \\
\hline & 418.2 & 0.0 & 44.5 & 0.7 & 191.5 & 2.3 & 143.2 & 1.2 & 244.1 & 2.1 & 113.8 & 1.0 \\
\hline ORESRE & $1,653.0$ & 100.0 & 43.0 & 2.6 & 502.0 & 30.4 & 330.1 & 19.9 & 461.8 & 27.9 & 316.2 & 19.2 \\
\hline & 171.2 & 0.0 & 9.5 & 0.6 & 62.6 & 3.1 & 75.8 & 3.4 & 92.5 & 4.3 & 60.2 & 3.4 \\
\hline NNRESRE & $2,251.7$ & 100.0 & 11.6 & 0.5 & 202.7 & 9.0 & 218.7 & 9.6 & 580.9 & 25.9 & $1,237.7$ & 55.1 \\
\hline & 420.0 & 0.0 & 15.0 & 0.7 & 70.7 & 3.2 & 107.2 & 4.0 & 126.7 & 4.5 & 306.1 & 6.2 \\
\hline BUS & $5,511.4$ & 100.0 & 21.4 & 0.4 & 489.7 & 8.9 & 573.1 & 10.2 & $1,490.2$ & 27.1 & $2,937.0$ & 53.5 \\
\hline & 799.6 & 0.0 & 6.4 & 0.1 & 75.1 & 1.2 & 300.7 & 4.2 & 374.9 & 4.6 & 454.2 & 5.8 \\
\hline OTHNFIN & 549.0 & 100.0 & 22.6 & 4.1 & 117.8 & 21.5 & 74.8 & 13.6 & 95.6 & 17.4 & 238.2 & 43.4 \\
\hline & 82.4 & 0.0 & 4.4 & 0.9 & 14.2 & 3.9 & 23.2 & 4.2 & 35.0 & 5.6 & 73.5 & 8.4 \\
\hline DEBT & 3,563.6 & 100.0 & 834.5 & 23.4 & $1,834.7$ & 51.5 & 353.5 & 9.9 & 347.3 & 9.8 & 193.6 & 5.4 \\
\hline & 162.4 & 0.0 & 43.1 & 1.6 & 97.8 & 2.2 & 85.9 & 2.1 & 55.7 & 1.6 & 78.7 & 2.0 \\
\hline MRTHEL & $2,445.0$ & 100.0 & 508.4 & 20.8 & $1,413.0$ & 57.8 & 241.8 & 9.9 & 211.0 & 8.6 & 70.8 & 2.9 \\
\hline & 114.7 & 0.0 & 36.3 & 1.7 & 81.0 & 2.5 & 52.5 & 1.9 & 42.3 & 1.7 & 42.4 & 1.6 \\
\hline RESDBT & 276.1 & 100.0 & 17.9 & 6.5 & 90.4 & 32.8 & 58.8 & 21.1 & 69.4 & 25.2 & 39.6 & 14.4 \\
\hline & 37.1 & 0.0 & 6.2 & 2.2 & 16.0 & 4.4 & 22.4 & 6.6 & 18.3 & 5.8 & 12.0 & 4.2 \\
\hline INSTALL & 594.2 & 100.0 & 245.2 & 41.3 & 258.3 & 43.5 & 32.7 & 5.5 & 36.2 & 6.1 & 21.9 & 3.7 \\
\hline & 41.9 & 0.0 & 13.0 & 3.0 & 17.9 & 3.0 & 8.5 & 1.4 & 9.8 & 1.6 & 34.4 & 4.8 \\
\hline OTHLOC & 65.9 & 100.0 & 4.9 & 7.7 & 7.1 & 10.9 & 7.9 & 11.6 & 5.5 & 8.6 & 40.5 & 61.3 \\
\hline & 24.6 & 0.0 & 1.0 & 4.3 & 2.7 & 6.9 & 5.9 & 7.9 & 4.1 & 8.9 & 22.1 & 16.7 \\
\hline CCBAL & 100.1 & 100.0 & 42.9 & 42.8 & 49.1 & 49.0 & 5.1 & 5.0 & 2.8 & 2.8 & 0.3 & 0.3 \\
\hline & 5.4 & 0.0 & 3.4 & 3.0 & 4.0 & 3.2 & 2.3 & 2.2 & 0.9 & 0.9 & 0.2 & 0.2 \\
\hline ODEBT & 82.3 & 100.0 & 15.2 & 18.6 & 16.8 & 20.4 & 7.3 & 8.6 & 22.4 & 27.5 & 20.6 & 25.0 \\
\hline & 16.0 & 0.0 & 5.2 & 6.6 & 4.4 & 5.7 & 7.9 & 8.5 & 9.7 & 10.7 & 12.5 & 11.1 \\
\hline Memo item & & & & & & & & & & & & \\
\hline EQUITY & $2,585.3$ & 100.0 & 40.7 & 1.6 & 534.5 & 20.7 & 306.8 & 11.7 & 766.1 & 29.7 & 937.4 & 36.2 \\
\hline & 290.6 & & 6.4 & 0.3 & 53.6 & 2.1 & 99.2 & 2.8 & 119.1 & 4.5 & 180.0 & 4.7 \\
\hline INCOME & $5,589.1$ & 100.0 & $1,358.1$ & 24.3 & $2,277.4$ & 40.8 & 499.2 & 8.9 & 688.0 & 12.3 & 766.5 & 13.7 \\
\hline & 219.3 & 0.0 & 35.6 & 1.1 & 84.8 & 1.5 & 75.3 & 1.2 & 98.1 & 1.7 & 148.3 & 2.3 \\
\hline \# observations & 3,14 & & 1,0 & & 1,0 & & 211 & & 35 & & 42 & \\
\hline \# families (mil.) & 93.0 & & 46. & & 37. & & 4.7 & & 3.7 & & 1.0 & \\
\hline Min. NW (thou.) & Neg & tive & $\mathrm{Ne}$ & ative & 68. & & 519 & & 902 & & 3,3 & 5.4 \\
\hline
\end{tabular}

See appendix table A1 for variable definitions. 
Wealth and demographics. From 1989 to 2004, the number of families in the SCF grew 20.7 percent. A potentially important factor in moving the wealth distribution is changes in the composition of those families. Over this period, the average number of people in an SCF

Table 12: Average number of people in the primary family by wealth percentile group, 1989-2004.

\begin{tabular}{|ccccccc|}
\hline Year & All & $0-50$ & $50-90$ & $90-95$ & $95-99$ & $99-100$ \\
1989 & 2.4 & 2.4 & 2.5 & 2.4 & 2.4 & 2.5 \\
1992 & 2.2 & 2.2 & 2.1 & 2.1 & 2.5 & 2.4 \\
1995 & 2.1 & 2.1 & 2.1 & 2.2 & 2.2 & 2.2 \\
1998 & 2.1 & 2.2 & 2.1 & 2.2 & 2.3 & 2.2 \\
2001 & 2.1 & 2.1 & 2.1 & 2.2 & 2.3 & 2.3 \\
2004 & 2.1 & 2.1 & 2.1 & 2.0 & 2.4 & 2.5 \\
\hline
\end{tabular}

primary family fell from 2.4 people to 2.1 people

(table 12). At the same time, the averages for the $95^{\text {th }}-99^{\text {th }}$ and $99^{\text {th }}-100^{\text {th }}$ wealth percentile groups were unchanged at 2.4 and 2.5 people respectively, while the average number in percentile groups lower in the distribution were at about the same level as the overall mean in both 1989 and 2004. Within the period, the average for the groups in the lower 95 percent of the wealth distribution tended to follow the overall mean, while those for the upper two groups declined less and then rebounded. Thus, over the period, the proportion of people in smaller, less-wealthy families rose more slowly than the proportion of people in the wealthiest 5 percent of families.

Table 13: Distribution of age of family head, by wealth percentile group, percent, 1989 and 2004.

\begin{tabular}{|crrrrrr|}
\hline \multirow{2}{*}{$\begin{array}{c}\text { Year } \\
\text { Age }\end{array}$} & \multicolumn{7}{c|}{ Wealth percentile } \\
\cline { 2 - 7 } 1989 & All & $0-50$ & $50-90$ & $90-95$ & $95-99$ & $99-100$ \\
$<35$ & & & & & & \\
$35-44$ & 28.1 & 44.2 & 13.5 & 7.3 & 6.9 & 1.6 \\
$45-54$ & 21.5 & 19.3 & 25.1 & 21.9 & 14.2 & 9.9 \\
$55-64$ & 15.1 & 10.6 & 18.6 & 23.8 & 23.3 & 26.8 \\
$64-74$ & 13.9 & 9.2 & 16.9 & 24.8 & 24.0 & 25.8 \\
$\geq 75$ & 12.6 & 9.1 & 15.6 & 13.1 & 21.6 & 22.3 \\
& 8.9 & 7.5 & 10.4 & 9.0 & 10.0 & 13.5 \\
2004 & & & & & & \\
$<35$ & & & & & & \\
$35-44$ & 22.2 & 36.0 & 9.9 & 1.8 & 2.8 & 0.7 \\
$45-54$ & 20.6 & 23.0 & 19.7 & 10.3 & 14.2 & 12.7 \\
$55-64$ & 20.8 & 16.8 & 25.0 & 23.5 & 22.9 & 25.4 \\
$65-74$ & 15.2 & 9.5 & 18.6 & 30.0 & 29.7 & 33.4 \\
$\geq 75$ & 10.5 & 7.6 & 12.2 & 20.7 & 15.0 & 18.4 \\
& 10.7 & 7.0 & 14.5 & 13.7 & 15.5 & 9.5 \\
\hline
\end{tabular}

In both 1989 and 2004, wealthier groups tended to have an age distribution more shifted toward older ages than was the case for the less wealthy groups, a pattern consistent with life cycle accumulation (table 14). A key demographic fact over this period was the progress of the bulge of the baby boom generation through the age distribution. For example, in 1989, 15.1 percent of families

were headed by a person aged 45-54, whereas in 2004 the proportion was 20.8 (table 13). The shift in the age distributions for the two lowest wealth groups roughly mirror the overall shift. But the wealthiest 10 percent became relatively more dense in families headed by a person over 
the age of 55 between 1989 and 2004, while the proportion of families in the 45-to-54 age group declined.

Preferences. Saving and portfolio decisions reflect preferences as filtered through various constraints and expectations. Economic theory suggests that time preferences and risk preferences should be key factors. Families with lower subjective discount factors should accumulate more than others and families with higher tolerances for risks should be relatively more invested in assets that yield returns that are relatively variable but higher on average. Although the SCF does not provide direct information on the subjective discount factors and coefficients of risk aversion that are common in the more theoretical literature, it does provide data on more informal measures.

Table 14: Planning period for saving and consumption decisions, by wealth percentile group, percent, 1989 and 2004.

\begin{tabular}{|c|c|c|c|c|c|c|}
\hline \multirow[t]{2}{*}{1989} & \multicolumn{6}{|c|}{ Wealth percentile group } \\
\hline & All & $0-50$ & $50-90$ & $90-95$ & $95-99$ & $99-100$ \\
\hline Next few months & 27.8 & 40.7 & 17.2 & 10.7 & 12.1 & 4.9 \\
\hline Next year & 13.6 & 15.8 & 12.2 & 7.9 & 8.9 & 8.7 \\
\hline Next few years & 25.0 & 22.2 & 28.6 & 25.6 & 22.0 & 29.5 \\
\hline Next 5-10 years & 20.6 & 13.8 & 26.7 & 31.5 & 28.6 & 35.1 \\
\hline Longer than 10 years & 13.0 & 8.5 & 15.4 & 24.4 & 28.5 & 21.7 \\
\hline \multirow[t]{2}{*}{2004} & \multicolumn{6}{|c|}{ Wealth percentile group } \\
\hline & All & $0-50$ & $50-90$ & $90-95$ & 95-99 & $99-100$ \\
\hline Next few months & 19.2 & 26.9 & 12.9 & 5.3 & 6.1 & 6.0 \\
\hline Next year & 14.0 & 17.6 & 10.8 & 10.1 & 7.5 & 7.6 \\
\hline Next few years & 27.8 & 27.7 & 29.3 & 23.5 & 21.5 & 15.4 \\
\hline Next 5-10 years & 25.7 & 19.3 & 30.4 & 39.5 & 37.6 & 42.1 \\
\hline Longer than 10 years & 13.3 & 8.4 & 16.7 & 21.8 & 27.3 & 28.9 \\
\hline
\end{tabular}

The survey asks respondents to chose the planning period that is most relevant for their saving and consumption decisions: the next few months, the next year, the next few years, the next 5-10 years, and more than the next 10 years. Over wealth groups, it is clear that the families in the top half of

the wealth distribution are more likely to report longer planning periods than those in the bottom half (table 14). The substantially larger fraction reporting "next few months” in the lowest group may be indicative of liquidity constraints among the group, but the fact that the next-longest planning period shows that same pattern across groups suggests that fundamental preferences may also be involved. Although the responses show what appears to be substantial variation from 2001 to 2004 for the lowest wealth group, examination of the intervening years of SCF data suggests that 1989 may be an outlier for this group. Among the wealthiest 1 percent of families in 2004, 63.0 percent reported a planning period of at least three years. 
Table 15: Risk attitude for investment decisions, by wealth percentile group, percent, 1989 and 2004.

\begin{tabular}{|lrrrrrl|}
\hline \multirow{2}{*}{1989} & \multicolumn{7}{c|}{ Wealth percentile group } & & & \\
& All & $0-50$ & $50-90$ & $90-95$ & $95-99$ & $99-100$ \\
& & & & & & \\
Substantial risk & 4.2 & 5.4 & 2.6 & 4.4 & 3.8 & 9.0 \\
Above avg. risk & 8.9 & 8.1 & 8.0 & 14.2 & 16.4 & 26.9 \\
Average risk & 37.9 & 29.6 & 44.2 & 52.8 & 57.4 & 46.4 \\
No risk & 49.1 & 56.9 & 45.2 & 28.6 & 22.5 & 17.6 \\
& & & & & & \\
$\mathbf{2 0 0 4}$ & Wealth percentile group & & & \\
& All & $0-50$ & $50-90$ & $90-95$ & $95-99$ & $99-100$ \\
& & & & & & \\
Substantial risk & 3.1 & 3.3 & 3.5 & 0.7 & 5.3 & 8.2 \\
Above avg. risk & 15.9 & 11.5 & 17.9 & 30.1 & 29.5 & 30.0 \\
Average risk & 38.4 & 29.3 & 46.2 & 53.0 & 53.0 & 51.8 \\
No risk & 42.3 & 56.0 & 32.3 & 16.2 & 12.2 & 10.0 \\
\hline
\end{tabular}

The survey asks

people to evaluate the

amount of financial risk

they are willing to bear:

substantial risks

expecting substantial

returns, above-average

risk expect above-

average returns, average

risk expecting average returns, or no risk at all.

The proportion of families reporting that they are willing to take substantial risks is small but not negligible in all wealth groups, and it is substantially higher for the wealthiest 1 percent of families (table 15). The proportion of families unwilling to take any financial risks drops with the level of wealth. These general patterns hold across different years of the survey.

\section{Wealth of African Americans and Hispanics}

This section examines the wealth of the two largest minority groups in the U.S., African Americans and Hispanics. In compliance with Federal guidelines, the 2004 SCF introduced a new means of classifying families by including a question that asks the survey respondent whether he considers himself "Hispanic or Latino in culture or origin.” Previously, families in the SCF could only be classified as Hispanic if they gave such a response to a question asking about their racial identification; a substantial fraction of families chose to do so. Because the new question on Hispanic identification precedes the racial identification question, the comparability of the racial identity question over time is potentially compromised. Thus, the focus here is on differences between the two minority groups in 2004 only. $^{24}$

\footnotetext{
${ }^{24}$ Kennickell [2003] provides detailed information on the change in the wealth of African Americans between 1989 and 2001. In the analysis here, families are treated as African American if the respondent did not respond positively to the question about Hispanic identification and if the respondent gave African American as the first of possible multiple responses about racial identification. Only 2.8 percent of families reported multiple races (where "Hispanic" was available as a racial classification as well as an ethnic classification) in 2004. Of those
} 
Table 16: Mean, $10^{\text {th }}$ and $25^{\text {th }}$ percentiles, median, $75^{\text {th }}$ and $90^{\text {th }}$ percentiles of the distribution of net worth; African Americans, Hispanics, thousands of 2004 dollars, 2004.

\begin{tabular}{|lcr|}
\hline & African Americans & Hispanics \\
Mean & 111.2 & 152.7 \\
& 18.0 & 13.8 \\
$10^{\text {th }}$ percentile & $-1.4^{*}$ & 0.0 \\
& 0.1 & 0.7 \\
$25^{\text {th }}$ percentile & $1.7^{*}$ & 2.8 \\
& 0.2 & 0.3 \\
Median & 20.6 & 18.6 \\
& 2.6 & 1.8 \\
$75^{\text {th }}$ percentile & 97.0 & 103.2 \\
& 10.6 & 8.4 \\
$90^{\text {th }}$ percentile & 248.0 & 304.1 \\
& 36.1 & 24.7 \\
Standard errors are given in italics. & \\
$*=$ value for African Americans significantly different from \\
value for Hispanics. \\
\hline
\end{tabular}

Differences in distributions. In 2004, the mean wealth of African Americans appears to have been substantially less than that of Hispanics (table 16), but the difference is not statistically significant. Indeed, it is only in the lower part of the wealth distributions for these groups, where values are negative, or positive and quite small, that the two distributions differ significantly; at the $10^{\text {th }}$ and $25^{\text {th }}$ percentiles, the values for Hispanics lie a small amount above those for African Americans. Although the distributions do not differ significantly across the higher percentiles, both are clearly significantly below

the corresponding points of the distribution for all families shown earlier in this paper.

To show these distributional differences more clearly, figure 6 provides the cumulative distributions of wealth for African Americans, Hispanics, and all families. What is most obvious from the figure is the much larger proportion of African American and Hispanic families that have zero or near-zero net worth than is the case for families in general. Above that level, the distributions for African Americans and Hispanics roughly parallel that for all families, up until about $\$ 200,000$ of wealth. At the top end, the distribution for all families remains more dense at high values than those for the two minority groups.

Table 17: Gini coefficient for net worth, African Americans and Hispanics, 2004.

\begin{tabular}{|ll|}
\hline African Americans & 0.7955 \\
& 0.0232 \\
Hispanics & 0.8334 \\
& 0.0185 \\
Memo: All families & 0.8047 \\
& 0.0049 \\
& \\
Standard errors are given in italics.
\end{tabular}

Gini coefficient. Although the point estimate of the Gini coefficients for Hispanics and African Americans appear to signal a greater disparity in the distribution of wealth among Hispanics than among African Americans, the estimates are not significantly different (table 17), at least in part because the estimates are imprecisely measured. Moreover, neither estimate differs significantly from the

measure computed for all families. 
Figure 6: Cumulative distribution of net worth; African Americans, Hispanics, and all families; 2004

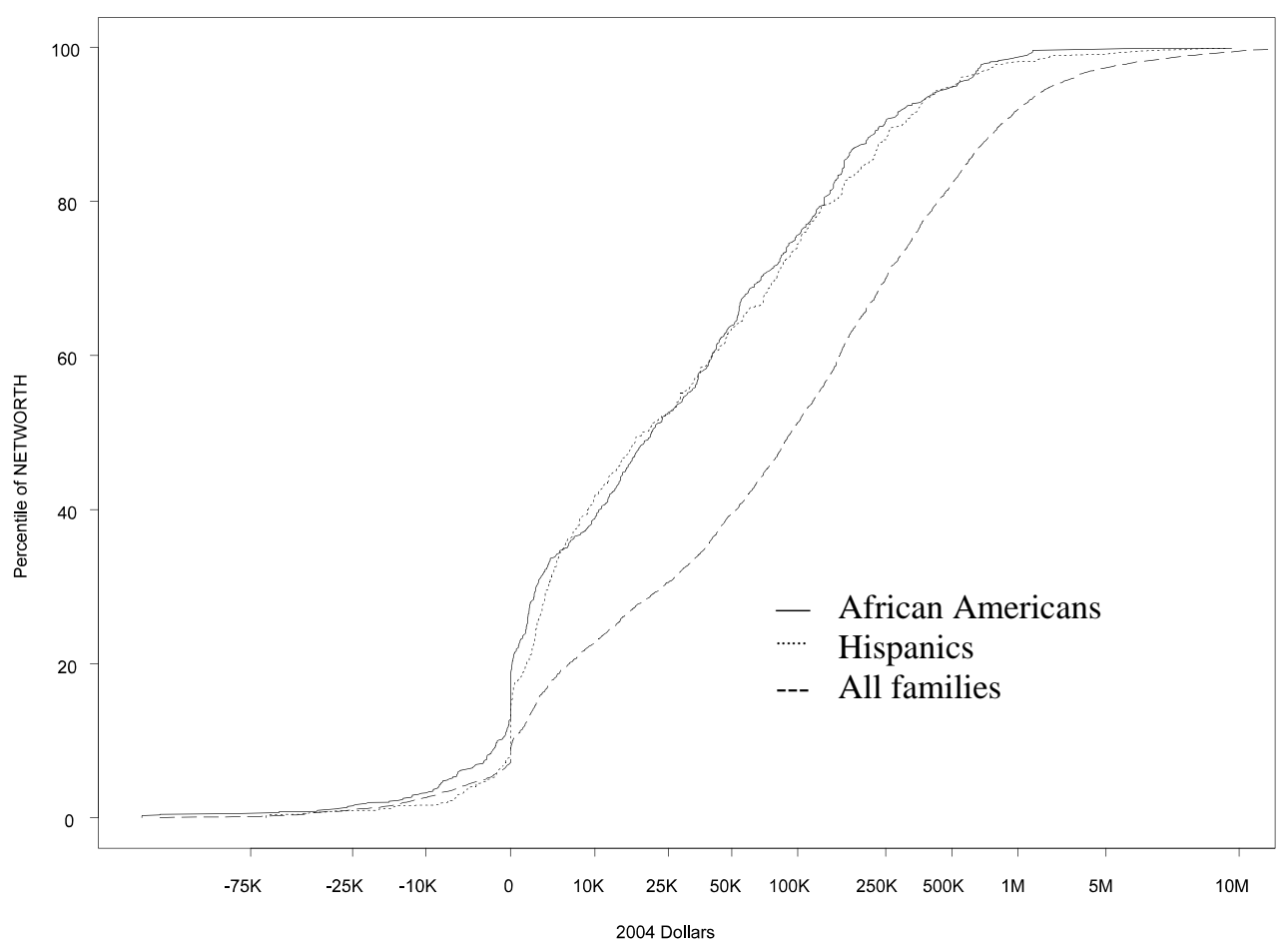

Portfolio composition. With a only few exceptions, the ownership of all types of asset and liability is less frequent among African American and Hispanic families than for families as a whole (table 18); in many cases the frequency of ownership is much less. For example, African Americans overall are 23.3 percentage points less likely to have direct or indirect holdings of publicly traded stocks than all families; Hispanics are 28.3 percent less likely. At the same time, African Americans overall are about as likely as all families to have a category of assets including cash value life insurance and miscellaneous financial assets, credit card debt, and a category of debt including installment loans and miscellaneous other debt; Hispanics overall are about as likely as all families to have credit card balances. Most of the differences in ownership still hold when the two minority groups are divided by the distributions of wealth for each group; a notable exception is the greater frequency of the use of various types of debt among upper wealth groups of the two minorities than is the case among the comparable wealth groups for all families. 
Table 18: Ownership of assets and liabilities, by net worth percentile groups; African Americans, Hispanics, and all Families; percent; 2004.

\begin{tabular}{|c|c|c|c|c|c|c|c|c|c|c|c|c|}
\hline \multirow[b]{3}{*}{ ASSET } & \multicolumn{4}{|c|}{$\begin{array}{l}\text { African Americans } \\
\text { Prcntile of group distribution }\end{array}$} & \multicolumn{4}{|c|}{$\begin{array}{l}\text { Hispanics } \\
\text { Prcntile of group distribution }\end{array}$} & \multicolumn{4}{|c|}{$\begin{array}{l}\text { All families } \\
\text { Prcntile of group distribution }\end{array}$} \\
\hline & All & $0-50$ & $50-90$ & $90-100$ & All & $0-50$ & $50-90$ & $90-100$ & All & $0-50$ & $50-90$ & $90-100$ \\
\hline & 93.1 & 86.3 & 100.0 & 100.0 & 93.6 & 87.1 & 100.0 & 100.0 & 97.9 & 95.9 & 100.0 & 100.0 \\
\hline FIN & 86.4 & 76.2 & 95.6 & 100.0 & 78.9 & 66.7 & 88.7 & 100.0 & 93.8 & 87.9 & 99.6 & 100.0 \\
\hline LIQ+CDS+SAVBND & 79.8 & 69.9 & 88.2 & 95.2 & 76.9 & 64.0 & 87.1 & 100.0 & 91.9 & 84.6 & 99.0 & 100.0 \\
\hline RETQLIQ & 32.1 & 15.7 & 46.0 & 58.5 & 26.6 & 9.5 & 35.6 & 75.6 & 49.7 & 28.7 & 67.7 & 82.2 \\
\hline BOND+STOCKS+OTHMA+NMMF & 10.4 & 3.7 & 10.5 & 42.4 & 9.7 & 2.1 & 11.2 & 41.1 & 32.1 & 11.6 & 45.0 & 83.2 \\
\hline CASHLI+OTHFIN & 24.8 & 16.0 & 31.4 & 41.7 & 8.3 & 1.1 & 10.3 & 35.2 & 24.2 & 13.5 & 32.6 & 43.6 \\
\hline NFIN & 80.2 & 62.0 & 98.4 & 98.4 & 86.3 & 73.2 & 99.1 & 100.0 & 92.5 & 85.6 & 99.3 & 99.9 \\
\hline VEHIC & 70.7 & 55.8 & 85.8 & 84.8 & 80.0 & 71.3 & 86.6 & 96.1 & 86.3 & 79.5 & 93.2 & 93.1 \\
\hline HOUSES+ORESRE & 50.6 & 16.3 & 83.5 & 89.2 & 47.8 & 10.2 & 82.7 & 94.2 & 69.1 & 43.3 & 94.3 & 96.9 \\
\hline NNRESRE+BUS & 9.4 & 2.0 & 11.4 & 37.7 & 9.9 & 1.1 & 11.6 & 47.1 & 17.5 & 5.2 & 23.4 & 55.6 \\
\hline OTHNFIN & 3.7 & 1.9 & 4.2 & 1.1 & 2.6 & 1.1 & 2.1 & 12.3 & 7.8 & 4.2 & 9.6 & 18.8 \\
\hline DEBT & 71.7 & 59.8 & 84.4 & 79.7 & 70.9 & 50.8 & 90.4 & 92.5 & 76.4 & 74.4 & 80.0 & 72.4 \\
\hline MRTHEL+RESDBT & 37.1 & 13.7 & 59.7 & 63.3 & 36.5 & 7.6 & 60.3 & 83.9 & 48.9 & 33.0 & 65.3 & 62.3 \\
\hline CCBAL & 47.2 & 36.3 & 58.9 & 54.5 & 46.5 & 33.4 & 59.9 & 58.2 & 46.2 & 49.2 & 48.2 & 23.3 \\
\hline INSTALL+OTHLOC+ODEBT & 50.8 & 48.3 & 54.7 & 47.9 & 43.5 & 34.7 & 54.7 & 42.6 & 49.8 & 53.7 & 48.9 & 34.1 \\
\hline Memo item: & & & & & & & & & & & & \\
\hline EQUITY & 25.6 & 9.1 & 33.8 & 74.3 & 20.5 & 5.7 & 28.8 & 60.8 & 48.5 & 25.8 & 66.5 & 90.6 \\
\hline
\end{tabular}

The two minority groups also differ from each other in some important ways. The data show that ownership for Hispanics substantially exceeds that for African Americans for only one category-vehicles. African Americans are much more likely than Hispanics to hold taxdeferred retirement assets, cash value life insurance and other miscellaneous financial assets, installment debt and miscellaneous other debt, and directly- or indirectly-held publicly traded stocks. Although most of the differences also persist across wealth percentile groups for each minority population, there are a few exceptions; for example, the wealthiest 10 percent of Hispanics is more likely to have tax-deferred retirement assets and to have home-secured debt than is the top wealth group of African Americans.

Relative holdings of assets and liabilities. To compare the relative holdings of the components of wealth between groups of different sizes, an adjustment is needed for the number of families in each group. Unconditional means are the most straightforward such adjustment. Ratios of such means for different assets and liabilities indicate that the differential patterns in ownership across groups are also largely reflected in the amount of holdings, but that some differences in the amounts are even sharper (table 19). In particular, among African Americans the average holding of directly- and indirectly-held publicly traded stock was only 9.9 percent of the figure for all families, and for Hispanics the figure was 15.4 percent; this result also holds 
across the wealth spectrum for these groups. Overall, compared to Hispanics, African Americans have lower average holdings of most portfolio items; exceptions are tax-deferred retirement accounts and a category of debt including installment debt and miscellaneous other debts, of which African Americans have substantially larger average holdings. By wealth group, the finding that African Americans have lower average holdings is clearest for the top 10 percent of the wealth distribution for each minority group. But the results are quite different for the wealth components of the least wealthy 50 percent of the two minority groups. The average holdings of both assets and liabilities are generally larger for African Americans in this group; however, because their higher assets are entirely offset by their higher debt, their average net worth is zero. 
Table 19: Average wealth of African American Families and of Hispanic families as a percent of average wealth of all families and wealth of African American families as a percent of wealth of Hispanic families, by wealth percentile groups, 2004.

\begin{tabular}{|c|c|c|c|c|c|c|c|c|c|c|c|c|}
\hline & \multicolumn{4}{|c|}{$\begin{array}{l}\text { Avg. for African American } \\
\text { families } \div \text { avg. for all families }\end{array}$} & \multicolumn{4}{|c|}{$\begin{array}{l}\text { Avg. for Hispanic families } \div \\
\text { avg. for all families }\end{array}$} & \multicolumn{4}{|c|}{$\begin{array}{l}\text { Avg. for African American } \\
\text { families } \div \text { avg. for Hispanic families }\end{array}$} \\
\hline & All & $0-50$ & $50-90$ & $90-100$ & All & $0-50$ & $50-90$ & $90-100$ & All & $0-50$ & $50-90$ & $90-100$ \\
\hline NETWORTH & 24.8 & 0.0 & 27.9 & 23.5 & 34.1 & 12.5 & 31.5 & 34.5 & 72.8 & 0.0 & 88.4 & 68.0 \\
\hline ASSET & 29.3 & 31.7 & 35.2 & 25.1 & 39.1 & 27.2 & 42.6 & 36.9 & 75.0 & 116.5 & 82.7 & 67.9 \\
\hline FIN & 19.9 & 28.0 & 22.0 & 18.0 & 21.9 & 17.5 & 14.8 & 23.7 & 90.8 & 159.9 & 148.6 & 76.2 \\
\hline LIQ+CDS+SAVBND & 23.5 & 28.6 & 23.8 & 21.9 & 27.1 & 26.4 & 19.3 & 30.7 & 86.6 & 108.3 & 123.3 & 71.2 \\
\hline RETQLIQ & 31.9 & 26.1 & 21.8 & 37.2 & 22.0 & 15.9 & 16.0 & 25.3 & 144.8 & 164.3 & 136.5 & 147.1 \\
\hline BOND+STOCKS+OTHMA+NMMF & 6.5 & 10.7 & 5.5 & 6.4 & 13.0 & 8.0 & 4.8 & 13.8 & 50.2 & 133.1 & 113.6 & 46.3 \\
\hline CASHLI+OTHFIN & 51.6 & 48.3 & 85.2 & 35.8 & 82.9 & 6.7 & 27.1 & 110.0 & 62.2 & 715.4 & 314.4 & 32.5 \\
\hline NFIN & 34.5 & 32.3 & 40.9 & 29.9 & 48.6 & 29.0 & 54.4 & 45.9 & 71.1 & 111.7 & 75.1 & 65.0 \\
\hline VEHIC & 53.2 & 53.4 & 49.4 & 58.7 & 69.9 & 59.9 & 73.8 & 70.4 & 76.1 & 89.2 & 66.9 & 83.4 \\
\hline HOUSES+ORESRE & 42.0 & 28.3 & 43.8 & 41.5 & 54.0 & 22.4 & 57.8 & 54.9 & 77.9 & 126.5 & 75.8 & 75.6 \\
\hline NNRESRE+BUS & 19.4 & 8.3 & 15.0 & 19.1 & 35.8 & 6.7 & 20.0 & 36.5 & 54.0 & 124.8 & 75.2 & 52.4 \\
\hline OTHNFIN & 6.5 & 10.7 & 16.1 & 2.9 & 41.8 & 38.7 & 6.2 & 52.0 & 15.6 & 27.7 & 258.6 & 5.6 \\
\hline DEBT & 54.8 & 50.6 & 59.2 & 48.5 & 67.4 & 35.9 & 78.7 & 72.0 & 81.3 & 140.7 & 75.3 & 67.3 \\
\hline MRTHEL+RESDBT & 50.4 & 32.4 & 57.3 & 49.1 & 67.9 & 30.5 & 76.9 & 76.1 & 74.2 & 106.4 & 74.5 & 64.6 \\
\hline CCBAL & 66.5 & 46.8 & 66.9 & 177.1 & 74.1 & 48.8 & 88.0 & 135.1 & 89.7 & 95.8 & 75.9 & 131.1 \\
\hline INSTALL+OTHLOC+ODEBT & 79.6 & 109.9 & 73.9 & 34.1 & 62.4 & 50.3 & 91.8 & 36.3 & 127.5 & 218.3 & 80.6 & 93.8 \\
\hline \multicolumn{13}{|l|}{ Memo items: } \\
\hline EQUITY & 10.3 & 13.8 & 10.2 & 9.8 & 15.5 & 10.6 & 10.6 & 16.1 & 66.6 & 130.7 & 96.4 & 61.0 \\
\hline INCOME & 55.3 & 72.7 & 58.6 & 38.5 & 58.6 & 71.0 & 63.4 & 43.3 & 94.4 & 102.4 & 92.4 & 88.9 \\
\hline
\end{tabular}

See appendix table A1 for variable definitions. 
Concentration of assets and liabilities within groups. As suggested by the Gini coefficient estimates for the two minority groups, the shares of group wealth held by the wealthiest 10 percent of African Americans and by the wealthiest 10 percent of Hispanics do not differ significantly from each other, and neither differs significantly from the wealth share of the wealthiest 10 percent of the population in general (tables 20a and 20b). Indeed, overall there are few statistically significant differences between the minority groups in the shares of portfolio items held by different wealth groups, again in part because the sample sizes are relatively small. The most interesting significant exceptions concern the relative holdings of debt. Among the 50 percent least wealthy in each minority group, African Americans hold a larger share of the total debt held by that group overall. It is also noteworthy that the income shares across the wealth groups are very similar for these two groups, but compared to the population as a whole, more of total group income is received by the least wealthy 50 percent and less by the wealthiest 10 percent. 
Table 20a: Amounts (billions of 2004 dollars) and shares of net worth and components distributed by net worth groups, African American families, 2004.

\begin{tabular}{|c|c|c|c|c|c|c|c|c|}
\hline & \multicolumn{8}{|c|}{ Wealth percentile group } \\
\hline & \multicolumn{2}{|c|}{ All families } & \multicolumn{2}{|l|}{$0-50$} & \multicolumn{2}{|l|}{$50-90$} & \multicolumn{2}{|l|}{$90-100$} \\
\hline & Amount & Share & Amount & Share & Amount & Share & Amount & Share \\
\hline \multirow[t]{2}{*}{ NETWORTH } & $1,671.7$ & 100.0 & 0.0 & 0.0 & 526.0 & 31.5 & $1,145.7$ & 68.5 \\
\hline & 215.8 & 0.0 & 11.5 & 0.7 & 38.5 & 4.6 & 214.2 & 4.5 \\
\hline \multirow[t]{2}{*}{ ASSET } & $2,322.5$ & 100.0 & 145.0 & 6.2 & 868.6 & 37.4 & $1,308.8$ & 56.3 \\
\hline & 238.3 & 0.0 & 17.6 & 1.0 & 65.4 & 4.3 & 234.0 & 4.9 \\
\hline \multirow[t]{2}{*}{ FIN } & 561.8 & 100.0 & 19.8 & 3.5 & 161.6 & 28.8 & 380.4 & 67.6 \\
\hline & 62.4 & 0.0 & 2.6 & 0.6 & 12.6 & 4.0 & 63.0 & 4.3 \\
\hline \multirow[t]{2}{*}{ LIQ+CDS+SAVBND } & 115.6 & 100.0 & 6.9 & 6.0 & 42.0 & 36.4 & 66.6 & 57.7 \\
\hline & 17.6 & 0.0 & 0.9 & 1.1 & 6.9 & 6.7 & 16.0 & 7.1 \\
\hline \multirow[t]{2}{*}{ RETQLIQ } & 288.5 & 100.0 & 7.9 & 2.7 & 75.8 & 26.4 & 204.9 & 70.9 \\
\hline & 38.5 & 0.0 & 1.5 & 0.7 & 11.5 & 5.6 & 40.4 & 6.0 \\
\hline \multirow[t]{2}{*}{ BOND+STOCKS+OTHMA+NMMF } & 84.4 & 100.0 & 0.8 & 1.0 & 9.4 & 11.4 & 74.1 & 87.6 \\
\hline & 24.4 & 0.0 & 0.3 & 0.5 & 3.6 & 6.1 & 24.7 & 6.3 \\
\hline \multirow[t]{2}{*}{ CASHLI+OTHFIN } & 73.3 & 100.0 & 4.3 & 5.8 & 34.3 & 46.9 & 34.7 & 47.3 \\
\hline & 20.8 & 0.0 & 1.0 & 2.4 & 5.3 & 13.6 & 20.2 & 15.2 \\
\hline \multirow[t]{2}{*}{ NFIN } & $1,760.7$ & 100.0 & 125.2 & 7.1 & 707.0 & 40.2 & 928.4 & 52.7 \\
\hline & 196.0 & 0.0 & 16.9 & 1.2 & 57.7 & 4.9 & 190.3 & 5.6 \\
\hline \multirow[t]{2}{*}{ VEHIC } & 138.8 & 100.0 & 37.3 & 26.9 & 64.2 & 46.3 & 37.3 & 26.8 \\
\hline & 9.9 & 0.0 & 3.3 & 2.2 & 5.3 & 2.9 & 6.7 & 3.7 \\
\hline \multirow[t]{2}{*}{ HOUSES+ORESRE } & $1,289.2$ & 100.0 & 87.0 & 6.7 & 612.3 & 47.5 & 589.9 & 45.7 \\
\hline & 104.9 & 0.0 & 15.4 & 1.2 & 52.3 & 4.6 & 100.1 & 5.0 \\
\hline \multirow[t]{2}{*}{ NNRESRE+BUS } & 327.4 & 100.0 & 0.6 & 0.2 & 27.4 & 8.3 & 299.5 & 91.5 \\
\hline & 128.6 & 0.0 & 0.4 & 0.1 & 6.7 & 4.6 & 128.2 & 4.7 \\
\hline \multirow[t]{2}{*}{ OTHNFIN } & 5.1 & 100.0 & 0.3 & 6.0 & 3.1 & 59.7 & 1.7 & 34.3 \\
\hline & 1.3 & 0.0 & 0.2 & 5.4 & 1.1 & 14.9 & 0.7 & 13.6 \\
\hline \multirow[t]{2}{*}{ DEBT } & 650.7 & 100.0 & 145.0 & 22.3 & 342.6 & 52.6 & 163.1 & 25.1 \\
\hline & 43.6 & 0.0 & 22.4 & 3.0 & 39.8 & 5.0 & 30.5 & 4.5 \\
\hline \multirow[t]{2}{*}{ MRTHEL+RESDBT } & 501.0 & 100.0 & 66.9 & 13.4 & 288.9 & 57.7 & 145.2 & 29.0 \\
\hline & 36.6 & 0.0 & 13.3 & 2.5 & 36.3 & 5.7 & 29.0 & 5.5 \\
\hline \multirow[t]{2}{*}{ CCBAL } & 23.7 & 100.0 & 7.6 & 31.9 & 11.2 & 47.4 & 4.9 & 20.7 \\
\hline & 2.9 & 0.0 & 1.2 & 4.4 & 2.4 & 6.3 & 1.2 & 5.0 \\
\hline \multirow[t]{2}{*}{ INSTALL+OTHLOC+ODEBT } & 126.0 & 100.0 & 70.6 & 56.1 & 42.4 & 33.7 & 13.0 & 10.3 \\
\hline & 16.7 & 0.0 & 16.1 & 6.8 & 5.8 & 5.6 & 2.4 & 2.4 \\
\hline \multicolumn{9}{|l|}{ Memo items: } \\
\hline EQUITY & 138.1 & 100.0 & 2.2 & 1.6 & 27.5 & 20.1 . & 108.4 & 78.3 \\
\hline & 28.5 & 0.0 & 0.7 & 0.6 & 5.2 & 5.3 & 28.7 & 5.6 \\
\hline INCOME & 587.6 & 100.0 & 183.5 & 31.2 & 249.8 & 42.5 & 154.3 & 26.3 \\
\hline & 29.0 & 0.0 & 11.6 & 1.8 & 17.3 & 2.7 & 23.5 & 3.3 \\
\hline \# observations & 478 & & & 68 & 157 & & 53 & \\
\hline \# families (mil.) & 15.0 & & & 5 & 6.0 & & 1.6 & \\
\hline Min. NW (thou.) & Neg & tive & & egative & 20.6 & & 233. & \\
\hline
\end{tabular}


Table 20b: Amounts (billions of 2004 dollars) and shares of net worth and components distributed by net worth groups, Hispanic families, 2004.

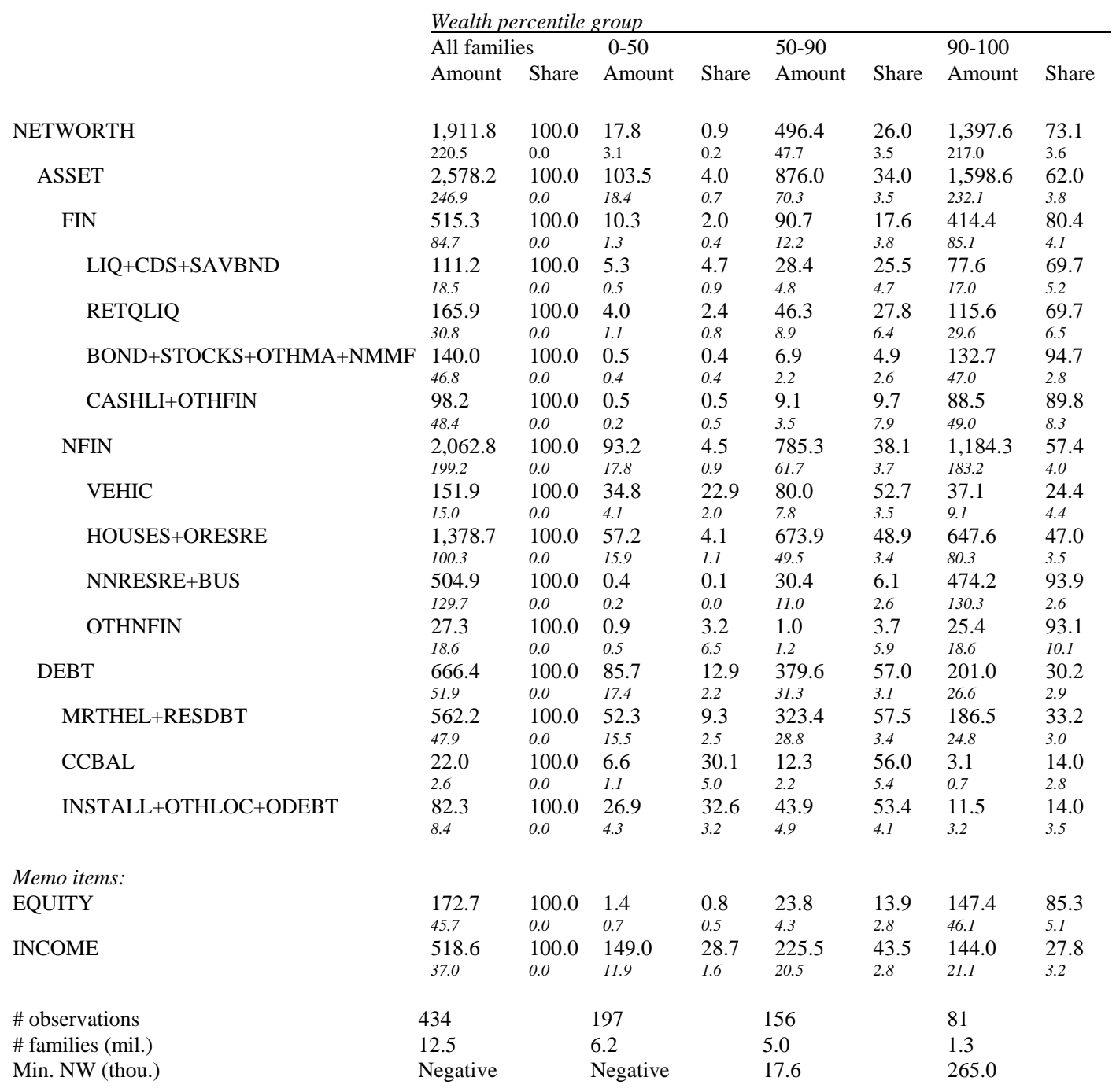

See appendix table A1 for variable definitions. 
Table 21: Usual saving behavior and saving behavior last year; African Americans, Hispanics, and all families; by percentile of the group distribution of net worth; percent; 2004.

\begin{tabular}{|c|c|c|c|}
\hline & $\begin{array}{l}\text { African } \\
\text { Americans }\end{array}$ & $\begin{array}{l}\text { Hispanics } \\
\text { families }\end{array}$ & $\begin{array}{l}\text { All } \\
\text { families }\end{array}$ \\
\hline \multicolumn{4}{|c|}{ Usual saving: } \\
\hline \multicolumn{4}{|c|}{ Spend more than income } \\
\hline All & 12.0 & 10.6 & 7.0 \\
\hline $0-50$ & 15.7 & 12.2 & 10.5 \\
\hline $50-90$ & 1.1 & 6.9 & 3.9 \\
\hline $90-100$ & 0.0 & 0.0 & 2.2 \\
\hline \multicolumn{4}{|c|}{ Spend same as income } \\
\hline All & 19.3 & 22.3 & 16.3 \\
\hline $0-50$ & 22.4 & 26.1 & 23.6 \\
\hline $50-90$ & 10.9 & 11.5 & 9.6 \\
\hline $90-100$ & 0.6 & 17.6 & 6.1 \\
\hline \multicolumn{4}{|c|}{ Save "left over" income } \\
\hline All & 24.7 & 29.6 & 30.2 \\
\hline $0-50$ & 22.8 & 28.8 & 31.9 \\
\hline $50-90$ & 23.6 & 32.3 & 29.1 \\
\hline $90-100$ & 31.2 & 24.6 & 26.5 \\
\hline \multicolumn{4}{|c|}{ Some saving plan } \\
\hline All & 44.0 & 37.5 & 46.5 \\
\hline $0-50$ & 37.1 & 32.9 & 33.9 \\
\hline $50-90$ & 64.4 & 49.3 & 57.4 \\
\hline $90-100$ & 68.2 & 57.8 & 65.2 \\
\hline \multicolumn{4}{|c|}{ Saving last year: } \\
\hline \multicolumn{4}{|c|}{ Spent more than income } \\
\hline All & 23.9 & 20.8 & 15.4 \\
\hline $0-50$ & 26.0 & 22.3 & 20.6 \\
\hline $50-90$ & 18.7 & 16.0 & 10.9 \\
\hline $90-100$ & 0.0 & 21.6 & 7.7 \\
\hline \multicolumn{4}{|c|}{ Spent same as income } \\
\hline All & 32.8 & 35.8 & 28.5 \\
\hline $0-50$ & 37.7 & 41.0 & 35.2 \\
\hline $50-90$ & 19.5 & 23.1 & 23.1 \\
\hline $90-100$ & 2.1 & 3.2 & 16.3 \\
\hline \multicolumn{4}{|c|}{ Spent less than income } \\
\hline All & 43.3 & 43.5 & 56.1 \\
\hline $0-50$ & 36.3 & 36.7 & 44.2 \\
\hline $50-90$ & 61.7 & 60.8 & 66.0 \\
\hline $90-100$ & 97.7 & 75.2 & 76.0 \\
\hline
\end{tabular}

Saving and capital gains.

The patterns of saving behavior for the two minority groups are similar to each other, but differ somewhat from that for the population overall (table 21). In terms of both usual saving practices and saving over the past year, African Americans and Hispanics were less likely to be savers than families overall.

However, when the groups are divided by wealth deciles computed separately for each group, this pattern is less clear. Among the wealthiest 10 percent of African Americans the proportion of families with a saving plan and the proportion that spent less than their income is higher than in the case of families overall. For Hispanics, the proportion with a saving plan is lower than the figure for all families, but the proportion spending less than their income was nearly the same as that for all families. ${ }^{25}$

\footnotetext{
${ }^{25}$ For wealthiest 10 percent of Hispanics, the proportion that spent more than their income in the previous year is 21.6 percent, a figure substantially higher than for either of the other groups. Although a strictly comparable classification of Hispanics is not possible in earlier years of the survey, the closest approximation suggests that this figure may be an outlier. In 2001, 0.0 percent of Hispanic families in this group spent more than their income, 28.4 percent spent about the same, and 71.6 percent spent less than their income; in 1998, the corresponding figures were 12.7 percent, 2.9 percent and 84.4 percent.
} 
Table 22: Median ratio of capital gains to assets and ratio of aggregate capital gains to aggregate assets; for African Americans, Hispanics, and all families; by percentiles of the group wealth distribution; 2004; percent.

\begin{tabular}{|llr|}
$\begin{array}{c}\text { Group } \\
\text { Wealth group }\end{array}$ & $\begin{array}{l}\text { Aggregate } \\
\text { ratio }\end{array}$ & $\begin{array}{l}\text { Median } \\
\text { ratio }\end{array}$ \\
African Americans & & \\
All & 34.2 & 0.0 \\
$0-50$ & 12.3 & 0.0 \\
$50-90$ & 26.8 & 23.4 \\
$90-100$ & 41.5 & 29.8 \\
Hispanics & & \\
All & 35.2 & 0.0 \\
$0-50$ & 4.4 & 0.0 \\
$50-90$ & 28.7 & 22.7 \\
$90-100$ & 40.8 & 35.9 \\
All families & & \\
All & 30.7 & 11.2 \\
$0-50$ & 14.3 & 0.0 \\
$50-90$ & 27.3 & 24.6 \\
$90-100$ & 33.8 & 28.3 \\
\hline
\end{tabular}

As with the overall population, unrealized capital gains explain a large part of the observed wealth of African Americans and Hispanics (table 22). In 2004, 34.2 percent of the wealth of African Americans and 35.2 percent of the wealth of Hispanics was explained by net capital gains on the set of assets in the SCF for which such information is available, as discussed earlier in this paper. These shares are slightly higher than that for the population as a whole, though the shares for the minority groups based on a much lower average value than in the case of the population overall. The minority groups differ notably in the estimate of the median amount of gain, where the median is taken over all families whether or not they have assets. ${ }^{26}$ For the minority groups the fraction is zero, whereas for the population as a whole the figure is 11.2 percent.

\section{The Use of Debt}

Many assets - particularly real estate and vehicles-are routinely financed as a part of their purchase. Stock holdings may be financed in part with margin loans. For personal businesses, borrowing may play a key role in the expansion of assets, but such borrowing may be subsumed within the business in some cases and, thus, not appear in the family balance sheet collected in the SCF. ${ }^{27}$

\footnotetext{
${ }^{26}$ For families with no assets, the value of the ratio was taken to be zero.
}

${ }^{27}$ The survey does collect separate mortgage information for the nonresidential real estate category included in the analysis in this paper. However, it appears that a large share of such properties are not substantively distinct from businesses in the survey where the reported value is net of borrowing. In large part for this reason, the nonresidential real estate values used are net of balances on any outstanding mortgages on the properties. 
Table 23: Leverage ratio, by wealth groups, 1989-2004.

\begin{tabular}{|llllrrr|}
\hline \multicolumn{7}{|c|}{ Wealth percentile group } \\
\cline { 2 - 7 } & All & $0-50$ & $50-90$ & $90-95$ & $95-99$ & $99-100$ \\
1989 & 12.1 & 52.2 & 19.2 & 9.5 & 5.3 & 2.4 \\
1992 & 14.6 & 59.2 & 21.5 & 11.0 & 6.8 & 2.9 \\
1995 & 14.5 & 56.8 & 21.0 & 10.9 & 7.9 & 3.3 \\
1998 & 14.2 & 61.4 & 20.9 & 10.6 & 7.9 & 2.6 \\
2001 & 12.0 & 56.2 & 19.4 & 8.9 & 5.9 & 2.4 \\
2004 & 15.0 & 62.6 & 23.5 & 10.9 & 7.8 & 3.7 \\
\hline
\end{tabular}

From 1989 to 2004, the total debt of all families as measured in the SCF rose 148.6 percent in real terms. As a proportion of assets, debt varied between 12.0 percent and 15.0 percent over the period (table 23). As noted earlier, holdings of debt are disproportionately

concentrated among wealthy families. But compared with assets, debt is much more equally distributed across wealth groups. In 2004, the least wealthy 50 percent of families held 24.2 percent of the total outstanding debt, the next 40 percent of the distribution held 48.6, and the wealthiest 10 percent held the remaining 27.1 percent; in contrast the least wealthy half held 5.8 percent of total assets, the next 40 percent held 31.0 percent, and the wealthiest 10 percent held 63.1 percent (see table 11a). Thus, leverage rates drop across the wealth percentile groups. In part, this pattern reflects differences in the age distribution within the wealth groups and the differences across age groups in the typical use of debt.

Overall, home-secured debt grew as a share of all family borrowing from 1989 to 2004, but within that period the increase was not consistent (table 24). Spotty declines were spread throughout the remaining types of loan other than mortgages for other residential real estate and credit card balances, whose shares did not shift consistently over the period. When borrowing is disaggregated by wealth groups, additional patterns emerge. Mortgage borrowing as a share of all borrowing peaks in the $50^{\text {th }}$-to- $90^{\text {th }}$ percentile group and then declines at higher points in the wealth distribution. Some of the decline for the upper groups is offset by the rise in borrowing for other residential real estate, which is highly concentrated among wealthy families. The category "other debt," which includes margin loans, loans against insurance policies, as well as miscellaneous personal and other loans, tends to be most important for the highest wealth groups. Installment borrowing and credit card balances tend to be relatively more important in the portfolios of the lower wealth groups.

Home-secured debt may be taken out (or increased through mortgage refinancing or additional equity-based loans) for many purposes other than the purchase of a home. Indeed, 
Table 24: Percentage distribution of debt by types of debt, by wealth groups, 2001 and 2004.

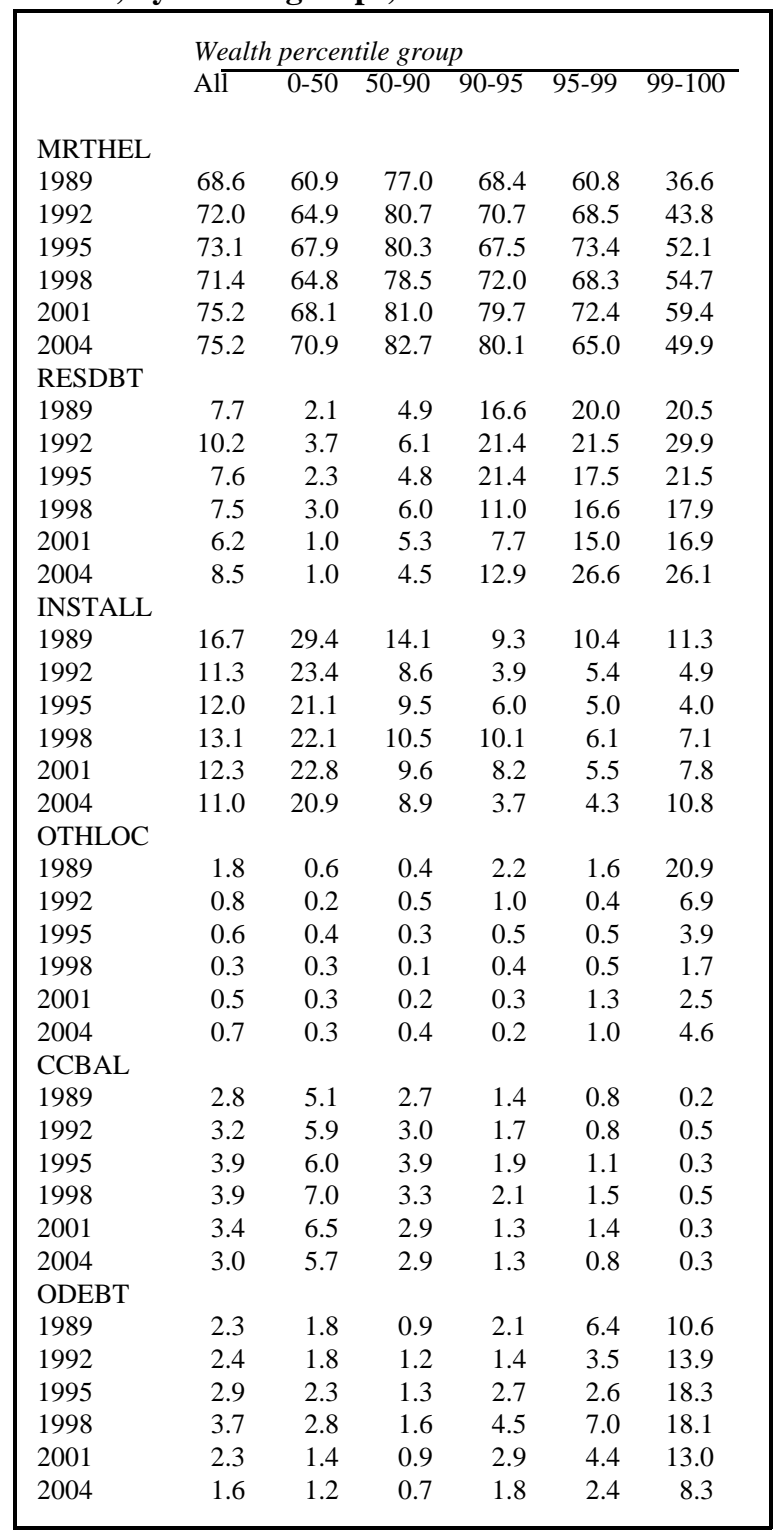

Table 25: Percent of outstanding debt attributable to various purposes, by wealth group, 2004.

\begin{tabular}{|lrrrrrr|}
\hline \multicolumn{7}{c|}{ Wealth } \\
\cline { 2 - 7 } & All & $0-50$ & $50-90$ & $90-95$ & $95-99$ & $99-100$ \\
Home purchase & 67.6 & 66.8 & 75.3 & 68.4 & 51.6 & 43.2 \\
Home improvement & 2.8 & 2.0 & 3.2 & 2.5 & 3.8 & 1.4 \\
Other residential real estate & 9.7 & 1.3 & 5.2 & 16.6 & 29.7 & 27.1 \\
Investment & 2.3 & 0.2 & 0.7 & 1.9 & 5.3 & 16.1 \\
Education & 3.2 & 8.1 & 2.0 & 1.4 & 0.4 & 0.3 \\
Vehicle purchase & 6.7 & 10.5 & 7.1 & 3.4 & 3.1 & 1.8 \\
Good and services & 7.1 & 10.0 & 6.1 & 5.0 & 5.3 & 9.2 \\
Other & 0.6 & 1.1 & 0.2 & 0.7 & 0.6 & 0.8 \\
\hline
\end{tabular}

because of the fungibility of loan proceeds, it is impossible in a strict sense to say precisely how such funds are used. However, as a first approximation, the survey asks respondents to report the use of funds borrowed on most types of loan; important exceptions are credit card balances and miscellaneous personal loans. The most complete such information is available in the 2004 SCF. According to the survey for that year, borrowing for a home purchase is the largest single share of borrowing in all the wealth groups; that fraction declines from 66.8 percent for the least wealthy 50 percent of families to 43.2 percent for the wealthiest 1 percent of families (table 25). The next largest share of the aggregate, borrowing for residential real estate other than a principal residence, is substantial only for the wealthiest 10 percent of families. In contrast, borrowing for vehicles or education is a larger share of the borrowing of families in the least wealthy 50 percent. Borrowing for goods and services, a category that includes all outstanding credit card balances, is in the range of 5 to 10 percent across all wealth groups. Borrowing for investments, the next smallest share of the aggregate after the 
residual category, is a substantial share of the borrowing of only the two groups in the highest 5 percent of the wealth distribution; for the wealthiest 1 percent, this purpose represents 16.1 percent of their total borrowing.

\section{Conclusion}

The data used in this paper are not sufficient to address changes in the wealth of individual families over time, but they can be used to characterize the overall wealth distribution. Over the 1989-2004 period considered, inflation-adjusted net worth as measured in the triennial SCF grew broadly. The share of families with negative net worth was about unchanged, but otherwise the distribution of family wealth shifted higher. Over the fifteen-year period, mean wealth rose 61.2 percent whereas the median rose 35.3 percent, a disproportion that suggests the shares of wealth held by different groups may also have shifted over the period. Indeed, by some measures, the data do show significant changes in the concentration of wealth across the distribution, but the result does not hold unambiguously across a set of plausible alternative measures, in part because different measures answer different questions and in part because the measures severely test the statistical power of the survey data. The Gini coefficient shows significant increases in the concentration of wealth in 2004 relative to 1989, 1992, and 1995; but the estimates from the 1998 and 2001 surveys are not significantly different from that from the 2004 survey. On the other hand, estimates of the total amount of wealth held by different subgroups of the wealth distribution show that the share of the least wealthy 50 percent of families fell significantly from the 1992-2001 surveys (the high point was 3.6 percent in 1995) to about 2.5 percent of total family wealth in 2004; but the data are not sufficient to identify what offsetting group or groups gained that amount. Graphical analysis indicates that over the 1989-2004 period, there were statistically significant gains across the wealth distribution and that the level of gains was largest by far for the top few percent of the distribution. However, when taken as a proportion of wealth in 1989, the increases are closer to uniform across much of the distribution, though the upward spike at the top of the distribution remains. Over the more recent term, from 2001 to 2004, the data show little statistically significant change.

Data from Forbes, which are intended to represent the wealthiest 400 people in the U.S., show a peak in several measures of the concentration of wealth within that group in 1999. But 
comparison with SCF data where the two sources overlap in time suggests that movements in the wealth of the Forbes group may be only loosely coupled with the wealth of the remaining 99.9996 percent of the population. In 2004, the wealth of the Forbes group was about 2 percent of the sum of total wealth measured in that source and the SCF.

The SCF data also provide information on the variability of the cross-sectional distribution of wealth over time. When the data are detrended for average growth over the 1989-2004 period by percentile of net worth, the proportional variability of wealth appears to have been greatest below the $20^{\text {th }}$ percentile of the distribution, to have hit a minimum at about the $35^{\text {th }}$ percentile, and then to have increased linearly until near the top of the distribution. This pattern marks a transition from groups of families with very small buffers against shocks, to those with fairly conservative portfolios, to those who incorporate more risky assets into their portfolios.

The sources of wealth and changes in wealth are much more difficult to characterize. Variations in realized income and in saving practices are surely important factors, but a very large factor is capital gains. In 2004 among the wealthiest 1 percent of families, unrealized capital gains accounted for 31.2 percent of gross assets at the median; for the whole population the median was 11.2 percent. Thus, variations in the ownership of assets subject to capital gains appear to be very important over time as a determinant of wealth. Gain-intensive assets, such as stocks, businesses, and real estate are disproportionately held by the wealthiest families. The major source of gains at lower levels is appreciation of the value of a principal residence.

Inheritances and substantial gifts are also important factors in the distribution of family wealth. In 2004, such past transfers accounted for about 6 to 17 percent of total net worth, depending on the measure used. Over the 1989-2004 period, inheritances may have declined in importance for the families at the top of the wealth distribution.

The paper also compares the wealth of African American families and Hispanic families in 2004. Despite some relatively small dollar-level differences in the lowest part of the wealth distributions for these two groups, their overall distributions are far more similar to each other than either is to that for the set of all families. The main distinguishing characteristic for both groups is the relatively large fraction of families who have zero or near-zero wealth. Aside from holdings of credit card and installment loan balances, ownership of various assets and liabilities is much less common among these groups than among the population as a whole. 
For some families, borrowing is an instrument for acquiring assets. Vehicles and real estate are often financed, but borrowing can also be quite important for investment in stocks and personal businesses. Like assets, debts are relatively concentrated among the wealthiest families, but the disproportion is less. For example, the wealthiest 10 percent of families held about 26 percent of all family debt in 2004, but they also held 63 percent of total family assets. Borrowing related to residential real estate is the largest share of families' outstanding debt, and this is true across the spectrum of wealth groups considered. But for the wealthiest 1 percent of families in 2004, over 16 percent of their outstanding debt was related to investments other than real estate. Among the least wealthy 50 percent, 10 percent of their borrowing was to finance a vehicle.

By now, there are six comparably measured cross sectional observations of family wealth from the SCF covering a period containing two recessions. Future work should begin to make a more thorough examination of macroeconomic influences on the times series of wealth movements. Possibly one of the largest constraints in gaining a more detailed understanding of wealth dynamics is the absence of a panel dimension in the SCF, aside from the relatively small 1983-89 panel. Cross sectional data can only provide information on changes for groups. Although panel data are of obvious utility for studying wealth dyanmics and many other problems in economics, that potential utility must be weighed against both the cost of creating such data and the quality of the information that could be obtained. Examination of wealth dynamics using the wealth supplements to the Panel Study on Income Dynamics may provide helpful insights into the tradeoffs. 
Avery, Robert B. and Arthur B. Kennickell [1991] "Household Saving in the U.S.," Review of Income and Wealth, (December 1991) pp. 409-432.

Board of Governors of the Federal Reserve System [2005] "Z.1 Release: Flow of Funds Accounts of the United States: Annual Flows and Outstandings,” http://www.federalreserve.gov/releases/Z1/Current/data.htm.

Bucks, Brian K., Arthur B. Kennickell, and Kevin B. Moore [2006] "Recent Changes in U.S. Family Finances: Evidence from the 2001 and 2004 Survey of Consumer Finances,” Federal Reserve Bulletin, vol. 92, www.federalreserve.gov/pubs/bulletin/2006/financesurvey.pdf, posted February 2006.

Canterbury, E. Ray and E. Joe Nosari [1985] “The Forbes Four Hundred: The Determinants of Super-Wealth,” Southern Economic Journal, v. 51 (April), pp. 1073-1982.

Gale, William G. and Karen M. Pence [2005] "Household Wealth Accumulation in the 1990s: The Role of Demographic Factors," unpublished manuscript, October.

Kopczuk, Woiciech and Emmanuel Saez [2003] "Top Wealth Shares in the United States, 1916-2000: Evidence from Estate Tax Returns,” working paper.

Kennickell, Arthur B. [2005] "Darkness Made Visible: Field Management and Nonresponse in the 2004 SCF," September 2005. SRMS proceedings Proceedings of the Section on Survey Research Methods, 2005 Annual Meetings of the American Statistical Association, Minneapolis, MN.

Kennickell, Arthur B. [2003] “A Rolling Tide: Changes in the Distribution of Wealth in the U.S., 1989-2001,, www.federalreserve.gov/pubs.oss/oss2/method.html.

Kennickell, Arthur B. [2000] "Revisions to the Variance Estimation Procedure for the SCF," working paper, www.federalreserve.gov/pubs.oss/oss2/method.html.

Arthur B. Kennickell [2000] "Wealth Measurement in the Survey of Consumer Finances: Methodology and Directions for Future Research,” working paper Board of Governors of the Federal Reserve System, www.federalreserve.gov/pubs/oss/oss2/method.html.

Kennickell, Arthur B. [2001] "Modeling Wealth with Multiple Observations of Income: Redesign of the Sample for the 2001 Survey of Consumer Finances,” Proceedings of the Section on Survey Research Methods, 2001 Annual Meetings of the American Statistical Association, Atlanta, August.

Kennickell, Arthur B. [1999] "Revisions to the SCF Weighting Methodology: Accounting for Race/Ethnicity and Homeownership,” working paper, www.federalreserve.gov/pubs.oss/oss2/ method.html. 
Kennickell, Arthur B. [1998] "Multiple Imputation in the Survey of Consumer Finances," Proceedings of the Section on Business and Economic Statistics, Annual Meetings of the American Statistical Association, Dallas, Texas.

Kennickell, Arthur and Annika E. Sundén, "Pensions, Social Security, and the Distribution of Wealth," Finance and Economics Discussion Series 1997-55 (Board of Governors of the Federal Reserve System, October 1997).

Kennickell, Arthur B. and R. Louise Woodburn [1999] "Consistent Weight Design for the 1989, 1992, and 1995 SCFs, and the Distribution of Wealth,” Review of Income and Wealth (Series 45, number 2), June, pp. 193-215.

Rubin, Donald B. [1987] Multiple Imputation for Nonresponse in Surveys, Wiley: New York. 
Variable Definitions: Tables 10, 11a,1b, 18, 19, 20a, 20b, 24, A1-A7

NETWORTH: ASSET-DEBT.

ASSET: FIN+NFIN.

FIN: LIQ+CDS+SAVBND+BOND+STOCKS+NMMF+RETQLIQ+CASHLI+OTHMA+OTHFIN.

LIQ: Holdings of checking, savings, money market, and call accounts.

CDS: Holdings of certificates of deposit.

SAVBND: Holdings of savings bonds.

BOND: Direct holdings of bonds. ${ }^{*}$

STOCKS: Direct holdings of publicly traded stocks."

NMMF: Mutual funds other than money market mutual funds, and hedge funds.

RETQLIQ: IRAs, Keogh accounts, and other pension accounts where withdrawals or loans may be taken (such as 401(k) accounts).

CASHLI: Cash value of life insurance.

OTHMA: Equity holdings of annuities, trusts, and managed investment accounts.

OTHFIN: Value of miscellaneous financial assets (e.g., futures contracts, oil leases, royalties, etc.).

NFIN: VEHIC+HOUSES+ORESRE+BUS+OTHNFIN.

VEHIC: Market value of all personally owned automobiles, trucks, motor homes, campers, motorcycles, boats, airplanes, helicopters, and miscellaneous vehicles.

HOUSES: Market value of principal residences.

ORESRE: Market value of residential real estate other than principal residences.

NNRESRE: Net equity in real estate other than HOUSES and ORESRE.

BUS: Net equity in closely held businesses.

OTHNFIN: Value of miscellaneous nonfinancial assets (e.g., antiques, artwork, etc.).

DEBT: MRTHEL+INSTALL+OTHLOC+CCBAL+ODEBT.

MRTHEL: Amount outstanding on mortgages and home equity lines of credit secured by principal residences.

RESDBT: Amount outstanding on mortgages secured by residential real estate other than a principal residence.

INSTALL: Amount outstanding on installment debt.

OTHLOC: Amount outstanding on lines of credit other than home equity lines of credit.

CCBAL: Amount outstanding on credit cards.

ODEBT: Amount outstanding on miscellaneous debts (e.g., debts to family members, borrowing against insurance policies or pension accounts, margin debt, etc.).

EQUITY: Total value of direct and indirect stock holdings (included in STOCKS and RETQLIQ).*

INCOME: Total income for the year preceding the survey year.

* Direct holdings are those held outside of a managed asset such as mutual funds, trusts, managed investment accounts, annuities, and tax-deferred retirement accounts. 
Table A1: Amounts (billions of 2004 dollars) and shares of net worth and components distributed by net worth groups, 1992.

\begin{tabular}{|c|c|c|c|c|c|c|c|c|c|c|c|c|}
\hline & \multicolumn{12}{|c|}{ Wealth percentile group } \\
\hline & \multicolumn{2}{|c|}{ All families } & \multicolumn{2}{|l|}{$0-50$} & \multicolumn{2}{|l|}{$50-90$} & \multicolumn{2}{|l|}{$90-95$} & \multicolumn{2}{|l|}{$95-99$} & \multicolumn{2}{|l|}{$99-100$} \\
\hline & Amount & Share & Amount & Share & Amount & Share & Amount & Share & Amount & Share & Amount & Share \\
\hline \multirow[t]{2}{*}{ NETWORTH } & 23621.3 & 100 & 781.6 & 3.3 & 6999.7 & 29.6 & 2963.2 & 12.5 & 5753.1 & 24.4 & 7123.7 & 30.2 \\
\hline & 699.6 & 0 & 41 & 0.2 & 197.8 & 1.1 & 175.1 & 0.7 & 359.8 & 1.3 & 474 & 1.4 \\
\hline \multirow[t]{2}{*}{ ASSET } & 27616.5 & 100 & 1809.6 & 6.6 & 8864.4 & 32.1 & 3325.5 & 12 & 6248.1 & 22.6 & 7368.9 & 26.7 \\
\hline & 737.4 & 0 & 63.8 & 0.3 & 244.7 & 1.1 & 194.2 & 0.7 & 382.9 & 1.2 & 486.4 & 1.3 \\
\hline \multirow[t]{2}{*}{ FIN } & 8707 & 100 & 295.5 & 3.4 & 2470 & 28.4 & 1266.3 & 14.5 & 2375.7 & 27.3 & 2299.5 & 26.4 \\
\hline & 252.9 & 0 & 13.5 & 0.2 & 106.1 & 1.4 & 88.8 & 1 & 171.2 & 1.7 & 182.9 & 1.7 \\
\hline LIQ & 1518.2 & 100 & 98.6 & 6.5 & 528.1 & 34.8 & 208.9 & 13.8 & 346.4 & 22.8 & 336.2 & 22.1 \\
\hline & 61.7 & 0 & 5.1 & 0.4 & 32.2 & 2.2 & 19.9 & 1.3 & 39.7 & 2.4 & 50.1 & 2.7 \\
\hline CDS & 697.8 & 100 & 26.6 & 3.8 & 332.8 & 47.7 & 172.1 & 24.7 & 106.9 & 15.3 & 59.4 & 8.5 \\
\hline & 50.2 & 0 & 4 & 0.6 & 31.2 & 4.4 & 27.5 & 3.5 & 17.4 & 2.4 & 29.8 & 3.8 \\
\hline SAVBND & 99.1 & 100 & 9.9 & 10 & 46.7 & 47.1 & 17.1 & 17.2 & 16.5 & 16.6 & 8.9 & 9 \\
\hline & 9.2 & 0 & 1.5 & 1.8 & 4.9 & 4.7 & 6.2 & 5.4 & 3.8 & 3.6 & 3.2 & 3.1 \\
\hline BOND & 732.4 & 100 & 2.1 & 0.3 & 46.2 & 6.3 & 81.1 & 11.1 & 222.3 & 30.3 & 380.7 & 52 \\
\hline & 74 & 0 & 1 & 0.1 & 8.4 & 1.4 & 22.1 & 3 & 42.8 & 5 & 58.9 & 5.1 \\
\hline STOCKS & 1432.2 & 100 & 11.8 & 0.8 & 164.5 & 11.5 & 129.8 & 9.1 & 426.4 & 29.7 & 699.6 & 48.9 \\
\hline & 114.7 & 0 & 1.9 & 0.2 & 15.1 & 1.5 & 21.2 & 1.4 & 74.3 & 4.1 & 81.2 & 3.9 \\
\hline NMMF & 663.5 & 100 & 8.5 & 1.3 & 154.3 & 23.3 & 102.9 & 15.6 & 225.9 & 34 & 171.9 & 25.8 \\
\hline & 69.7 & 0 & 1.8 & 0.3 & 18.7 & 3.2 & 20 & 3.4 & 46.5 & 4.8 & 32.8 & 3.7 \\
\hline RETQLIQ & 2231.7 & 100 & 72.8 & 3.3 & 794.2 & 35.6 & 383.8 & 17.2 & 661.6 & 29.6 & 319.3 & 14.3 \\
\hline & 116.1 & 0 & 6.5 & 0.3 & 43.4 & 2.5 & 36 & 1.4 & 71.8 & 2.6 & 75.7 & 2.9 \\
\hline CASHLI & 531.7 & 100 & 44 & 8.3 & 253.4 & 47.7 & 64.3 & 12.1 & 131.1 & 24.6 & 39 & 7.3 \\
\hline & 53.1 & 0 & 3.2 & 1.2 & 23.3 & 4.7 & 14.2 & 2.6 & 42.1 & 6 & 5.7 & 1.1 \\
\hline OTHMA & 473.2 & 100 & 3.6 & 0.8 & 71.4 & 15.1 & 70.9 & 15 & 144 & 30.4 & 183.2 & 38.7 \\
\hline & 65 & 0 & 1.8 & 0.4 & 12.9 & 2.5 & 17.4 & 3.7 & 37 & 5.4 & 43.3 & 5.2 \\
\hline OTHFIN & 327.3 & 100 & 17.6 & 5.4 & 78.4 & 23.9 & 35.5 & 10.8 & 94.6 & 29 & 101.2 & 30.9 \\
\hline & 38.9 & 0 & 2 & 1 & 12.7 & 3.6 & 11.7 & 3.4 & 26.9 & 6.9 & 23.7 & 5.7 \\
\hline NFIN & 18909.6 & 100 & 1514.1 & 8 & 6394.4 & 33.8 & 2059.2 & 10.9 & 3872.4 & 20.5 & 5069.4 & 26.8 \\
\hline & 603.8 & 0 & 57.7 & 0.4 & 177.8 & 1.3 & 139.5 & 0.7 & 275.5 & 1.2 & 430.6 & 1.6 \\
\hline VEHIC & 1074.2 & 100 & 292.4 & 27.2 & 512 & 47.7 & 97 & 9 & 118.8 & 11.1 & 53.9 & 5 \\
\hline & 22.3 & 0 & 9.5 & 1 & 16.8 & 1.2 & 8.3 & 0.7 & 9.1 & 0.7 & 6.5 & 0.6 \\
\hline HOUSES & 8874.1 & 100 & 1104.4 & 12.4 & 4685.4 & 52.8 & 1082.6 & 12.2 & 1370 & 15.4 & 631.7 & 7.1 \\
\hline & 196 & 0 & 48.4 & 0.6 & 139 & 1.4 & 86 & 0.9 & 104.7 & 1 & 75.1 & 0.8 \\
\hline ORESRE & 1598.6 & 100 & 52.6 & 3.3 & 434.3 & 27.2 & 295.2 & 18.5 & 446.2 & 27.9 & 370.3 & 23.2 \\
\hline & 88.5 & 0 & 9.8 & 0.6 & 38.2 & 2.3 & 41.6 & 2.5 & 49.9 & 2.5 & 50.7 & 2.6 \\
\hline NNRESRE & 2067.1 & 100 & 14.8 & 0.7 & 223.9 & 10.8 & 171.6 & 8.3 & 516.3 & 25 & 1140.4 & 55.2 \\
\hline & 227.7 & 0 & 3.4 & 0.2 & 22.2 & 1.3 & 35.1 & 1.6 & 82.4 & 3 & 173.5 & 3.6 \\
\hline BUS & 4982 & 100 & 35.6 & 0.7 & 445.3 & 9 & 391.2 & 7.9 & 1343.8 & 27 & 2766.1 & 55.5 \\
\hline & 396.5 & 0 & 7 & 0.2 & 39.8 & 1 & 63.1 & 1.2 & 170.7 & 3 & 305.3 & 3.1 \\
\hline OTHNFIN & 313.6 & 100 & 14.2 & 4.5 & 93.5 & 29.8 & 21.5 & 6.9 & 77.2 & 24.7 & 107.1 & 34.1 \\
\hline & 33.5 & 0 & 2.1 & 0.8 & 14.7 & 4 & 5.6 & 1.7 & 18.6 & 5.1 & 21.5 & 5.2 \\
\hline DEBT & 3995.2 & 100 & 1028 & 25.7 & 1864.7 & 46.7 & 362.3 & 9.1 & 495 & 12.4 & 245.2 & 6.1 \\
\hline & 116.6 & 0 & 53.5 & 1.3 & 80.6 & 1.6 & 42.6 & 1 & 47.7 & 1.1 & 27.9 & 0.6 \\
\hline MRTHEL & 2874.9 & 100 & 667 & 23.2 & 1505.1 & 52.4 & 256 & 8.9 & 339.2 & 11.8 & 107.5 & 3.7 \\
\hline & 89 & 0 & 40.6 & 1.4 & 68.5 & 2 & 36.1 & 1.2 & 36.8 & 1.2 & 14.5 & 0.5 \\
\hline RESDBT & 409 & 100 & 38.3 & 9.4 & 113.7 & 27.8 & 77.4 & 18.9 & 106.2 & 25.9 & 73.4 & 17.9 \\
\hline & 38.4 & 0 & 14.7 & 3.2 & 18.5 & 4.1 & 18.7 & 4.1 & 18.2 & 3.7 & 13.8 & 3.1 \\
\hline INSTALL & 453 & 100 & 240.4 & 53.1 & 160 & 35.3 & 14 & 3.1 & 26.6 & 5.9 & 12.1 & 2.7 \\
\hline & 25.6 & 0 & 22.6 & 2.5 & 8.4 & 1.8 & 2.7 & 0.6 & 5 & 1.1 & 2.6 & 0.6 \\
\hline OTHLOC & 33.3 & 100 & 2.5 & 7.4 & 8.6 & 26 & 3.5 & 10.6 & 1.8 & 5.2 & 16.9 & 50.8 \\
\hline & 7.9 & 0 & 0.4 & 2 & 3.5 & 9 & 2.8 & 8 & 1.1 & 3.1 & 6.4 & 11.3 \\
\hline CCBAL & 127.8 & 100 & 60.9 & 47.6 & 55.3 & 43.3 & 6.2 & 4.8 & 4.2 & 3.3 & 1.2 & 0.9 \\
\hline & 6.1 & 0 & 3.5 & 2.1 & 3.8 & 2.1 & 2.5 & 1.8 & 0.8 & 0.6 & 0.5 & 0.4 \\
\hline ODEBT & 97.2 & 100 & 18.9 & 19.4 & 21.9 & 22.6 & 5.2 & 5.3 & 17.1 & 17.5 & 34.1 & 35.1 \\
\hline & 13.5 & 0 & 4.2 & 4.9 & 4.2 & 4.9 & 1.9 & 1.9 & 5.5 & 5.4 & 11 & 8.1 \\
\hline Memo item & & & & & & & & & & & & \\
\hline EQUITY & 2942.1 & 100 & 50 & 1.7 & 613.3 & 20.9 & 339.9 & 11.6 & 898.5 & 30.5 & 1040.4 & 35.4 \\
\hline & 169.9 & 0 & 4.4 & 0.2 & 31.4 & 1.7 & 39.8 & 1.2 & 120.8 & 3 & 102.1 & 2.6 \\
\hline INCOME & 5061 & 100 & 1421.6 & 28.1 & 2117.3 & 41.8 & 453.2 & 9 & 639.4 & 12.6 & 429.4 & 8.5 \\
\hline & 68.8 & 0 & 34.7 & 0.7 & 65.6 & 1.2 & 33.4 & 0.6 & 39 & 0.7 & 38.6 & 0.7 \\
\hline \# observations & 3,91 & & 1,4 & & 1,1 & & 242 & & 449 & & 644 & \\
\hline \# families (mil.) & 95. & & 47. & & 38. & & 4.8 & & 3.9 & & 1.0 & \\
\hline Min. NW (thou.) & $\mathrm{Neq}$ & ative & $\mathrm{Neg}$ & ative & 64. & & 457 & & 847. & & 3,17 & \\
\hline
\end{tabular}

See appendix table A1 for variable definitions. 
Table A2: Amounts (billions of 2004 dollars) and shares of net worth and components distributed by net worth groups, 1995.

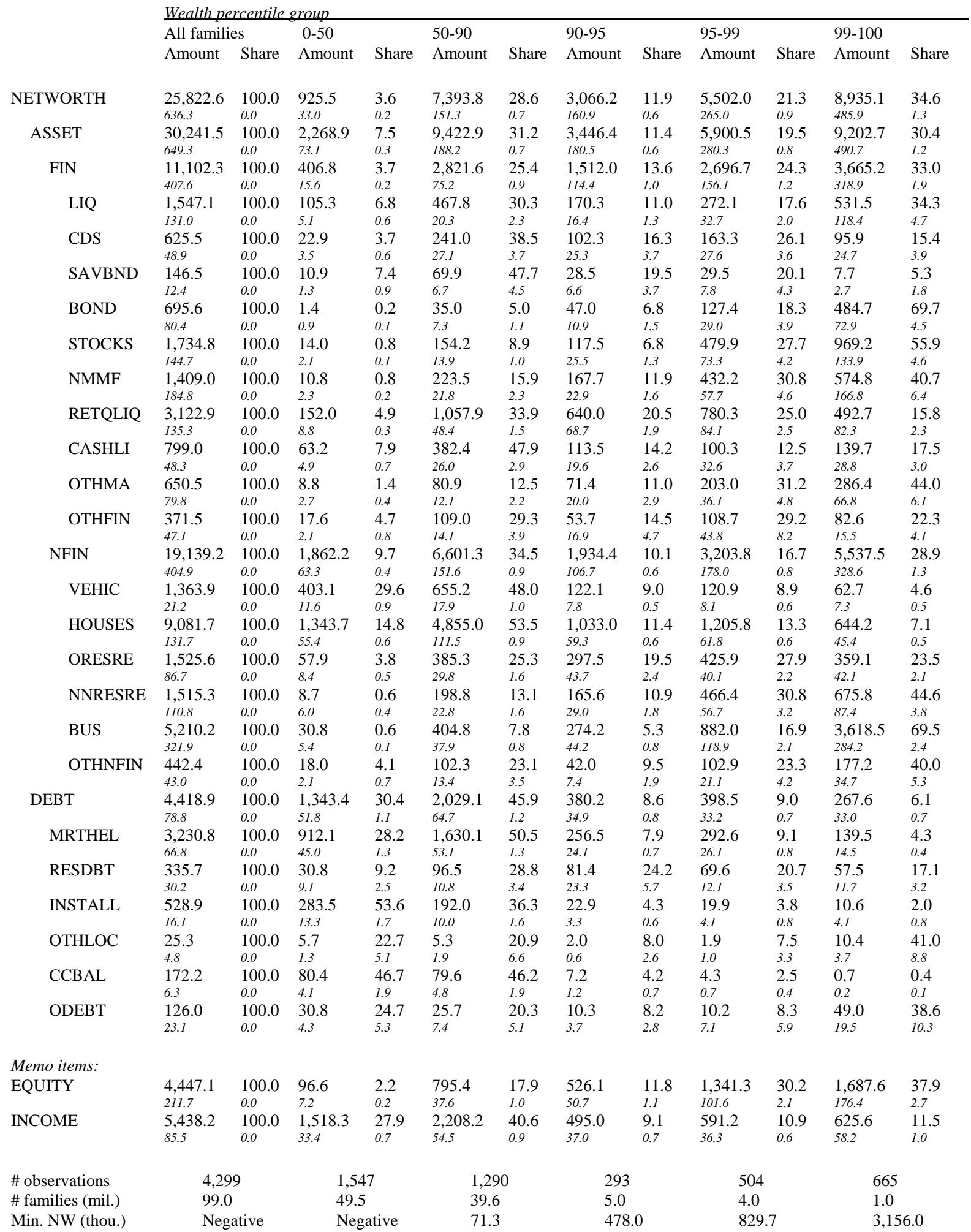

See appendix table A1 for variable definitions. 
Table A3: Amounts (billions of 2004 dollars) and shares of net worth and components distributed by net worth groups, 1998.

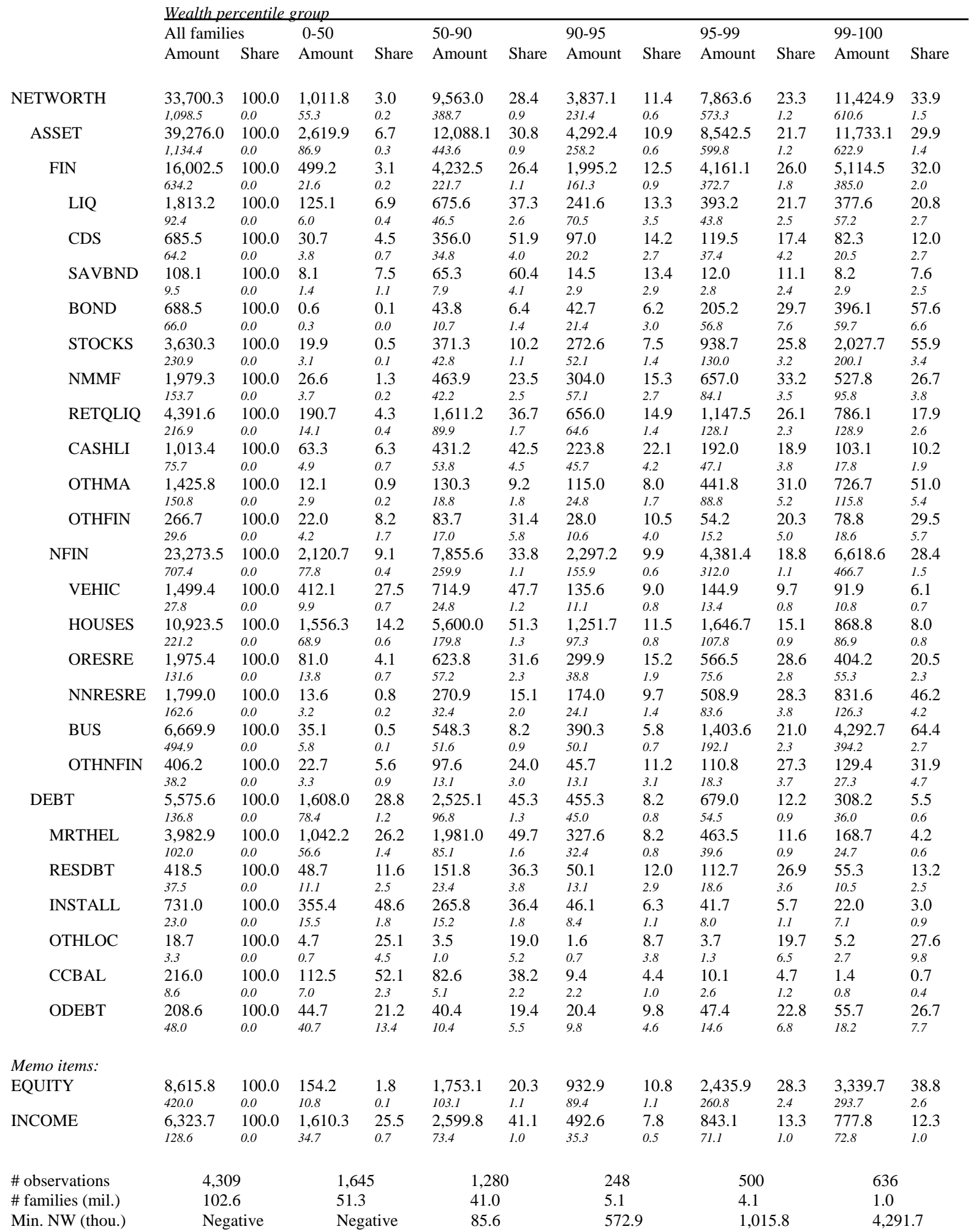

See appendix table A1 for variable definitions. 
Table A4: Amounts (billions of 2004 dollars) and shares of net worth and components distributed by net worth groups, 2001.

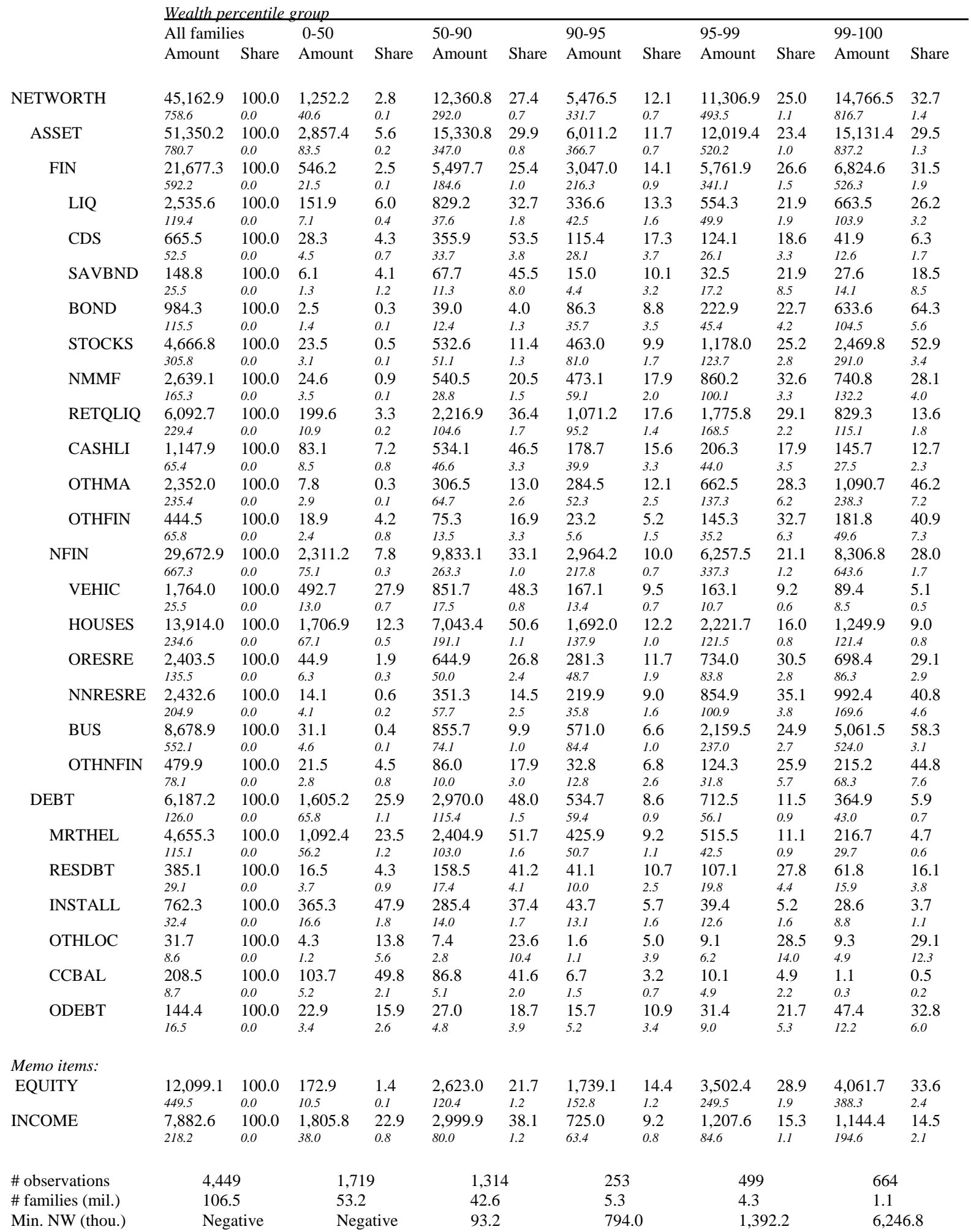

See appendix table A1 for variable definitions. 
Table A5: Percent real change in holdings and percentage point change in share of all holding, by wealth group, 1989 to 2004.

\begin{tabular}{|c|c|c|c|c|c|c|c|c|c|c|c|c|}
\hline & \multicolumn{12}{|c|}{ Wealth percentile group } \\
\hline & \multicolumn{4}{|c|}{ All families } & \multicolumn{2}{|l|}{$50-90$} & \multicolumn{2}{|l|}{$90-95$} & \multicolumn{2}{|l|}{ 95-99 } & \multicolumn{2}{|l|}{$99-100$} \\
\hline & $\begin{array}{l}\text { Amount } \\
\% \text { chg. }\end{array}$ & $\begin{array}{l}\text { Share } \\
\text { pp chg. }\end{array}$ & $\begin{array}{l}\text { Amount } \\
\% \text { chg. }\end{array}$ & $\begin{array}{l}\text { Share } \\
\text { pp chg. }\end{array}$ & $\begin{array}{l}\text { Amount } \\
\% \text { chg. }\end{array}$ & $\begin{array}{l}\text { Share } \\
\text { pp chg. }\end{array}$ & $\begin{array}{l}\text { Amount } \\
\% \text { chg. }\end{array}$ & $\begin{array}{l}\text { Share } \\
\text { pp chg. }\end{array}$ & $\begin{array}{l}\text { Amount } \\
\% \text { chg. }\end{array}$ & $\begin{array}{l}\text { Share } \\
\text { pp chg. }\end{array}$ & $\begin{array}{l}\text { Amount } \\
\% \text { chg. }\end{array}$ & $\begin{array}{l}\text { Share } \\
\text { pp chg. }\end{array}$ \\
\hline NETWORTH & $94.4 *$ & 0.0 & $67.5^{*}$ & -0.5 & $82.1^{*}$ & -2.0 & $78.6^{*}$ & -1.0 & $94.8^{*}$ & 0 & $115.7^{*}$ & 3.3 \\
\hline ASSET & $100.9 *$ & 0.0 & $114.3^{*}$ & 0.4 & $92.2^{*}$ & -1.5 & $81.4 *$ & -1.2 & $100.0^{*}$ & -0.1 & $118.6^{*}$ & 2.4 \\
\hline FIN & 132.4* & 0.0 & $69.9 *$ & $-0.9 *$ & $115.6^{*}$ & -2.0 & 132.4* & 0.0 & $128.9 *$ & -0.4 & 159.9* & 3.3 \\
\hline LIQ & $64.7^{*}$ & 0.0 & $49.3^{*}$ & -0.6 & $70.8^{*}$ & 1.1 & 40.4 & -2.0 & $104.9 *$ & 5.3 & 40.4 & -3.8 \\
\hline CDS & -12.9 & 0.0 & $-51.0 *$ & $-1.8 *$ & -15.7 & -1.5 & 12.8 & 4.9 & -23.6 & -3 & -0.8 & 1.3 \\
\hline SAVBND & -15.1 & 0.0 & 24.4 & 3.1 & -9.2 & 3.4 & -30.8 & -3.8 & -13.7 & 0.6 & -53.6 & -3.3 \\
\hline BOND & 24.2 & 0.0 & -79.3 & -0.2 & $-54.0^{*}$ & $-4.9 *$ & -65.1 & $-7.9 *$ & 1.1 & -5.4 & 68.8 & 18.4 \\
\hline STOCKS & $167.9^{*}$ & 0.0 & 25.3 & -0.6 & $74.5^{*}$ & $-5.5^{*}$ & $163.7^{*}$ & 0.0 & $140.6^{*}$ & -3.2 & $229.5^{*}$ & 9.6 \\
\hline NMMF & $537.4^{*}$ & 0.0 & $411.4^{*}$ & -0.2 & $661.5^{*}$ & 2.9 & $321.9^{*}$ & -5.5 & $510.2 *$ & -1.4 & $615.8^{*}$ & 4.1 \\
\hline RETQLIQ & $250.7^{*}$ & 0.0 & $249.9 *$ & 0.0 & $232.4 *$ & -2.2 & $356.5^{*}$ & 4.5 & 233.8* & -1.1 & $223.2^{*}$ & -1.2 \\
\hline CASHLI & 15.9 & 0.0 & -13.9 & -2.3 & -2.0 & -6.6 & -22.2 & -5.3 & 75.6 & 8.5 & 56.6 & 5.7 \\
\hline OTHMA & $151.4^{*}$ & 0.0 & $325.9 *$ & 0.3 & $235.2 *$ & 4.5 & 171.8 & 1.3 & 85.0 & -8.4 & $161.5^{*}$ & 2.3 \\
\hline OTHFIN & -4.7 & 0.0 & 2.0 & 0.3 & -10.9 & -1.4 & -45.5 & -6.5 & -56.5 & -17.9 & 79.8 & $25.5^{*}$ \\
\hline NFIN & $86.9 *$ & 0.0 & $125.0^{*}$ & $1.3^{*}$ & $83.7 *$ & -0.6 & $56.1^{*}$ & -2.0 & $83.1^{*}$ & -0.4 & $99.1^{*}$ & 1.7 \\
\hline VEHIC & $72.9 *$ & 0.0 & $81.2^{*}$ & 1.2 & $76.8^{*}$ & 1.1 & $44.3^{*}$ & -1.6 & $59.9 *$ & -0.8 & 73.1 & 0 \\
\hline HOUSES & 106.6* & 0.0 & $149.0^{*}$ & $2.0^{*}$ & $86.0^{*}$ & $-5.6^{*}$ & $91.5^{*}$ & -0.9 & $123.4 *$ & 1.2 & $209.4 *$ & $3.3^{*}$ \\
\hline ORESRE & $127.3^{*}$ & 0.0 & 32.6 & -1.1 & $65.0 *$ & $-8.4^{*}$ & 65.4 & -5.4 & $164.6^{*}$ & 4.6 & $249.4 *$ & $10.2 *$ \\
\hline NNRESRE & 23.1 & 0.0 & 69.8 & 0.2 & $122.8^{*}$ & 7.3 & 42.9 & 1.7 & 16.6 & -1.5 & 5.9 & -7.8 \\
\hline BUS & $78.6^{*}$ & 0.0 & 59.3 & -0.1 & $85.4^{*}$ & 0.3 & -2.3 & -4.5 & 48.2 & -4.7 & 108.7* & 8.8 \\
\hline OTHNFIN & 6.6 & 0.0 & -7.5 & -0.5 & 21.4 & 2.9 & -44.9 & -6.6 & 75.8 & 11.3 & -11 & -7.2 \\
\hline DEBT & $148.6^{*}$ & 0.0 & $157.0^{*}$ & 0.8 & $134.6^{*}$ & -2.9 & $108.7^{*}$ & -1.6 & $194.0 *$ & 1.7 & $235.8^{*}$ & 1.9 \\
\hline MRTHEL & 172.4* & 0.0 & 199.1* & 2.0 & $152.0 *$ & -4.3 & $144.4^{*}$ & -1.0 & $214.6^{*}$ & 1.4 & $358.5^{*}$ & 2 \\
\hline RESDBT & $172.0^{*}$ & 0.0 & 24.0 & -3.5 & $112.8^{*}$ & -7.1 & 62.4 & -8.4 & $290.8^{*}$ & 10.9 & $328.3^{*}$ & 8.1 \\
\hline INSTALL & $63.4^{*}$ & 0.0 & $83.1^{*}$ & 4.9 & $47.6^{*}$ & -4.2 & -16.8 & -2.7 & 20.2 & -1.6 & 219.6 & 3.5 \\
\hline OTHLOC & -2.7 & 0.0 & 42.9 & 3.2 & 128.2 & 14.2 & -84.8 & -9.7 & 78.2 & 6.7 & -25.9 & -14.4 \\
\hline CCBAL & $165.7 *$ & 0.0 & $183.2^{*}$ & 2.9 & $154.0^{*}$ & -2.1 & 90.2 & -1.4 & $192.9 *$ & 0.3 & 533.3 & 0.4 \\
\hline ODEBT & $77.2^{*}$ & 0.0 & 62.5 & -1.7 & $76.8^{*}$ & -0.1 & 79.5 & 0.3 & 8.9 & -10.7 & 161.7 & 12 \\
\hline \multicolumn{13}{|l|}{ Memo items: } \\
\hline EQUITY & $284.6^{*}$ & 0.0 & 184.3* & -0.4 & $268.1^{*}$ & -0.9 & $326.2^{*}$ & 1.4 & $274.6^{*}$ & -0.8 & 292.9* & 0.8 \\
\hline INCOME & $41.9 *$ & 0.0 & $39.0 *$ & -0.5 & $39.4^{*}$ & -0.8 & 34.6 & -0.4 & $62.4^{*}$ & 1.8 & 40.9 & -0.1 \\
\hline
\end{tabular}

See appendix table A1 for variable definitions. 
Table A6: Percent real change in holdings and percentage point change in share of all holding, by wealth group, 2001 to 2004.

\begin{tabular}{|c|c|c|c|c|c|c|c|c|c|c|c|c|}
\hline & \multicolumn{12}{|c|}{ Wealth percentile group } \\
\hline & \multicolumn{4}{|c|}{ All families } & \multicolumn{2}{|l|}{$50-90$} & \multicolumn{2}{|l|}{$90-95$} & \multicolumn{2}{|l|}{$95-99$} & \multicolumn{2}{|l|}{$99-100$} \\
\hline & $\begin{array}{l}\text { Amount } \\
\text { \% chg. }\end{array}$ & $\begin{array}{l}\text { Share } \\
\text { pp chg. }\end{array}$ & $\begin{array}{l}\text { Amount } \\
\% \text { chg. }\end{array}$ & $\begin{array}{l}\text { Share } \\
\text { pp chg. }\end{array}$ & $\begin{array}{l}\text { Amount } \\
\% \text { chg. }\end{array}$ & $\begin{array}{l}\text { Share } \\
\text { pp chg. }\end{array}$ & $\begin{array}{l}\text { Amount } \\
\% \text { chg. }\end{array}$ & $\begin{array}{l}\text { Share } \\
\text { pp chg. }\end{array}$ & $\begin{array}{l}\text { Amount } \\
\% \text { chg. }\end{array}$ & $\begin{array}{l}\text { Share } \\
\text { pp chg. }\end{array}$ & $\begin{array}{l}\text { Amount } \\
\% \text { chg. }\end{array}$ & $\begin{array}{l}\text { Share } \\
\text { pp chg. }\end{array}$ \\
\hline NETWORTH & $11.3^{*}$ & 0.0 & 2.1 & $-0.3^{*}$ & $13.6^{*}$ & 0.5 & 10.0 & -0.1 & 7.2 & -0.9 & 13.6 & 0.7 \\
\hline ASSET & $15.1^{*}$ & 0.0 & $19.8^{*}$ & 0.2 & $19.7^{*}$ & 1.1 & 12.5 & -0.3 & 9.4 & -1.2 & $15.2^{*}$ & 0.0 \\
\hline FIN & -2.7 & 0.0 & -3.1 & 0.0 & -0.4 & 0.6 & -5.5 & -0.5 & -3.7 & -0.3 & -2.4 & 0.1 \\
\hline LIQ & 9.6 & 0.0 & -0.5 & -0.6 & 11.6 & 0.6 & -7.3 & -2.1 & $35.2^{*}$ & 5.1 & -3.3 & -3.1 \\
\hline CDS & 17.3 & 0.0 & $-36.4 *$ & $-2.0 *$ & -7.1 & $-11.2 *$ & 45.4 & 4.2 & 40.5 & 3.7 & 114.1 & 5.2 \\
\hline SAVBND & -23.6 & 0.0 & 83.6 & $5.7^{*}$ & -14.3 & 5.5 & 16.7 & 5.2 & -30.5 & -2.0 & -83.7 & -14.5 \\
\hline BOND & 13.3 & 0.0 & -76.0 & -0.2 & -17.9 & -1.1 & -59.7 & -5.7 & 18.7 & 1.0 & 23.6 & 5.9 \\
\hline STOCKS & $-20.5^{*}$ & 0.0 & -9.4 & 0.1 & $-28.4 *$ & -1.1 & -19.0 & 0.2 & -11.3 & 3.0 & -23.6 & -2.0 \\
\hline NMMF & 17.5 & 0.0 & -8.5 & -0.2 & 4.4 & -2.3 & -29.8 & $-7.2 *$ & 18.1 & 0.1 & 57.5 & 9.5 \\
\hline RETQLIQ & 10.8 & 0.0 & 13.4 & 0.1 & 16.7 & 1.9 & 23.3 & 2.0 & -4.2 & -3.9 & 10.6 & 0.0 \\
\hline CASHLI & $-45.5^{*}$ & 0.0 & $-50.8^{*}$ & -0.7 & $-57.7^{*}$ & $-10.3^{*}$ & $-62.5^{*}$ & -4.9 & -24.5 & 7.0 & -7.1 & $8.9^{*}$ \\
\hline OTHMA & $-28.4 *$ & 0.0 & 47.4 & 0.4 & -2.1 & 4.8 & -24.8 & 0.6 & -46.5 & -7.3 & -26.3 & 1.6 \\
\hline OTHFIN & -2.1 & 0.0 & 36.0 & 1.7 & -2.3 & 0.0 & 57.3 & 3.2 & -54.4 & -17.4 & 28.2 & 12.6 \\
\hline NFIN & $28.1^{*}$ & 0.0 & $25.2^{*}$ & -0.2 & $30.9 *$ & 0.8 & $31.1^{*}$ & 0.2 & $21.4^{*}$ & -1.1 & $29.6^{*}$ & 0.3 \\
\hline VEHIC & $10.2 *$ & 0.0 & 5.9 & -1.1 & $13.7^{*}$ & 1.5 & -7.7 & -1.6 & 14.9 & 0.4 & 26.6 & 0.7 \\
\hline HOUSES & $37.3^{*}$ & 0.0 & $31.3^{*}$ & -0.6 & $35.9 *$ & -0.5 & $34.2 *$ & -0.3 & $41.1^{*}$ & 0.4 & $51.2^{*}$ & 0.9 \\
\hline ORESRE & $56.3^{*}$ & 0.0 & 26.9 & -0.4 & $28.4^{*}$ & -4.8 & $94.1^{*}$ & 2.8 & $66.5^{*}$ & 2.0 & $58.2 *$ & 0.3 \\
\hline NNRESRE & 14.0 & 0.0 & 39.7 & 0.1 & 28.6 & 1.8 & 42.2 & 2.3 & -20.8 & $-10.7^{*}$ & 32.1 & 6.5 \\
\hline BUS & 13.4 & 0.0 & 9.6 & -0.1 & 6.1 & -0.7 & -1.9 & -0.9 & 2.3 & -2.5 & 21.1 & 4.0 \\
\hline OTHNFIN & 21.9 & 0.0 & -2.8 & -0.9 & $66.3^{*}$ & 6.5 & 25.6 & 0.2 & 35.2 & 2.8 & -1.5 & -8.6 \\
\hline DEBT & $43.2^{*}$ & 0.0 & $33.6^{*}$ & -1.7 & $44.9 *$ & 0.6 & $37.9 *$ & -0.3 & $43.3^{*}$ & 0.0 & $78.2^{*}$ & 1.4 \\
\hline MRTHEL & $43.1^{*}$ & 0.0 & $39.2 *$ & -0.7 & $48.1^{*}$ & 1.8 & $38.7^{*}$ & -0.3 & $28.8^{*}$ & -1.1 & 49.8 & 0.2 \\
\hline RESDBT & $95.0^{*}$ & 0.0 & 34.5 & -1.3 & 21.4 & $-15.5^{*}$ & $132.4 *$ & 2 & $153.2^{*}$ & 8.3 & 174.4 & 6.4 \\
\hline INSTALL & $27.4^{*}$ & 0.0 & $22.9 *$ & -1.7 & $33.6^{*}$ & 1.9 & -37.8 & -2.9 & 10.4 & -0.7 & 144.8 & 3.5 \\
\hline OTHLOC & $102.2^{*}$ & 0.0 & 62.8 & -2.9 & 118.9 & 1.5 & -25 & -3.1 & 7.7 & -13.2 & 222.6 & 17.8 \\
\hline CCBAL & $27.6^{*}$ & 0.0 & $17.2^{*}$ & -4.1 & $43.7^{*}$ & 5.3 & 44.8 & 0.4 & -18.8 & -1.8 & 72.7 & 0.2 \\
\hline ODEBT & 1.0 & 0.0 & 7.9 & 1.0 & 10.0 & 1.6 & -16.6 & -2 & -22.3 & -4.9 & 13.7 & 4.2 \\
\hline \multicolumn{13}{|l|}{ Memo items: } \\
\hline EQUITY & $-17.8^{*}$ & 0.0 & $-33.1^{*}$ & -0.2 & $-25.0^{*}$ & -1.9 & $-24.8^{*}$ & -1.3 & $-18.1^{*}$ & 0.0 & -9.3 & 3.4 \\
\hline INCOME & 0.6 & 0.0 & 4.5 & 0.9 & 5.8 & 1.9 & -7.3 & -0.7 & -7.5 & -1.2 & -5.7 & -0.9 \\
\hline
\end{tabular}

See appendix table A1 for variable definitions. 
Table A7: Assets and Liabilities as a share of assets, African American families, Hispanic families, and all families, percent, 2004.

\begin{tabular}{|c|c|c|c|c|c|c|c|c|c|c|c|c|}
\hline & \multicolumn{4}{|c|}{ African American families } & \multicolumn{4}{|c|}{ Hispanic families } & \multicolumn{4}{|c|}{ All families } \\
\hline & All & $0-50$ & $50-90$ & $90-100$ & All & $0-50$ & $50-90$ & $90-100$ & All & $0-50$ & $50-90$ & $90-100$ \\
\hline NETWORTH & 72.0 & 0.0 & 60.6 & 87.5 & 74.2 & 17.2 & 56.7 & 87.4 & 85.0 & 37.3 & 76.5 & 93.5 \\
\hline ASSET & 100.0 & 100.0 & 100.0 & 100.0 & 100.0 & 100.0 & 100.0 & 100.0 & 100.0 & 100.0 & 100.0 & 100.0 \\
\hline FIN & 24.2 & 13.7 & 18.6 & 29.1 & 20.0 & 10.0 & 10.4 & 25.9 & 35.7 & 15.5 & 29.9 & 40.4 \\
\hline LIQ_CDS_SAVBND & 5.0 & 4.8 & 4.8 & 5.1 & 4.3 & 5.1 & 3.2 & 4.9 & 6.2 & 5.3 & 7.2 & 5.8 \\
\hline RETQLIQ & 12.4 & 5.4 & 8.7 & 15.7 & 6.4 & 3.9 & 5.3 & 7.2 & 11.4 & 6.6 & 14.1 & 10.6 \\
\hline BOND_STOCKS_OTHMA_NMMF & 3.6 & 0.6 & 1.1 & 5.7 & 5.4 & 0.5 & 0.8 & 8.3 & 16.3 & 1.6 & 7.0 & 22.2 \\
\hline CASHLI_OTHFIN & 3.2 & 3.0 & 3.9 & 2.7 & 3.8 & 0.5 & 1.0 & 5.5 & 1.8 & 1.9 & 1.6 & 1.9 \\
\hline NFIN & 75.8 & 86.3 & 81.4 & 70.9 & 80.0 & 90.0 & 89.6 & 74.1 & 64.3 & 84.5 & 70.1 & 59.6 \\
\hline VEHIC & 6.0 & 25.7 & 7.4 & 2.8 & 5.9 & 33.6 & 9.1 & 2.3 & 3.3 & 15.2 & 5.3 & 1.2 \\
\hline HOUSES_ORESRE & 55.5 & 60.0 & 70.5 & 45.1 & 53.5 & 55.3 & 76.9 & 40.5 & 38.7 & 67.1 & 56.7 & 27.2 \\
\hline NNRESRE_BUS & 14.1 & 0.4 & 3.2 & 22.9 & 19.6 & 0.4 & 3.5 & 29.7 & 21.3 & 1.6 & 7.4 & 30.0 \\
\hline OTHNFIN & 0.2 & 0.2 & 0.4 & 0.1 & 1.1 & 0.9 & 0.1 & 1.6 & 1.0 & 0.6 & 0.8 & 1.1 \\
\hline DEBT & 28.0 & 100.0 & 39.4 & 12.5 & 25.8 & 82.8 & 43.3 & 12.6 & 15.0 & 62.6 & 23.5 & 6.5 \\
\hline MRTHEL_RESDBT & 21.6 & 46.1 & 33.3 & 11.1 & 21.8 & 50.5 & 36.9 & 11.7 & 12.5 & 45.1 & 20.5 & 5.7 \\
\hline CCBAL & 1.0 & 5.2 & 1.3 & 0.4 & 0.9 & 6.4 & 1.4 & 0.2 & 0.5 & 3.5 & 0.7 & 0.1 \\
\hline INSTALL_OTHLOC_ODEBT & 5.4 & 48.7 & 4.9 & 1.0 & 3.2 & 26.0 & 5.0 & 0.7 & 2.0 & 14.0 & 2.3 & 0.7 \\
\hline \multicolumn{13}{|l|}{ Memo item: } \\
\hline EQUITY & 5.7 & 1.3 & 3.1 & 7.9 & 6.6 & 1.2 & 2.6 & 9.2 & 16.8 & 3.4 & 10.7 & 21.1 \\
\hline INCOME & 25.3 & 126.6 & 28.8 & 11.8 & 20.1 & 144.0 & 25.7 & 9.0 & 13.4 & 55.1 & 17.3 & 7.7 \\
\hline
\end{tabular}

See appendix table A1 for variable definitions. 